RENNÉ PANDURO ALEGRIA

\title{
Análise de itens lexicais do discurso oral do paciente com doença de Alzheimer
}

\author{
(Versão corrigida)
}

Tese apresentada ao Instituto de Psicologia da Universidade de São Paulo, como parte dos requisitos para obtenção do grau de Doutor em Psicologia.

Área de Concentração:

Neurociências e Comportamento

Orientador: Prof. Dr. Maria Inês Nogueira

Co-orientador: Prof. Dr. Cássio M. Campos Bottino

São Paulo

2012 
AUTORIZO A REPRODUÇÃO E DIVULGAÇÃO TOTAL OU PARCIAL DESTE TRABALHO, POR QUALQUER MEIO CONVENCIONAL OU ELETRÔNICO, PARA FINS DE ESTUDO E PESQUISA, DESDE QUE CITADA A FONTE.

Catalogação na publicação

Biblioteca Dante Moreira Leite

Instituto de Psicologia da Universidade de São Paulo

Alegria, Renné Panduro.

Análise de itens lexicais do discurso oral do paciente com doença de Alzheimer / Renné Panduro Alegria; orientadora Maria Inês Nogueira. -São Paulo, 2012.

$108 f$.

Tese (Doutorado - Programa de Pós-Graduação em Psicologia. Área de Concentração: Neurociências e Comportamento) - Instituto de Psicologia da Universidade de São Paulo.

1. Doença de Alzheimer 2. Léxico 3. Linguagem 4.Comunicação

5. Relações profissional-paciente 6.Cuidadores 7. Comunicação verbal

I. Título.

RC523 


\section{FOLHA DE APROVAÇÃO}

Renné Panduro Alegria

Análise de itens lexicais do discurso oral do paciente com doença de Alzheimer

Tese apresentada ao Instituto de Psicologia da Universidade de São Paulo para obtenção do título de Doutor em Psicologia.

Aprovado em; ___ I _ I

\section{Banca Examinadora}

Prof (a), Dr(a),

Instituição; Assinatura;

Prof (a), Dr(a),

Instituição; Assinatura;

Prof (a), Dr(a),

Instituição; Assinatura;

Prof (a), Dr(a),

Instituição;

Assinatura;

Prof (a), Dr(a),

Instituição; Assinatura; 
Dedico esta Tese a mínha mãe Noemi pelo seu grande apoío em todos os momentos da mínha vida, a Angélica, pela paciência e a minha filha Natalie, pela sua compreensão nos momentos de ausêncía. 


\section{AGRADECIMENTOS}

À Prof. Dra. Maria Inês Nogueira, minha orientadora, pelos seus ensinamentos compreensão, incentivos e apoios em todas as etapas da pesquisa.

Ao Prof. Dr. Cássio Machado de Campos Bottino, co-orientador deste trabalho, que me aceitou para desenvolver pesquisas com os pacientes do PROTER, pelo apoio e ótimos ensinamentos durante o estudo.

À Prof. Dra Elissa D. Asp da Saint Mary's University, pelos ensinamentos e estimulo durante o estágio naquela universidade

À Prof. Dra Maria Aparecida Barbosa, pelos seus ensinamentos do léxico.

À Prof. Dra Marly Gondim, pela colaboração com o uso do Stablex

A Prof. Dra Maria Zilda Zaparolli, pela ajuda com o programa Stablex

À Sra Rosana Duarte Prisco estatística do Instituto de Ciências Biomédicas, pela inestimável colaboração nas análises dos resultados.

Ao Sr. Bernardo dos Santos, estatístico do CEAPESQ, Instituto de Psiquiatria do HC FMUSP, pela sua grande ajuda nas analises.

Aos médicos do Ambulatório de demências do PROTER, Dra Célia Gallo, Dra Vanessa Satomi, Dra Mirian Gracy Bolso, Dra Claúdia Martins Santana, Dra Rita de Cássia Gomes Marques, e aos médicos do Ambulatório didático: Dr Tibor Rilho Perroco e Dra Rita Cecília Ferreira, pelos seus ensinamentos.

À todos os idosos e seus familiares, que participaram do estudo.

A todos os colegas do PROTER, Dr Ricardo Barcelos Ferreira, pelos ensinamentos e colaboração nas discussões com os pacientes.

À Alessandra Vieira Rodrigues, assistente do PROTER, pela considerável ajuda no programa. 
À minha mãe Noemi Alegria Ramos, pelo seu apoio incondicional.

À minha querida filha Natalie, pela sua grande compreensão.

À minha querida amiga Dra Rita de Cássia Gomes Marques, pela sua ajuda incondicional.

À Maria Joana Leopoldo de Andrade, pelo seu apoio e companheirismo.

Ao Wellington Carlos de Lacerda, pela sua grande colaboração com os trabalhos de informática.

À minha irmã Martha Isabel P. Alegria, pelo apoio e compreensão incondicionais.

Aos colegas do Laboratório de Neurociências do Instituto de Ciências Biomédicas, Silvia Honda e Roberto Torres Tangoa, pela amizade impar e companheirismo.

À Sra. Maria Clarice Ferreira da Silva, secretaria do curso de Neurociências e Comportamento do Instituto de Psicologia, pela sua colaboração nas questões acadêmicas.

Ao Programa de Pós-Graduação em Neurociências e Comportamento do Instituto de Psicologia da USP, Prof. Marcelo Fernandes Costa, pelas oportunidades.

Aos colegas da Biblioteca do Instituto de Ciências Biomédicas da USP, pela sua colaboração com os materiais didáticos e livros.

À Neusa Maria Nascimento, pela sua grande ajuda.

À CAPES- Coordenação de Aperfeiçoamento de Pessoal de Nível Superior, pela bolsa de estudo e oportunidade de crescimento cientifico e profissional. 
De tudo na vida

Ficaram três coísas

A certeza de que estamos sempre começando A certeza de que precisamos continuar,...

F.Pessoa 


\section{RESUMO}

Alegria, R. P. (2012), Análise de itens lexicais do discurso oral do paciente com doença de Alzheimer, Tese de Doutorado, Programa de Neurociências e Comportamento, Instituto de Psicologia, Universidade de São Paulo, São Paulo.

A doença de Alzheimer, doença neurodegenerativa, em que a dificuldade de encontrar palavras é um dos déficits mais presentes, mesmo em estágios iniciais já ocorrem alterações focalmente no hipocampo e giros parahipocampais. Com o avanço da doença, a dificuldade de encontrar palavras e o uso de itens lexicais efetivos ficam muitas vezes mais comprometidos sugerindo distribuição difusa da doença no encéfalo. A dificuldade em encontrar palavras ou anomia se deve consensualmente à deterioração do processamento semântico e ao déficit da memória operacional. Ainda, mesmo nesses estágios iniciais da doença, muitos pacientes relatam dificuldades em encontrar os itens lexicais adequados para seguir uma conversação, o que os constrange causando isolamento e falta de interações comunicativas verbais. Esse relato indica que eles têm consciência dessa perda cognitiva. Nas conversações ou interações sociais entre pacientes e cuidadores, muitas vezes a dificuldade de encontrar os itens lexicais não é claramente percebida. Entretanto, com o progresso da doença essa incompreensão se acentua, gerando situações estressantes e de sobrecarga, especialmente para o cuidador. A presente pesquisa objetivou analisar os itens lexicais no discurso oral dos pacientes com doença de Alzheimer, verificar aquelas palavras mais preservadas, que visem à elaboração de estratégias linguísticas adequadas e que permitam o desenvolvimento de mecanismos discursivos, a fim de identificar estratégias que possam melhorar a interação entre cuidadores e pacientes. Neste estudo avaliaram-se os itens lexicais verbos e substantivos, hápax e as oito outras categorias gramaticais da língua portuguesa de 23 pacientes com doença de Alzheimer e 23 idosos controles sadios. Os itens selecionados foram extraídos de conversações livres por no máximo 20 minutos com os temas: cidade, família, educação, alimentação, saúde e religião. Foi utilizado o programa Stablex que efetua o tratamento computacional de itens lexicais e confecções de léxico para identificar os itens lexicais mais frequentes e com maior peso ou valor. Os resultados indicam que os pacientes têm maior dificuldade em nomear substantivos, especialmente seres vivos, $\mathrm{p}<0,05$. Ainda, esses pacientes apresentam maior preservação de itens lexicais concretos em relação aos itens lexicais abstratos. Além disso, foi observada maior preservação de verbos do que de substantivos, hápax fica preservado nos pacientes com doença de Alzheimer, $\mathrm{p}<0.001$. Os adjetivos, $\mathrm{p}<0,001$, interjeições, $\mathrm{p}<0,001$, artigos e preposições $\mathrm{p}<0,001$, também são significantes na doença. Conclui-se, assim, que embora os pacientes tenham perda lexical progressiva, suas habilidades comunicativas, semântico-pragmáticas não estão muito alteradas e que os pacientes ao serem estimulados com frases curtas, com aquelas palavras mais preservadas no seu léxico ainda podem se comunicar e interagir oralmente. Portanto, as análises de itens lexicais nos discursos orais dos pacientes com doença de Alzheimer não só contribuirão para o entendimento dos déficits de linguagem, mas também oferecerão formas de melhorar a comunicação entre pacientes e cuidadores.

Palavras-chave: doença de Alzheimer; item lexical; linguagem e comunicação; interação cuidador-paciente; Stablex. 


\begin{abstract}
Alegria, R. P. Analysis of lexical items in oral discourse of Alzheimer's disease patients. Doctoral Thesis, Institute of Psychology, University of São Paulo
\end{abstract}

Alzheimer's disease, neurodegenerative disease, wherein the word-finding difficulty is one of the most common deficits, even at early stages alterations occur focally in the hippocampus and parahippocampal gyri. With disease progression, the word-finding difficulty and effective use of lexical items are often more affected suggesting diffuse distribution of the disease in the brain. The word-finding difficulty or anomie is consensually to the deterioration of semantic processing or the occurrence of impaired connection between the lexical and semantic level as well as the working memory impairment. Yet, even in these early stages of the disease, many patients report difficulties in finding suitable lexical items to follow a conversation, therefore the patients get constrained, causing isolation and lack of verbal communicative interactions. This indicates that they are aware of this cognitive loss. In conversations or social interactions between patients and caregivers, often the difficulty of finding lexical items is not clearly perceived. These caregivers often help the patient to complete the words and sentences inferring meanings thereby masking the stage of disease. However, with the progress of the disease misunderstanding increases, causing overload and stressful situations, especially for the caregiver. The current study aimed at analyzing the lexical items in oral discourse of patients with Alzheimer's disease, to verify the most retained words in order to develop appropriate linguistic strategies enabling the development of discursive mechanisms to identify strategies to improve the interaction between caregivers and patients. This study evaluated the lexical items, verbs, nouns hápax and the other eight grammatical categories of Portuguese language of 23 patients with Alzheimer's disease and 23 healthy elderly controls. The selected items were drawn from free conversations of at least 20 minutes with the themes: city, family, education, food, health and religion. We used Stablex program that performs the computational treatment of lexical items and creates lexicons to identify more frequently lexical items and with their weight or value. The results indicate patients have greater difficulty in naming living things, $\mathrm{p}<0.05$. Also, these patients have higher retention of concrete lexical items in relation to abstract lexical items. Moreover, hapax is retained in Alzheimer's disease, $\mathrm{p}<0.001$. It is attributed to the greater number of nouns in the languages compared to verbs or because, perhaps, the frontal areas of the brain where the verbs are represented are affected later. Also, it was observed that the lexical item hapax is significant in patients with Alzheimer's disease. Adjectives, $\mathrm{p}<0,001$, interjections, $\mathrm{p}<0,001$, articles and prepositions, $\mathrm{p}<0,001$, are also significant during the disease, We conclude, therefore, that although patients have progressive lexical loss, their communication and semantic-pragmatic skills are not much changed, and when patients are stimulated with short sentences with words that are more retained in their lexicons they can still communicate and interact verbally. Therefore, the analysis of lexical items in oral discourse of patients with Alzheimer's disease not only contributes to the understanding of language deficits, but also it will offer ways to improve communication between patients and caregivers.

Keywords: Alzheimer's disease; lexical items; language and communication; interaction caregiver-patient; Stablex. 


\section{LISTA DE FIGURAS}

Figura1- Imagem histológica das placas neuríticas (proteína $\beta$ - amiloide)......................... 20

Figura 2. Imagem histológica dos emaranhados neurofibrilares (proteína tau).................... 21

Figura 3 - Regiões principais envolvidas no processamento da linguagem.......................... 27

Figura 4 - Percentagem do léxico preferencial dos pacientes e controles ............................ 47

Figura 5 - Percentagem do léxico básico dos pacientes e controles....................................... 47

Figura 6 - Percentagem do léxico diferencial dos pacientes e controles.................................. 48

Figura 7 - Percentagem do léxico particular dos pacientes e controles.................................. 48

Figura 8- Valores lexicais e mediana dos substantivos dos controles e dos pacientes........... 54

Figura 9 - Valores lexicais e mediana dos verbos dos controles e dos pacientes.................. 54

Figura 10 - Percentagem e mediana dos valores lexicais dos substantivos dos controles e

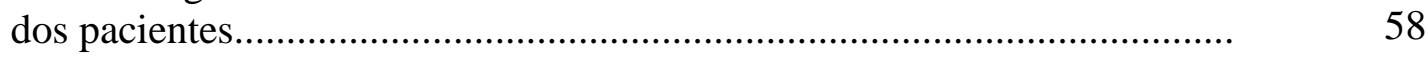

Figura 11 - Percentagem e mediana dos valores lexicais dos verbos dos controles e dos

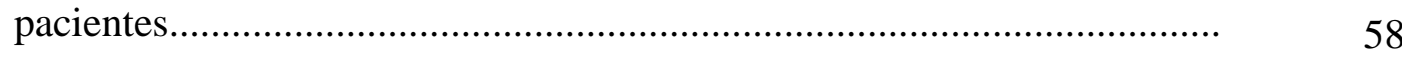

Figura 12 - Número e mediana dos hápax dos controles e dos pacientes................................ 60

Figura 13 - Percentagem e mediana dos hápax dos controles e dos pacientes...................... 60

Figura 14 - Número e mediana dos adjetivos dos controles e dos pacientes......................... 62

Figura 15- Percentagem e mediana dos adjetivos dos controles e dos pacientes................. 62

Figura 16 - Número e mediana dos advérbios dos controles e dos pacientes........................ 64

Figura 17 - Percentagem e mediana dos advérbios dos controles e os pacientes................... 64

Figura 18 - Número e mediana dos pronomes dos controles e dos pacientes........................ 66

Figura 19 - Percentagem e mediana dos pronomes dos controles e dos pacientes................ 66

Figura 20 - Número e mediana dos numerais dos controles e dos pacientes......................... 68

Figura 21 - Percentagem e mediana dos numerais dos controles e dos pacientes................. 68

Figura 22 - Número e mediana das interjeições dos controles e dos pacientes........................ 70

Figura 23 - Percentagem e mediana das interjeições dos controles e dos pacientes............... 70

Figura 24 - Número e mediana das conjunções dos controles e dos pacientes.................... 72

Figura 25- Percentagem e mediana das conjunções dos controles e dos pacientes.............. $\quad 72$

Figura 26- Número e mediana dos artigos dos controles e dos pacientes............................ 74 
Figura 27 - Percentagem e mediana dos artigos dos controles e dos pacientes.................. 74

Figura 28 - Número e mediana das preposições dos controles e dos pacientes.................. 76

Figura 29- Percentagem e mediana das preposições dos controles e dos pacientes............ 76 


\section{LISTA DE TABELAS}

Tabela 1- Dados Demográficos e clínicos do grupo DA, $\mathrm{n}=23(\mathrm{M}=10, \mathrm{~F}=13) \ldots \ldots \ldots \ldots \ldots \ldots . . . . . . . . . .43$

Tabela 2- Dados demográficos e exames do grupo Controle $\mathrm{n}=23(\mathrm{M}=8, \mathrm{~F}=15) \ldots \ldots \ldots \ldots \ldots . . . . . . .44$

Tabela 3 - Perfil dos controles e dos pacientes em estágios leve e moderado da DA............ 45

Tabela 4 - Média e desvio padrão, mediana, valor mínimo e máximo da percentagem de itens lexicais particulares dos controles e dos pacientes nos estágios leve e moderado da DA.

Tabela 5 - Média e desvio padrão, mediana, valor mínimo e máximo do número de itens lexicais preferenciais, básicos, diferenciais, particulares e totais dos controles e dos pacientes nos estágios leve e moderado da DA.

Tabela 6 - Média e desvio padrão, mediana, valor mínimo e máximo da percentagem de itens lexicais preferenciais, básicos, diferenciais e particulares dos controles e dos pacientes nos estágios leve e moderado da DA

Tabela 7 - Média e desvio padrão, mediana, valor mínimo e máximo dos valores lexicais dos verbos e substantivos dos controles e dos pacientes nos estágios leve e moderado da DA

Tabela 8 - Média e desvio padrão, mediana, valor mínimo e máximo da percentagem dos valores lexicais dos verbos e substantivos dos controles e pacientes nos estágios leve e moderado da DA

Tabela 9 - Média e desvio padrão, mediana, valor mínimo e máximo do número e percentagem do hápax dos controles e dos pacientes nos estágios leve e moderado da DA.

Tabela 10- Média e desvio padrão, mediana, valor mínimo e máximo do número e percentagem dos adjetivos dos controles e dos pacientes nos estágios leve e moderado da DA

Tabela 11- Média e desvio padrão, mediana, valor mínimo e máximo do número e percentagem dos advérbios dos controles e dos pacientes nos estágios leve e moderado da DA

Tabela12 - Média e desvio padrão, mediana, valor mínimo e máximo do número e percentagem dos pronomes dos controles e dos pacientes nos estágios leves e moderados da DA

Tabela 13- Média e desvio padrão, mediana, valor mínimo e máximo do número e percentagem dos numerais dos controles e dos pacientes nos estágios leve e moderado da DA

Tabela 14. Média e desvio padrão, mediana, valor mínimo e máximo do número e percentagem das interjeições dos controles e dos pacientes nos estágios leve e 
moderado da DA

Tabela 15- Média e desvio padrão, mediana, valor mínimo e máximodo número e percentagem das conjunções dos controles e dos pacientes nos estágios leve e moderado da DA

Tabela 16- Média e desvio padrão, mediana, valor mínimo e máximo do número e percentagem dos artigos dos controles e dos pacientes nos estágios leve e moderado da DA

Tabela 17- Média e desvio padrão, mediana, valor mínimo e máximo do número e percentagem das preposições dos controles e dos pacientes nos estágios leve e moderado da DA

Tabela 18 - Dez primeiras palavras pela frequência.

Tabela 19- Dez primeiros verbos e dez primeiros substantivos 


\section{LISTA DE ABREVIATURAS E SIGLA}

APA American Psychological Association

DA Doença de Alzheimer

DSM-IV Diagnostic and Statistical Manual of Mental Disorders- IV

F Feminino

FMUSP Faculdade de Medicina da Universidade de São Paulo

HC Hospital das Clínicas

HD Hemisfério Direito

HE Hemisfério Esquerda

IBGE Instituto Brasileiro de Geografia e Estatística

IPq Instituto de Psiquiatria

M Masculino

MEEM Mini Exame do Estado Mental

NINCDS- "National Institute of Neurological and Communicative

ADRDA Disease and Stroke/Alzheimer's Disease and related Disorder's Association"

OMS Organização Mundial da Saúde

PROTER Programa Terceira Idade

S Substantivo

V Verbo 


\section{SUMÁRIO}

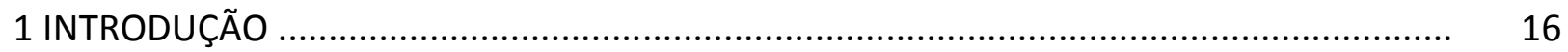

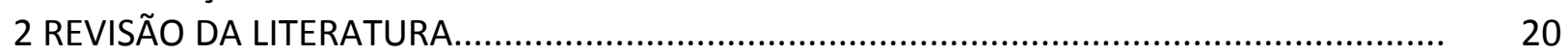

2.1 Doença de Alzheimer........................................................................................ 20

2.2 Linguagem................................................................................................ 23

2.3 Memória e linguagem..................................................................................... 27

2.4 Abordagem pragmática da linguagem................................................................... 29

2.5 Alterações da linguagem no envelhecimento......................................................... 30

2.6 Linguagem na doença de Alzheimer........................................................................... 30

2.7 Alterações da memória semântica........................................................................... 31

2.8 Alterações da memória operacional...................................................................... 32

2.9 Alterações no nível pragmático-discursivo............................................................. 32

2.10 Alterações de verbos e substantivos na doença de Alzheimer................................ 33

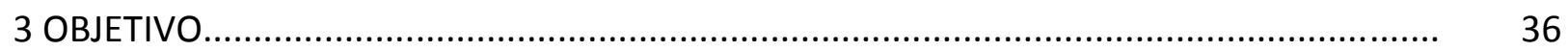

3.1 Objetivo geral............................................................................................ 36

3.2 Objetivos específicos...................................................................................... 36

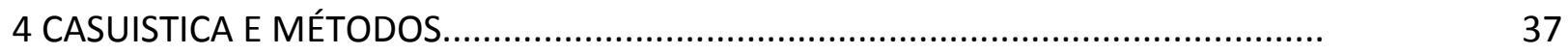

4.1 Critérios de Exclusão....................................................................................... 37

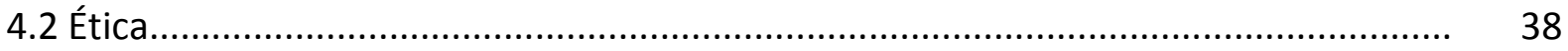

4.3 Instrumentos de avaliação.............................................................................. 38

4.4 Stablex........................................................................................................ 38

4.5 Procedimento geral....................................................................................... 40

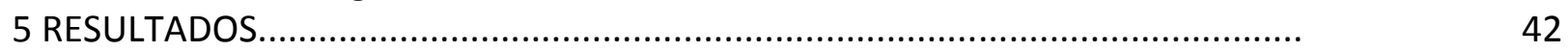

5.1 Limitações da metodologia Stablex...................................................................... 42

5.2 Levantamento dos dados demográficos e clínicos................................................... 42

5.3 Análises das entrevistas dos grupos..................................................................... 45

5.3.1 Análise da frequência e do valor dos itens lexicais........................................... 46

5.3.2 Seleção das classes gramaticais e hápax dos léxicos........................................ 51

5.4 Análise dos itens lexicais verbos e substantivos................................................ 51

5.5 Análise da comparação dos hápax......................................................................... 59

5.6 Análise da comparação dos adjetivos ................................................................. 61

5.7 Análise da comparação dos advérbios................................................................. 63

5.8 Análise da comparação dos pronomes................................................................ 65

5.9 Análise da comparação dos numerais .............................................................. 67

5.10 Análise da comparação das interjeições.............................................................. 69

5.11 Análise da comparação das conjunções ............................................................ 71

5.12 Análise da comparação dos artigos.................................................................... 73

5.13 Análise da comparação das preposições............................................................ 75

5.14 Análise da influência dos dados sócio-demográficos nos itens lexicais............................. 78

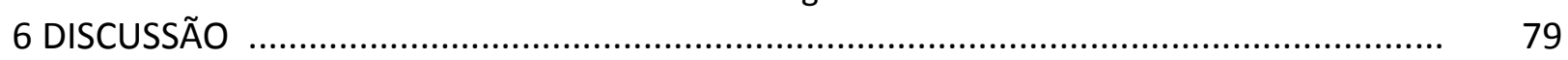

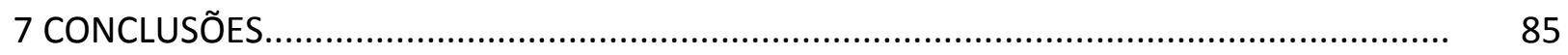

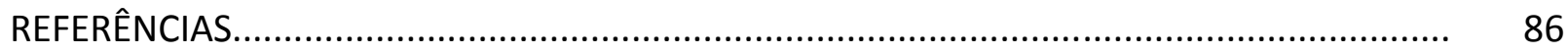

ANEXOS 


\section{INTRODUÇÃO}

A comunicação entre pacientes com doença de Alzheimer, seus cuidadores, e/ou seus parentes se torna bastante afetada na doença de Alzheimer (Asp, \& Villiers, 2010; Burgeois,1990; Bucks et al., 2000; Egan et al., 2010; Gentry \& Fisher 2007; Mansur, 1996).

Segundo Abbott (2011), o mundo está ficando mais rico, mas ao mesmo tempo com a riqueza chegam várias dificuldades. As pessoas prósperas vivem mais o que aumenta a prevalência de doenças. Nos Estados Unidos, 5,1\% da população tem atualmente mais de 65 anos. No Brasil, em 2010, segundo o Instituto Brasileiro de Geografia e Estatística (IBGE), houve diminuição da proporção de jovens, mas aumentou a de idosos significativamente, o alargamento do topo da pirâmide etária pode ser observado pelo crescimento da participação relativa da população com 65 anos ou mais, que era de 4,8\% em 1991, passando a 5,9\% em 2000 e chegando a 7,4\% em 2010.

A população idosa, nos últimos dez anos aumentou em quase 15 milhões a maioria vivendo em centros urbanos. Previsões do IBGE indicam que essa população, em 20 anos, ultrapassará os 30 milhões. Sendo que atualmente para cada 100 mulheres idosas, no Brasil há $86,1 \%$ de homens idosos.

Até 2025, o Brasil será o sexto país do mundo com o maior número de pessoas idosas, segundo dados da Organização Mundial de Saúde (OMS). Por isso, o governo brasileiro deve ter necessidade de criar, rapidamente, políticas sociais e políticas de saúde publica que preparem a sociedade para essa realidade, da mesma forma, segundo o IBGE, de 2008 a 2050, o Brasil passa da quinta à oitava posição no ranking dos países mais populosos, aumentando a relação de idosos na sociedade.

A questão do envelhecimento populacional é fenômeno mundial, consequentemente há maior incidência de diversos problemas de saúde, com consequente aumento do índice de demências. É importante esclarecer que demência não é uma doença especifica, este é um termo geral para designar o declínio na habilidade cognitiva que pode apresentar implicações bastante severas e interferir nas atividades diárias do paciente. A perda de memória é um exemplo de demência, sendo que e a doença de Alzheimer é o tipo mais comum de demência. Há estimativas que existam 35 milhões de indivíduos, no mundo, com a doença e Alzheimer, sendo que no Brasil a estimativa é de 1.200,000 de casos. Em 2010 o impacto das demências na economia global foi 
de 604 bilhões de dólares, incluindo custos com cuidadores. Esse valor ultrapassa os custos de câncer e doenças do coração com prevalência em países ricos e em países em desenvolvimento (Abbott, 2011).

Interessante é observar dados sobre idosos com mais de 100 anos que indicam que a doença de Alzheimer não resulta necessariamente do envelhecimento; não obstante, as probabilidades de diagnóstico da doença de Alzheimer após os 85 anos aumentam, quando as chances ultrapassam a proporção de um em cada três indivíduos (Cummings \& Cole, 2002; Den Dunnen et al., 2008).

O diagnóstico da doença de Alzheimer é clínico e obedece a critérios como: definido, provável e possível, embora a confirmação definitiva se dê por exames anatomopatológicos onde são identificadas placas senis e emaranhados neurofibrilares. Além do diagnóstico clínico, o diagnóstico é feito por meio de neuroimagem, exames laboratoriais e neuropsicológicos. Contudo, a conclusão do diagnóstico pode ser difícil e demorada (Diagnostic and Statistical Manual of Mental Disorders (DSM-IV), 1994; Rockwood \& MacKnight, 2001; Swerdlow, 2007).

Entretanto, é importante esclarecer que existem muitas alterações cerebrais relacionadas ao envelhecimento tais como diminuição do peso encefálico, decréscimo da quantidade de células neurais e gliais por morte celular ou mesmo de suas conexões ou alterações metabólicas (Kandel et al. 2000). É importante ressaltar que na doença de Alzheimer, o processo degenerativo e que culmina com o encolhimento progressivo do encéfalo, ocasiona lesões em regiões e/ou circuitos relacionadas à memória semântica, memória episódica, memória operacional e linguagem, consequentemente afetando o acesso lexical e dificultando a interação verbal entre os indivíduos.

Além disso, aliado a essas alterações ocorrem com o avanço da idade, mudanças nos aspectos psicológicos, socioeconômicos e culturais que geram ou modulam novas formas de relacionamento interpessoal nos diferentes níveis etários, o que em geral ocasiona prejuízo no processo comunicativo efetivo pelo declínio das habilidades da linguagem e consequentemente na qualidade de vida (Grossman, 2008; Mansur, 1996; Mansur \& Radanovic, 2004; Obler \& Pekkala, 2008).

$\mathrm{Na}$ doença de Alzheimer, doença degenerativa e progressiva, os aspectos cognitivos que ficam comprometidos e declinam com o avanço da doença são: a linguagem e a memória, sobretudo a memória episódica, aquela memória que ajuda ao indivíduo a se lembrar de fatos 
passados; outro tipo de memória prejudicada é a memória semântica, que trata do conhecimento do mundo, dos significados.

Levando em consideração, que a comunicação verbal é fator preponderante na socialização, prejuízos nesse processo os quais dificultam ou impeçam a comunicação podem levar ao isolamento, condição em que o estado dos idosos e sua interação social são agravados. A literatura relativa a estudos da doença de Alzheimer indica que um dos papeis neuroprotetores é desempenhado pelo fator de interação social (Bennet et al., 2006; Verghese et al., 2003, Robio et al., 2005).

A interação comunicativa verbal é realizada pelo discurso com os enunciados e formada pelos vários componentes linguísticos: fonéticos, fonológicos, sintáticos, lexical, semântico e pragmático. Esse processo da interação verbal requer compreensão e interpretação dos enunciados sendo para isso necessário um léxico comum entre os falantes, além de que diante de qualquer símbolo linguístico, há de se lhe atribuir significado, interpretá-lo (Araujo, 2002). Nos indivíduos sadios o processo comunicativo, em todas as suas expressões inclusive a verbal ocorre de forma dinâmica e direcionada, de acordo com os interesses das partes envolvidas, reforçando ou enfraquecendo o discurso iniciado (Orlandi, 1996). Entretanto, no contexto de interação na população idosa a interação verbal, no geral, declina pelas alterações sensoriais e motoras, sendo que nos pacientes com doença de Alzheimer sua interação verbal se torna bastante prejudicada pelas alterações neurais.

Fato instigante nesse tema é a observação de que o baixo nível de escolaridade, aliado à vida sedentária, considerando os aspectos da atividade cognitiva e física, e o ambiente padrão, está associado a problemas de saúde e funcionalidade nos idosos, com aumento significativo do risco de doenças crônicas. Além disso, os indivíduos com baixo nível de escolaridade podem estar mais propensos a desenvolver doença de Alzheimer e outras demências. Outras causas dos diferentes estilos de vida associados à educação tais como nutrição, consumo de álcool e exposições educacionais podem levar ao desenvolvimento de doença de Alzheimer (Snowdow et al., 1996).

A interação comunicativa entre cuidadores e pacientes com pobreza de elementos lexicais se torna deficitária e comprometida, levando muitas vezes os parentes e/ou cuidadores a ficarem sobrecarregados e confusos o que agrava a progressão da doença e os sintomas comportamentais associados. 
Estudos da linguagem em doenças nas décadas passadas focavam no desenvolvimento de modelos cognitivos do discurso e na descrição de operações cognitivas, pela crença que estavam envolvidos na compreensão e expressão linguística. Desde a última década, há bastante interesse em explorar o discurso de indivíduos em vários tipos de demência, entre eles aquele da doença de Alzheimer (Orange \& Kertesz, 2000; Asp \& Villiers, 2010).

Estudos prévios da linguagem na doença de Alzheimer indicavam a preservação do domínio sintático e fonológico e deterioração no domínio lexical, principalmente quanto à nomeação de objetos, coerência, produção discursiva, incluindo poucos itens lexicais de informação, poucas proposições objetivas e o aumento de repetições (Snowdow et al., 1996), existe necessidade de diversificar os estudos nessa área a fim de verificar outras alterações de linguagem, uma vez que muitas pesquisas são efetuadas na avaliação efetuada apenas com base no conhecimento do pesquisador. Além disso, observa-se carência de estudos que comparem o discurso espontâneo de idosos e de pacientes com doença de Alzheimer que possam ser e parecer próximos daquele utilizado no dia a dia. Esses dados poderiam possibilitar uma má avaliação da linguagem usual e consequentemente detectar alterações precoces (Bucks et al., 2000). Existe, ainda, o fato de que muitos estudos da linguagem não abordam o nível discursivo-pragmático (Damasceno, 2000). Os resultados de semelhantes abordagens poderiam fornecer subsídios para melhorar e ampliar a comunicação e concomitantemente auxiliar o diagnóstico precoce da doença.

Pelo exposto, são claras as implicações da importância do estudo da linguagem na Neurociência Cognitiva (Bear et al., 2001; Kandel et al., 2000; Mesulam, 2001; Shapiro \& Caramazza, 2004; Stemmer \& Whitaker, 2008). A importância da análise desse tema no contexto clínico em pacientes com doença de Alzheimer é objeto deste estudo que busca analisar os itens lexicais verbos e substantivos com algumas subclasses, além da análise sem subclasses dos hápax, adjetivos, advérbios, pronomes, numerais, interjeições, conjunções, artigos e preposições expressos no discurso oral desses pacientes a fim verificar quais itens estão mais preservados para posteriormente melhorar e ampliar a comunicação verbal entre pacientes e cuidadores. 


\section{REVISÃO DA LITERATURA}

\subsection{Doença de Alzheimer}

A doença de Alzheimer é uma doença neurodegenerativa, relacionada à idade, normalmente tem causa esporádica (não hereditária) e familiar. A causa familiar pode se apresentar por volta dos 30 ou 40 anos, enquanto que a de causa esporádica em geral acontece após os 65 anos. As alterações neurais que a caracterizam são atrofia neural, perda de conexões sinápticas e acumulo de placas neuríticas. Sendo que os emaranhados neurofibrilares compreendem mais da metade dos casos desta síndrome. A Doença de Alzheimer tem sido relatada como a principal causa de demência (Asp \& Villiers, 2010; Balthazar, 2008; Bottino et al., 2002; Carthery-Goulart 2005; Egan et al 2010).

Há condições neuropatológicas estabelecidas, mas as causas da doença ainda são desconhecidas, embora muitos especialistas concordem que como qualquer doença crônica ela seja o resultado de múltiplas causas e não únicas. Entre as causas conhecidas para o desenvolvimento da doença está o acumulo da proteína $\beta$-amiloide fora da célula e proteína tau dentro da célula (Alzheimer's disease facts and figures, 2012). A Figura 1 mostra a imagem histológica da proteína $\beta$-amiloide e a Figura 2 mostra a imagem da proteína tau.(Petersen et al., 2006).

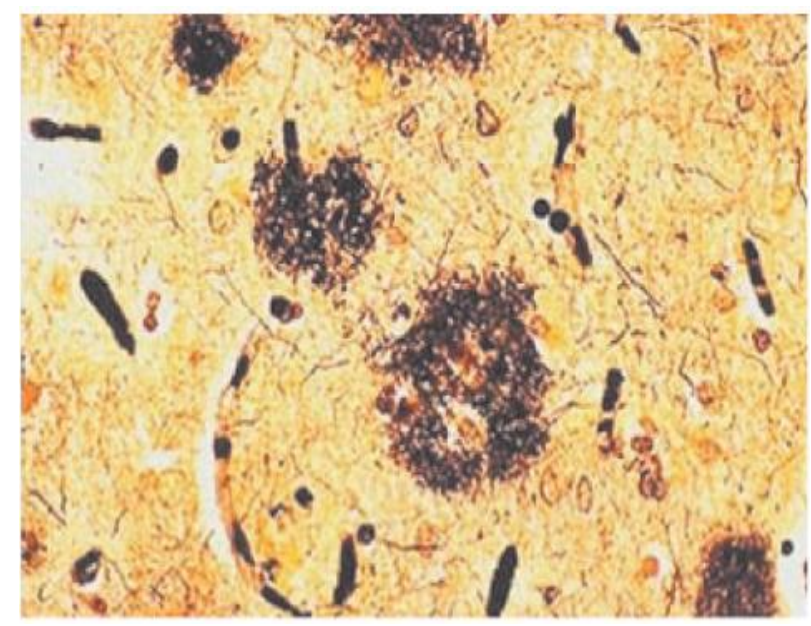

Figura 1. Imagem histológica das placas neuríticas (proteína $\beta$-amiloide) 


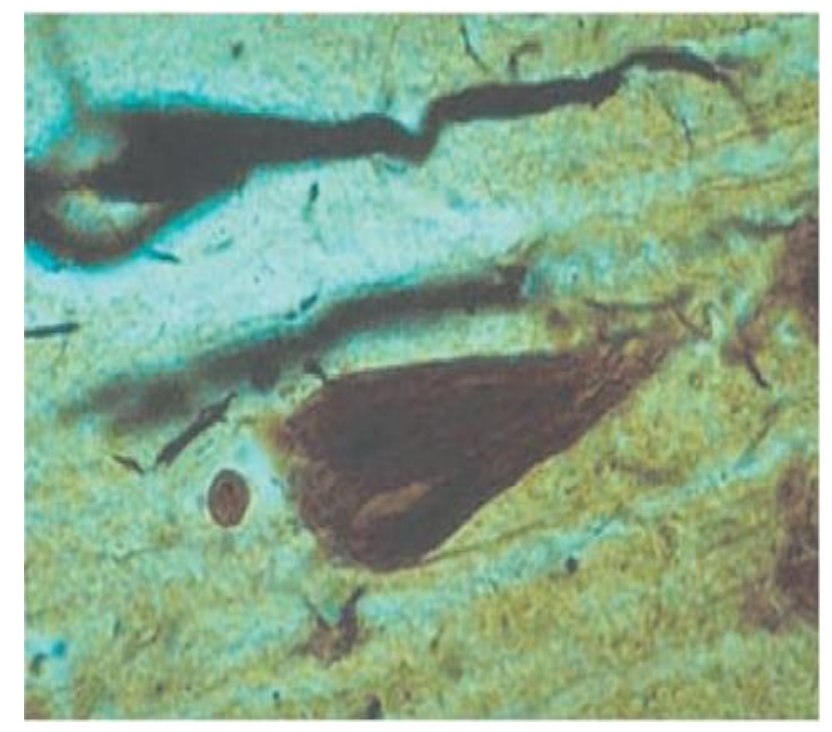

Figura 2. Imagem histológica dos emaranhados neurofibrilares (proteína tau

A incidência dessa doença se duplica a cada cinco anos a partir dos 65 anos de idade, com diagnóstico de 1275 novos casos por ano para cada 100,000 pessoas maiores de 65 anos. Além da idade, outros fatores influenciam o risco para a doença de Alzheimer, são eles os fatores genéticos, sobretudo o alelo da apolipoproteina E (APOE4), hipertensão, fatores de estilo de vida tais como o tipo de dieta, falta de exercícios físicos, baixo grau de envolvimento social ou intelectual e diabetes (Annaert \& De Strooper, 2002; Jerdziewsky et al., 2010 Rockwood \& Macknight, 2001; Walsh \& Selkoe, 2004).

Mais de 35 milhões de pessoas tem doença de Alzheimer em todo o mundo (Quefurth \& Laferla, 2010). Destes 5,5 milhões estão nos Estados Unidos, sendo que no Brasil esse índice é de aproximadamente $1.200,000$ pessoas.

O diagnóstico da doença de Alzheimer no Brasil e no mundo todo tem sido baseado nas últimas décadas nos critérios do (Diagnostic and Statistical Manual of Mental Disorders (DSM IV) e do National Institute of Neurological and Communicative Disorders and Stroke e Alzheimer's Disease and related Disorders Association (NINCDS-ADRDA).

Para que seja estabelecido o diagnostico como doença de Alzheimer, pelo menos duas funções cognitivas centrais devem estar significativamente comprometidas Entre elas: memória, comunicação e linguagem, habilidade de focar e prestar atenção, raciocínio e julgamento, 
percepção visual e mudanças comportamentais. Além disso, na doença de Alzheimer, constata-se que a capacidade de aprender novas informações ou de recordar informações recentemente aprendidas fica comprometida. São observadas, também, afasias, apraxias, agnosia e distúrbio do funcionamento executivo. Tem sido observado que após o diagnostico a sobrevida média é de 3 a 9 anos, contudo, alguns casos podem durar até 20 anos (Alzheimer's disease facts and figures, 2012; DSM IV, 1994).

Em relação aos comportamentos têm sido observados que estes também podem estar alterados. Alguns pacientes apresentam alterações de personalidade, perda de interesse, agressão e apatia em graus variados (Bottino et al., 2002).

O principal sistema de memória comprometido é o da memória episódica, assim como o do da memória operacional e do da memória semântica. É importante ressaltar que essas memórias episódicas e semânticas estão relacionadas ao armazenamento geral do conhecimento de conceitos e fatos, que envolvem habilidades de recuperação e nomeação, enquanto que a memória operacional é uma memória de curta duração, porém quando sofre prejuízo, ocorre dificuldade de acesso episódico e semântico (Almor et al., 1999; Balthazar, 2008; Carthery-Goulart, 2005 MacDonald et al., 2001; McDonald, 2008; Wierenga et al., 2011). Esses pesquisadores também relatam que a ruptura da memória semântica na doença de Alzheimer é devida à alterações dos lobos temporais laterais inferiores ou dos lobos frontais, ocasionando baixa ativação e resgate da informação semântica.

Os prejuízos de memória relatados têm consequências na linguagem aparecendo sobretudo, como dificuldades em encontrar as palavras (Egan et al., 2010; Wierenga et al., 2011).

Como doença de evolução progressiva, a doença de Alzheimer classifica-se em três estágios: leve, moderado e grave. Esses estágios são julgamentos clínicos baseados em exames de neuroimagem e neuropsicológicos (Alzheimer's disease facts and figures, 2012; DSM IV, 1994; Rockwood \& Macknight, 2001).

No estágio leve, o paciente apresenta perda significativa do desempenho de tarefas da vida diária, mas ainda pode realizar tarefas de maneira independente. Nessa fase, a função mais comprometida é a memória recente, com diminuição da capacidade de aprender informações novas, enquanto a memória de procedimento em geral está preservada, sendo afetada mais tardiamente. Em relação à pontuação do Mini Exame do Estado Mental- MEEM nessa fase leve normalmente e superior a 22 pontos. No estágio moderado, como o comprometimento é maior, o 
indivíduo precisa de ajuda para realizar as atividades instrumentais e tarefas básicas do dia a dia. Nesta fase a pontuação do Mini Exame do Estado Mental - MEEM normalmente varia de 12 e 18 pontos (Rockwood \& Macknight, 2001).

\subsection{Linguagem}

A linguagem é uma faculdade extremamente complexa que nos permite codificar, elaborar e comunicar pensamentos e experiências pela mediação de símbolos arbitrários conhecidos como palavras (Catani \& Mesulam, 2008). Além disso, a linguagem se destaca por permitir organizar categorias em nosso mundo natural e social mesmo que ela não seja muito clara em transmitir os tipos de informação que os rostos, cheiros e emoções são capazes de transmitir. A linguagem parece ter se originado a partir de reforço oral de gestos simbólicos usados na comunicação tais como o sinal facial de raiva, tristeza, perplexidade, escárnio etc. ou mesmo e reiterá-los, de forma que as vias linguísticas puderam se desenvolver em paralelo (Bownds, 1999). Ademais, as mudanças cognitivas que são subjacentes à linguagem não necessariamente se desenvolveram para dar suporte à linguagem falada como agora a experimentamos, porque não poderia ter existido suporte para o sistema de aquisição da linguagem. Assim, as palavras e símbolos da linguagem provavelmente se originaram fora da linguagem como símbolos inicialmente inventados para propósitos não linguísticos (Bownds, 1999), mas se desconhece a origem real da linguagem.

Estudos sugerem que existem dois mecanismos biologicamente diferentes considerados cruciais para a aquisição da linguagem: o sistema de linguagem de domínio específico e um mecanismo social dedicado ao desenvolvimento do entendimento de outras mentes (TagerFlusberg, 2002).

A linguagem está firmemente inserida na experiência humana constituindo diferentes "níveis" da forma linguística e eles são a fonética, o léxico, a sintaxe, a semântica, a pragmática e o discurso, além de expressar emoção direita e indireta, implícita ou explicitamente é um sistema muito criativo. Todavia, para entender estes níveis é importante o conhecimento da relação cérebro e linguagem (Bear et al.,2001; Pinker, 1994; Van Lacker \& Pachama, 1998). Da mesma forma, a linguagem é a parte mais acessível da mente, mesmo sem verbalizar, pois ela propicia novas combinações de ideias, organiza a experiência sensorial e permite ao individuo 
expressar sua identidade, seus pensamentos, sentimentos e expectativas além de influir nos conhecimentos dos indivíduos e socialização (Bear et al., 2001; Kandel et al., 2000; Shapiro \& Caramazza, 2004).

Como toda atividade humana, a produção da linguagem também é realizada por atividade neural, o cérebro tem capacidade de manter as relações arbitrárias que ligam um grande número de palavras a conceitos subjacentes. Sua capacidade de combinar essas palavras virtualmente num número ilimitado de diferentes expressões é impressionante (Binder \& Price 2001; Démonet et al., 2005; Dronkers et al., 2000; Pulvemüller, 1999; Shapiro \& Caramazza, 2004 ).

Pulvemüller (1999) destaca que o córtex cerebral é uma memória associativa, e que um conjunto de células bem conectadas, uma rede neural, se forma quando neurônios em diferentes áreas corticais são frequentemente ativados ao mesmo tempo. A distribuição cortical desses conjuntos deve ser consequência do local onde a atividade neural correlacionada aconteceu durante o processo de ativação neural, por exemplo, por aprendizagem. Além disso, esse autor ressalta que o processo de aprendizagem tem implicações nas topografias corticais e na atividade dinâmica dos conjuntos de células que se formaram durante a aquisição de conhecimentos, como o caso da linguagem.

Assim, conjuntos de redes neurais que representam formas de palavra fonológica estão bem lateralizados e distribuídos nos córtices laterais; assim como conjuntos que representam palavras abstratas tais como palavras de função gramatical estão bem lateralizados e restritos a essas regiões laterais. Entretanto, conjuntos que representam palavras de conteúdo concreto incluem neurônios adicionais, que estão localizados em ambos os hemisférios; conjuntos que representam palavras relativas à estímulos visuais incluem neurônios nos córtices visuais e conjuntos que representam palavras relacionados à ações incluem neurônios dos córtices motores (Pulvemüller, 1999).

Técnicas de neuroimagem funcionais tais como PET- Tomografia por emissão de Prótons, RMF- Ressonância magnética funcional, MEG- Magnetoencefalografia tornaram possível mensurar vários índices de atividade neural ao vivo, entre elas a da linguagem. Essas técnicas mostram que o cérebro é uma rede muito eficiente, bem distribuída, funcionalmente ligada às regiões que continuamente compartilham informações com outras regiões. Atualmente, com a ajuda da neuroimagem funcional é possível, diretamente, correlacionar estruturas cerebrais e 
várias operações mentais (Apostolova et al., 2008; Binder et al., 1999; Démonet et al., 2005; Senhorini, 2010; Van den Heuvel \& Hulshoff Pol, 2010).

O léxico, conjunto de palavras ou de itens lexicais (palavras simples ou expressões que um indivíduo conhece), é o componente da linguagem mais sensível a transformações e adaptações porque as palavras ou itens lexicais mudam e estão em constante evolução. Os indivíduos são tão criativos para gerar novas palavras assim como para formar frases e sentenças. Portanto, as palavras são componentes morfológicos e sintáticos que possuímos para formar frases e discursos, então, notável é como fazemos uso automático dos itens lexicais com frequência (Pinker, 1994). Nesse sentido, Barbosa (2001) destaca a importância da formação lexical dos conceitos nos discursos, o que muitas vezes dificulta o processo comunicativo como, por exemplo, usar itens lexicais de baixa frequência ou de pouco uso.

Aspecto curioso é que em relação à predominância hemisférica, estudos de neuroimagem raramente encontram ativação limitada do hemisfério esquerdo, como imaginado em décadas passadas. Da mesma forma, estudos com pessoas destras tem mostrado atividade bilateral sem assimetria, o que pode ser determinado por estímulos auditivo, visual, estímulos figurativos versus simbólicos, itens lexicais isolados ou sentenças, compreensão versus produção, etc. (Apostolova et al., 2008; Démonet et al., 2005). Entretanto, em relação à linguagem, a questão da predominância hemisférica, descrita há mais de um século com estudos de afasia, continua e é ainda tema de pesquisa, podendo ser afirmado que nessa habilidade exista uma predominância temporal do hemisfério esquerdo (Démont et al., 2005).

O hemisfério esquerdo (HE) é tipicamente melhor do que o hemisfério direito (HD) para a percepção da fala e outras tarefas fonéticas tais como ritmo e nomeação de palavras e nãopalavras escritas. O HE também é dominante para determinar se uma sequência de letras forma uma palavra e para tratar de informação sintática na produção e compreensão da linguagem, por outro lado, de forma complementar o HD é superior na compreensão da prosódia ou entoação da fala. Lesões no HD também interferem na habilidade para entender certos tipos de piadas que dependem da habilidade de abstrair um contexto na sentença, iniciação da fala, interpretação de atos da fala e intenções (Hellice, 2008; Turgeon \& Macoir, 2008).

Em relação ao processamento, produção e compreensão da linguagem, estudos apontam que as rotas de entradas auditivas (palavras faladas e sons ambientais são processadas em regiões corticais variadas de vias auditivas) e rota visual (palavra escrita, língua de sinais, visão de fotos 
e cenários, nas áreas visuais), por sua vez, as palavras de ação ativam as áreas motoras (Démonet et al.,2005; Kovic et al., 2010; Mansur \& Radanovic, 2004; Martin et al., 2002; Pulvemüller, 1999). Além disso, há mecanismos para processamento do simbolismo-som que poderiam permanecer no emparelhamento das formas das letras e a forma do objeto na produção e compreensão da linguagem (Kovic et al., 2010).

A Figura 3 mostra as regiões principais envolvidas no processamento da linguagem, no hemisfério esquerdo se destacam as áreas dos lobos frontais, temporais, o giro supramarginal, o giro angular, giro temporal médio, giro temporal inferior, o giro superior, a junção occipital parietal, giro de Heschel, córtex auditivo primário, planum temporal, córtex motor e córtex prémotor. Na parte inferior se destaca a parte sagital do hemisfério esquerdo onde se destacam o córtex do cíngulo anterior, o córtex estriado, o giro lingual, o giro fusiforme e o polo temporal principalmente. 


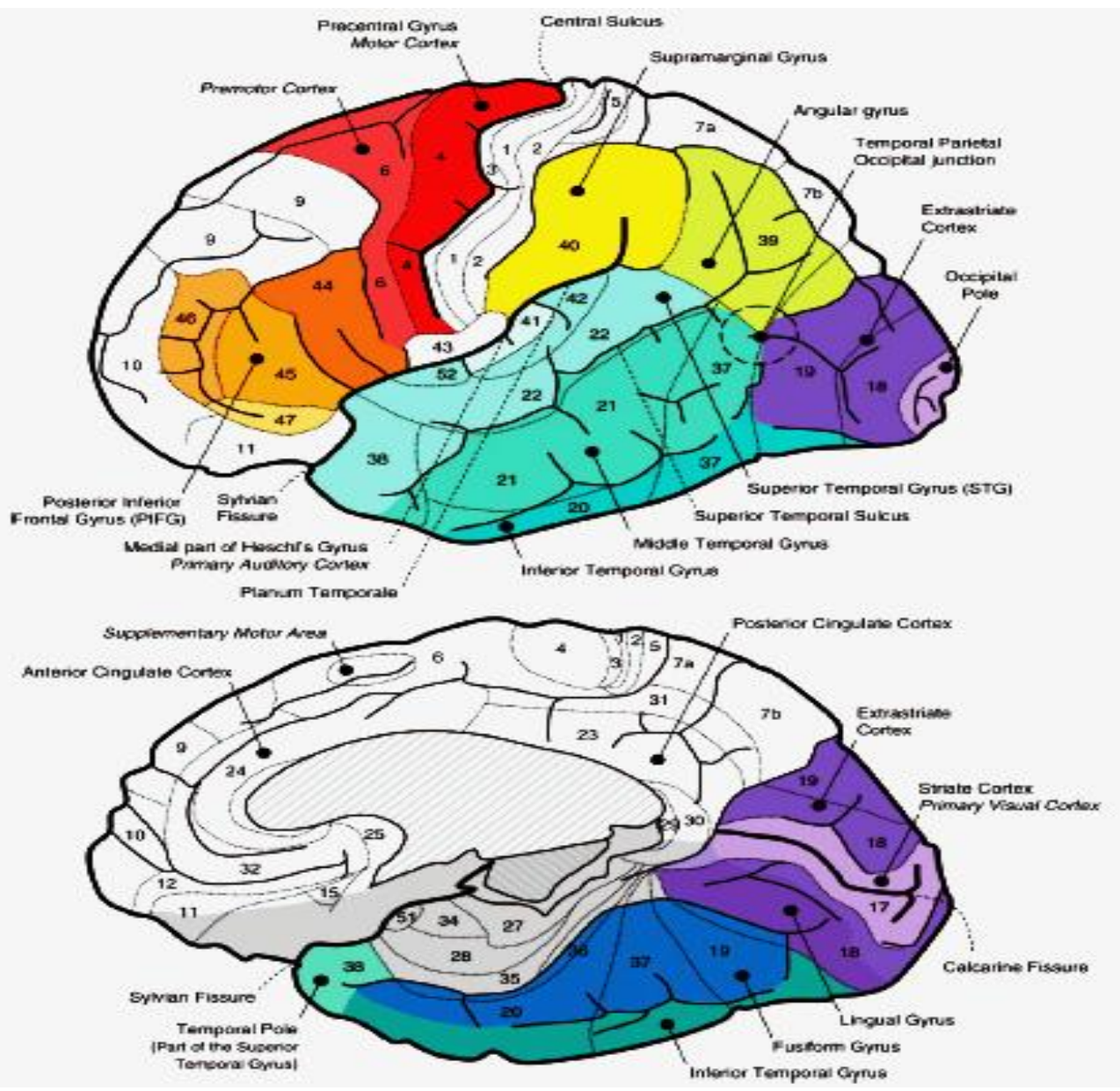

Figura 3. Regiões principais envolvidas no processamento da linguagem. No topo, vista lateral do hemisfério esquerdo humano. Na parte inferior, vista sagital média do hemisfério direito que foi inclinado externamente para mostrar a superfície basal do lobo temporal (área sombreada). (Démonet et al., 2005).

\subsection{Memória e linguagem}

Memória é o vocábulo usado para determinar o processo cognitivo para guardar e recuperar informações, ela está bem relacionada ao domínio da linguagem, pois não existe domínio cognitivo isolado.

O uso da linguagem no ser humano resulta da ação integrada das funções cognitivas da memória e da atenção para os processos de informação e comunicação. Anteriormente, as 
habilidades da linguagem eram consideradas isoladas de outras funções cognitivas, mas atualmente essa abordagem não se justifica mais porque os distúrbios da linguagem não acontecem de forma isolada, a afasia raramente acontece na ausência da perda de memória ou problemas de atenção e execução. A linguagem tem função central na cognição humana, uma vez que está intimamente relacionada a outras funções mentais superiores, tais como atenção e memória de trabalho (Turgeon \& Macoir, 2008).

A memória de trabalho encontra substrato neural em estruturas e mecanismos usados para armazenar temporariamente e manipular as informações. É um tipo de memória rápida de armazenamento temporário de pouca informação, que é usado para a recuperação de outras memórias, por exemplo, para o acesso à memória episódica. A memória operacional estabelece a conexão entre a memória semântica e a memória de longo prazo, esta requer muita repetição e treino (Almor et al., 1999; Bear et al; 2002; Orange \& Kertesz, 2000; Turgeon \& Macoir, 2008).

A memória episódica, considerada memória de longo prazo, é aquela utilizada para armazenamento de fatos e eventos, sendo indispensável no processo de acesso e recuperação da linguagem, dessa forma, os processos lexicais semânticos relacionam-se à memória de longo prazo, a qual é especializada em associações arbitrárias e está localizada em estruturas do lobo temporal. Da mesma forma, a memória declarativa, constituinte da memória episódica, aquela que permite a retenção de experiências que possibilitam o acesso consciente ao conteúdo de nossas informações esse sistema de memória tem sido localizado no hipocampo e nas regiões adjacentes (Ullman, 2008). Além disso, existem relações claras entre os sistemas de memória explicita nos indivíduos adultos enquanto efetuam a comunicação verbal que requeira a implicação de recursos atencionais dos participantes (Pulvemüller, 1999).

O sistema de memória semântica interpreta o significado individual da palavra, informação sintática, qual substantivo é o sujeito do verbo e o conhecimento geral do mundo para formar uma interpretação global de significação da sentença (Joubert et al., 2010).

O sistema semântico tem o envolvimento do córtex temporal inferior, córtex temporal médio e posterior, incluindo o giro angular e áreas de associações frontais, é um sistema de rede neural bem complexo e na sua maior parte funcionalmente localizada no hemisfério esquerdo. As regiões centrais incluem o córtex temporal superior posterior/córtex parietal inferior enquanto que o córtex do lobo frontal esquerdo está associado com a produção de verbos (itens lexicais de ação) enquanto que o córtex temporal esquerdo está associado à nomeação de objetos (Binder \& 
Price, 2001; Démonet et al., 2005, Grossman, 2008; Pulvemüller, 1999). Além disso, existem dúvidas se a área basal temporal da linguagem faz parte da habilidade de perceber o mundo em diferentes categorias, pois essa área é muito heterogênea e pode ser composta de muitas subpartes, muitas delas de modalidade específica, mas muito entrelaçadas entre si (Démonet et al., 2005; Grossman, 2008).

\subsection{Abordagem pragmática da linguagem}

A forma como a linguagem é usada e interpretada e a qual leva em consideração as características do falante e do ouvinte, bem como o efeito das variáveis contextuais e situacionais constituem a noção linguística da pragmática. A pragmática também inclui aspectos do discurso, na medida em que a produção e interpretação do discurso também dependem dela. Da mesma forma, a pragmática amplamente se direciona à habilidade do falante para inferir relações lógicas e pressuposições entre sentenças baseadas no conteúdo do que foi dito (Asp \& Villiers, 2010; Stemmer, 2008). Na comunicação, há necessariamente que existir interação, sendo que o resultado da interação comunicativa pode ocorrer em longo prazo, ou de forma não tão visível. Assim, visto que a comunicação é interação e que a relação entre os falantes ou ouvintes é marcada pela interpretação, os interlocutores são forçados a dar significados às enunciações (Araujo, 2002; Barbosa, 2001 Mussalim, 2000; Stemmer, 2008).

A linguagem é usada também na interpretação dos enunciados com suas marcas que remetem ao efeito de enunciação que é a realidade linguística concreta. Enuncia-se para interpretar (Fiorin, 2005). Outros aspectos da pragmática, além da manutenção do tópico no discurso, compõem a interpretação de linguagem não-literal, como atos de fala indiretos; o humor, a linguagem figurativa, o sarcasmo, a ironia e as metáforas e expressões idiomáticas (Stemmer, 2008). 


\subsection{Alterações de linguagem no envelhecimento}

Há declínio de linguagem no envelhecimento, que é observado por problemas com a recuperação e produção dos itens lexicais substantivos gerais e de nomes próprios, possivelmente pela baixa frequência de uso, mas também acontecem com outros tipos de substantivos e até mesmo com expressões idiomáticas, além disso, os idosos não se beneficiam de pistas semânticas na tarefa de nomeação, mas de pistas fonológicas. Além disso, os idosos têm problemas de compreensão, especialmente de material auditivo com textos complexos ou produção verbal em situações de barulho, ou mesmo padrões do discurso Esses problemas também podem estar associados a dificuldades de domínios cognitivos como atenção e memória que declinam com o envelhecimento (Asp \& Villiers, 2010; Grossman, 2008; Obler \& Pekkala, 2008).

Muitas vezes as dificuldades da linguagem acompanham o declínio dos órgãos sensoriais, órgãos relacionados à produção da linguagem, além disso, no sistema auditivo há perda periférica no sistema de transmissão e recepção dos sons ocasionando dificuldade na compreensão e produção da linguagem, e consequentemente pausas para encontrar palavras, o que gera circunlóquios e dificuldade para nomeação. Em comparação a jovens, ao serem perguntados, os idosos de forma geral dão respostas mais longas e cometem mais erros na fala (Gorssman, 2008 Mansur \& Radanovic, 2004; Obler \& Pekkala, 2008).

\subsection{Linguagem na doença de Alzheimer}

O discurso dos pacientes com doença de Alzheimer é frequentemente descrito como "vazio" porque sua proporção de palavras e expressões transmite pouca ou nenhuma informação e frequentemente as frases são incompletas (Almor et al., 1999; Grossman, 2008). Parece que a característica mais comum do discurso "vazio" dos pacientes é o uso frequente de itens lexicais com pouca carga semântica (negócio, coisa, trem,). Embora essas mesmas palavras "vazias" sejam comuns na linguagem geral, elas são palavras de alta frequência e seu uso é restrito a circunstâncias e temas particulares, mas analisadas no contexto clínico podem constituir ferramentas de diagnóstico e avaliação da resposta ao tratamento, assim pela sua compreensão é possível contribuir, ajudar a melhorar a comunicação entre pacientes e cuidadores (Almor et al., 1999; Asp \& Villiers 2010; Bucks et al., 2000; Garrard et al.,2005). 
No geral, os distúrbios da linguagem na doença de Alzheimer são precoces, paralelos ao acometimento da memória. A recuperação da palavra é um dos aspectos mais afetados na linguagem desses pacientes assim como a compreensão de sentenças sintaticamente complexas (Garrard et al.,2005; Grossmann, 2008; Mansur \& Radanovic, 2004; Obler \& Pekkala, 2008).

Grossman (2008) destaca que a afasia era atribuída aos déficits de atenção, memória e a outros déficits não linguísticos nos pacientes com doença de Alzheimer, mas esse autor afirma que o resultado das alterações da linguagem nessa doença é diferente das afasias porque a base morfológica das demências, no geral, é difusa, enquanto que a afasia compromete o funcionamento cerebral numa distribuição anatômica específica, focal dependendo do tipo de afasia.

Pacientes com doença de Alzheimer produzem mais erros parafrásicos semânticos mais do que erros fonêmicos. A pausa para procura de palavras (frequentemente na procura de palavras), circunlóquios (falar sobre um tópico e descrever uma palavra alvo quando não pode ser recuperada) e nomeação são muito comuns. Além disso, a dificuldade de nomeação é associada a deficiências na recuperação lexical e dificuldade da representação semântica. Julga-se que isto decorre da desconexão dos circuitos envolvidos na memória semântica (Almor et al., 1999; Almor et al., 2003; Astell \& Harley, 2002; Balthazar, 2008; Grossman, 2008; Kim \& Thompson, 2004; Mansur, 1996).

A dificuldade de nomeação pode variar dependendo da categoria semântica que foi perguntada, da mesma forma, os déficits de nomeação também podem ser sensíveis à subcategoria gramatical que está em análise, por exemplo, os verbos são mais difíceis de recuperar que os substantivos na doença de Alzheimer (Grossman, et al., 2004; Grossman, 2008).

Em estudo sobre a memória operacional e linguagem no envelhecimento normal na doença de Alzheimer, Carthery-Goulart (2005) aponta que a quantidade e qualidade das alterações da linguagem na comunicação diferem entre os vários pacientes sendo que as alterações de linguagem na doença são quantitativamente e qualitativamente diferentes do envelhecimento normal.

\subsection{Alterações da memória semântica}

A disfunção no córtex temporal superior direito pode contribuir no inicio dos déficits semânticos caracterizados pela perda de características especificas de conceitos, dificuldade em 
achar as palavras certas, uso de palavras inapropriadas na fala e uso de hiperônimos como animal ou fruta, da mesma forma. Assim, a deterioração semântica observada em pacientes com doença de Alzheimer é progressiva, primeiramente afeta atributos específicos e depois conhecimento conceitual amplo. Por exemplo, no inicio da doença os pacientes podem nomear os tipos de pássaros, "papagaio", mas falham ao diferenciá-los na categoria mais incomum que os diferencie, por exemplo, arara azul. Com o avanço da doença, os pacientes tem muita dificuldade em nomear as categorias e simplesmente expressam o nome genérico ave e depois somente decodificam a palavra animal. Da mesma forma no começo da doença de Alzheimer, os pacientes esquecem mais os nomes de pessoas famosas (nomes próprios), assim como existe a possibilidade de guardar mais as palavras adquiridas na infância, além de deteriorar o conteúdo e processamento semântico (Asp \& Villiers, 2010; Chertkow et al., 2008; Grossman, 2008; Guiffard et al., 2008; Joubert et al.,2010, Reilly et al. 2011; Venneri et al., 2008).

\subsection{Alterações da memória operacional}

Em função dos falantes serem orientados a reter uma dada informação para mantê-la enquanto interagem comunicativamente e ao processar os enunciados na conversação, a dependência da memória operacional é crucial, além de memória operacional estar implicada em várias categorias de informações durante as operações cognitivas (Almor et al., 1999). Essa condição remete à possibilidade de que a alteração da memória operacional possa ter uma função importante na fala "vazia" dos pacientes com doença de Alzheimer. Além disso, Almor et al (1999) colocam que a deterioração da memória operacional na doença de Alzheimer ocasiona um decréscimo total na ativação dos referentes de quem se fala no discurso verbal, portanto causando dificuldades nas expressões decodificadas (Almor et al., 1999; MacDonald et al., 2001; Zurif, 2000). Da mesma forma, o desempenho prejudicado desses pacientes pode ser evidência de dificuldade em manter todas as informações na memória operacional, necessária para executar tarefas com desempenho bem sucedido (Bucks et al., 2000).

\subsection{Alterações no nível pragmático-discursivo}

Os pacientes com doença de Alzheimer apresentam aumento significativo de repetições em relação aos idosos sadios, seus processos sintático-fonológicos respondem pelo número de ensaios 
para decodificar, além disso, esses pacientes realizam várias reformulações que aumentam com o desenvolvimento da doença. Assim, as interações verbais com esses pacientes estão repletas de mudanças de tópicos, uso de temas inapropriados, frases confusas, hesitações e conteúdo semântico anormal (Asp \& Villiers, 2010; Garcia \& Joanette, 1997; Grossman, 2008; Mansur, 1996; Orange \& Kertesz, 2000).

A literatura tem relatado que mesmo nas fases iniciais da doença o paciente pode apresentar problemas semântico-lexicais semelhantes aos encontrados nas afasias semânticas: empobrecimento do léxico, especialmente substantivos de baixa frequência, e dificuldades semântico-discursivas (Almor et al., 1999; Damasceno, 2000). Por sua vez, Ortiz \& Bertolucci (2005) encontraram diferenças significativas na realização de tarefas de compreensão auditiva nos discursos.

\subsection{Alterações dos verbos e substantivos na doença de Alzheimer}

Os pacientes com doença de Alzheimer apresentam principalmente dificuldades com os verbos, substantivos, porque esses itens lexicais são muito frequentes e podem ser ou não recuperados pelos déficits da memória operacional e memória semântica (Almor et al., 2003; Balthazar, 2008; Gonnermann et al., 2003, \& Macdonald et al., 2001).

Os pacientes produzem verbos e substantivos de forma inadequada e têm sido bastante relatada (Almor et al., 1999; Apostolova et al., 2008; Astell \& Harley, 2002; Chiarelli et al., 2005; Gonnerman et al., 2003; Joubert at al., 2010; Kim et al., 2004; Masterson et al., 2005; Mätzig et al., 2009; Rico Duarte et al., 2009). Com relação aos substantivos, os déficits de categorias específicas são consequência da organização semântica variável de categorias de substantivos vivos e não-vivos (Chan et al., 2001; Kim \& thompson, 2004), ademais, esses autores afirmam que a organização do conhecimento semântico na categoria "animais" está alterada nesses pacientes no estágio leve enquanto que a categoria de "ferramentas" está intacta. No começo da doença de Alzheimer as dificuldades aparecem no processo de informação especifico, integrando toda a gama de conceitos de seres vivos e não-vivos, isso degrada os conceitos de seres vivos, especificamente as características distintivas, por exemplo, cabeça longa, listras, etc, por outro lado, nos estágios leve e moderado, as características partilhadas parecem estar melhor 
preservadas do que as características distintivas (Chan et al., 2001; Masterson et al., 2005; Rico Duarte et al., 2009).

Contudo, estudos com análise de verbos e substantivos apresentam controvérsias. $\mathrm{O}$ estudo de Materson et al., (2007) mostra que quanto a preservação de verbos não foram encontradas diferenças entre verbos e substantivos, uma vez que os pacientes e controles tiveram mais rapidez ao nomear objetos do que as ações. No quesito compreensão, as respostas demoraram mais quando os itens lexicais eram verbos. Esses autores afirmam que é bem conhecido o fato de que os substantivos estão localizados nas regiões posteriores do encéfalo, enquanto os verbos estão mais nas regiões anteriores, embora na doença de Alzheimer, os sinais de neurodegeneração inicialmente aparecem no córtex temporal e límbico. Além disso, esses autores também afirmam que a degeneração encefálica depois se espalha gradualmente até alcançar os lobos frontais no estágio grave da doença, o que lhes permite inferirem que os verbos estão mais preservados nos primeiros estágios da doença de Alzheimer.

O léxico de qualquer língua contém mais substantivos do que verbos, mas a frequências no uso dos verbos é maior do que dos substantivos. Como os verbos são adquiridos depois, eles podem ser perdidos primeiro, além disso, considera-se que os verbos tendem a serem morfologicamente mais complexos do que os substantivos, o que leva a explicar as dificuldades no seu uso. Ainda, diferença semântica ou sintática entre substantivos e verbos pode ter uma função causal na aquisição tardia dos verbos e sua maior vulnerabilidade de perda desses itens lexicais no cérebro. Não obstante, a maior complexidade dos verbos em relação aos substantivos não explica a preservação ou não de verbos na doença de Alzheimer (Mätzig et al., 2009).

Assim, esta pesquisa se justifica pela consideração de que o uso da linguagem, no contexto biopsicossocial, é um dos principais comportamentos cognitivos de grande efeito na conduta humana, a qual é baseada no léxico e na gramática, principalmente (Dronkers et al., 2000). Sendo que a linguagem partilha na construção das abordagens linguístico-comunicativas, o estudo de suas alterações é significava. Além disso, a importância da linguagem oral aliada às dificuldades de comunicação dos pacientes com DA, mais o relativo desconhecimento das características da comunicação verbal desses pacientes e seus cuidadores no Brasil, reforça a relevância do tema.

De estudo piloto nesse tema emergiram as hipóteses que, mesmo os pacientes em estágio moderado, ao serem estimulados podem responder adequadamente as perguntas e manter conversações e assim, poderiam melhorar a sua qualidade de vida e de seus cuidadores antes de 
chegarem ao estágio grave. Essa estimulação adequada poderia advir do conhecimento da qualidade do uso do léxico presente nos diálogo desses pacientes que até certo grau, evidenciaram o uso de itens lexicais com significado sócio-cultural e ideológico. O conhecimento dos itens lexicais e seu uso adequado nas interações orais minimizaria o estresse na interação entre pacientes e cuidadores. 


\section{OBJETIVO}

\subsection{Objetivo geral}

Analisar os itens lexicais nos discursos orais de pacientes com doença de Alzheimer a fim de verificar quais itens estão mais preservados, visando a elaboração de estratégias linguísticas adequadas, que permitam o desenvolvimento de mecanismos discursivos para melhorar a interação entre cuidadores e pacientes.

\subsection{Objetivos específicos}

1- Identificar a presença de alteração quantitativa e qualitativa de itens lexicais nos discursos orais dos pacientes com doença de Alzheimer.

2- Avaliar os itens lexicais no discurso dos pacientes diagnosticados com doença de Alzheimer, a fim de compreender as mudanças lexicais a partir do seu contexto sóciocultural. 


\section{CASUÍSTICA E MÉTODOS}

Para este estudo foram selecionados 46 indivíduos. Eles foram reunidos em dois grupos 23 pessoas em cada: o grupo doença de Alzheimer (DA) com pacientes diagnosticados segundo critérios da American Psychiatry Association Committee on Nomenclature and Statistics Diagnostic and Statistical Manual of Mental Disorders (DSM-IV) e do National Institute of Neurological and Communicative Disorders and Stroke e Alzheimer's Disease and related Disorders Association (NINCDS-ADRDA) e o grupo controle, idosos sem demência. A pesquisa foi desenvolvida conforme protocolo da Comissão de Ética da Faculdade de Medicina, FMUSP. no.0372/10 de 10.09.2010

No grupo DA, os pacientes foram 13 do gênero feminino e 10 do gênero masculino, sendo que deste grupo, 12 pacientes estavam classificados no estágio leve e 11 pacientes no estágio moderado, cuja faixa etária oscilou entre 73 e 86 anos.

Todos os membros do grupo DA eram atendidos no ambulatório do Programa Terceira Idade do Instituto de Psiquiatria do Hospital das Clínicas da Faculdade de Medicina da Universidade de São Paulo (PROTER HC FMUSP).

Os idosos do grupo controle eram parentes dos pacientes ou moradores das diferentes zonas da cidade de São Paulo. Neste grupo, 15 controles eram do gênero feminino e 8 do gênero masculino, com idade entre 65 e 89 anos.

Todos os indivíduos selecionados neste estudo cumpriram com os critérios de exclusão, especificados nos próximos parágrafos. Quanto à escolaridade, esses membros participantes apresentaram na época do estudo, no mínimo quatro anos de escolaridade, sendo a língua portuguesa a língua materna de todos os participantes.

\subsection{Critérios de exclusão}

Para o grupo de pacientes com doença de Alzheimer os critérios foram:

- pontuação no Mini-Exame do Estado Mental - MEEM < 12 pontos

- presença de outras doenças cerebrais associadas à doença de Alzheimer

- presença de alterações sensoriais significativas: audição e visão 
- história pregressa ou atual de abuso de álcool e/ou outras drogas

Para o grupo controle, os critérios de exclusão foram:

- presença de doenças cerebrais ou sistêmicas graves

- pontuação no MEEM < 21 pontos

- pontuação acima de 6 no Self-Reporting Questionnaire 20 (SRQ-20)

- história pregressa ou atual de abuso de álcool e/ou drogas

\section{2 Ética}

Todos os pacientes, cuidadores e idosos do grupo controle foram informados por escrito dos objetivos e de todos os procedimentos do estudo. Eles assinaram o Termo de Consentimento Livre e Esclarecido. O projeto foi submetido à Comissão de Ética da Faculdade de Medicina da Universidade de São Paulo.

\subsection{Instrumentos de avaliação}

A coleta de dados foi realizada por meio de protocolo composto pelas escalas acima mencionadas. O Mini Exame do Estado Mental - MEEM (Folstein et al., 1975), é o instrumento de rastreio de comprometimento mais usado no estudo com demências e é formado por itens de orientação temporal e espacial, memória imediata, cálculo, evocação de palavras, linguagem (nomeação, repetição, comando verbal, leitura, escrita de frase) e cópia de desenho. A pontuação máxima é de 30 pontos e quanto menor a pontuação maior é o comprometimento cognitivo do individuo. Os indivíduos do grupo controle fizeram o Mini Exame do Estado Mental e o SelfReporting Questionnaire 20 - SRQ20, instrumento de rastreamento não psicótico com ponto de corte 7/8 para mulheres e 5/6 para homens (Mari \& Williams, 1986).

\subsection{Stablex}

O Stablex é um programa de análise lexical, textual e discursiva desenvolvida por André Camlong, da Universidade de Toulouse - le Mirail (Toulouse-França). O autor considera o 
programa como estatístico-paramétrico, objetivo, científico e indutivo (Camlog, 1996). Neste estudo foi usada a versão de Camlong \& Beltram (2004).

O programa Stablex apresenta várias ferramentas para a análise lexical, que por cálculo estatístico-paramétrico analisa os itens lexicais nos discursos e textos. Zaparolli \& Camlong (2002), Araújo (2002), Bragazza (2005) e Souza (2005) apontam que cabe ao pesquisador, observar e concluir a partir das evidências mostradas pelas análises matemáticas, estatísticas e algébricas do método. Assim, o Stablex evidencia como funciona o diálogo entre os valores numéricos e os elementos do discurso, assim como a tendência do léxico, seus valores, peso e frequência. Da mesma forma, Zaparolli \& Camlong (2002) e Souza (2005) afirmam que o programa é destinado à realização de confecções de léxicos, preferências aquele de maior importância, ou seja, a ordenação dos itens lexicais por ordem decrescente de preferência de emprego no texto, que compreende o vocabulário temático, e os elementos lexicais de maior peso na composição do texto e do discurso, além da criação de vocabulários básicos ou comum que é aquele grupo de itens cujo emprego se forma o lugar-comum, o corrente, finalmente o vocabulário diferencial ou deficitário ou de rejeição (Souza, 2005; Zaparolli \& Camlong, 2002). Da mesma forma, os autores postulam que dentro do vocabulário preferencial se encontra o vocabulário particular que é distintivo e próprio de cada indivíduo.

Há várias etapas a serem seguidas antes das análises para depois não serem modificadas, elas são: o texto deve estar em programa Word, texto com hífens, por exemplo, São Paulo, vira São-Paulo, e finalmente o texto a ser analisado deve estar na formatação TXT, antes da análise propriamente dita. A primeira etapa realizada pelo Stablex é a constituição dos léxicos por frequência e por cada variável, chamada de Tabela de Distribuição de Frequência. Após essa etapa, se realizam outros procedimentos e uso de fórmulas para chegar à Tabela dos Valores Lexicais onde se destacam o vocabulário preferencial, vocabulário básico e o vocabulário diferencial. Esses autores também afirmam que o resultado dos valores dos itens lexicais da Tabela dos Valores Lexicais e a sua distribuição combinatória obedecem a regras fundamentais e intrínsecas da composição lexical e discursiva. Portanto, além do peso dos itens lexicais corresponderem à orientação discursiva, assim o léxico é o caminho que conduz ao conhecimento do discurso (Zaparolli \& Camlong, 2002). 
Categorias de ordenação do léxico no texto

Vocabulário básico = vocabulário comum, corriqueiro.

Vocabulário preferencial = vocabulário temático, elementos com maio peso ou valor.

Vocabulário particular $=$ vocabulário distintivo, próprio de cada individuo.

Vocabulário diferencial = vocabulário de rejeição, de déficit.

\subsection{Procedimento geral}

Antes de gravar o diálogo com cada participante, este foi indagado se ele ou ela gostaria de participar do estudo. No caso dos pacientes com doença de Alzheimer, foi perguntado ao paciente e ao cuidador se ele ou ela autorizava a sua participação.

Os temas propostas na conversação livre foram temas da cultura propostos por Murdock apud Kolb \& Whishaw (2002) e do Projeto de Estudo de Norma Linguística Urbana Culta de São Paulo (PROJETO NURC-NUCLEO USP). Os temas abordados nos diálogos foram: cidade, educação, família, saúde, alimentação e religião. As gravações duraram em média 20 minutos e foram efetuadas usando um gravador digital (Panasonic RR-US450).

Para realizar os diálogos com os pacientes do ambulatório de Demências, o pesquisador seguiu as recomendações da Alzheimer's Association (2009), essa instituição determina que ao interagir verbalmente com pacientes com doença de Alzheimer, se tem que ter paciência e mostrar cooperação, oferecer conforto e segurança, dar mais um pouco de tempo para o paciente, mostrar interesse, evitar criticar e corrigir, evitar brigar e oferecer um palpite (www.alz.org). Além disso, seguimos as recomendações de Sabat (2001) que aponta que não somente a pessoa afetada com a doença precisa de mais tempo para formular seus pensamentos para encontrar as palavras, mas ele ou ela também precisa que os outros falem mais devagar. Durante a conversação, o pesquisador tinha em mente os temas a serem incluídos nos diálogos. Por exemplo, em relação ao tema cidade, a pergunta era quase sempre: Senhor $X$, fale, onde o senhor/ a senhora nasceu? Ou, há quanto tempo o senhor/a senhora mora em São Paulo? Sobre a escolaridade, a pergunta mais frequente era: Até que série o senhor/ a senhora estudou? Sobre a família: O senhor/ a senhora tem irmãos? ou fale sobre a sua família. Sobre a saúde: O senhor/ a senhora teve ou tem algum problema de saúde? Sobre a alimentação: fale sobre a sua alimentação no dia a dia e sobre o tema religião: qual a sua religião? ou o senhor/ a senhora 
acredita em Deus? Os temas eram abordados à medida que o participante completava a resposta, sempre com perguntas abertas, mas nem sempre obedeciam a mesma sequencia, a fim de manter a confiança e fluidez no diálogo/entrevista.

Além disso, foi considerado o comentário de Preti (1991), que destaca que os idosos gostam de serem ouvidos sobre os assuntos que mais marcaram suas vidas e que tais assuntos destacam itens que são marcantes na memória dos indivíduos, sendo que muitos se emocionam quando questionados sobre esses temas.

As aplicações de testes e conversações com os pacientes foram realizadas no ambulatório de Demências do PROTER- Programa Terceira Idade - Instituto de Psiquiatria do Hospital das Clínicas da Faculdade de Medicina da Universidade de São Paulo (PROTER-IPqHCFMUSP). Alguns dos controles, que eram cuidadores, esposos que acompanhavam os pacientes realizaram os diálogos no ambulatório do PROTER, outros realizaram os diálogos nos seus domicílios, depois de estabelecido ambiente de confiança e tranquilidade.

As conversações foram transcritas ou digitadas no programa Word, depois cada transcrição foi passada a hifenização manualmente para conversão em item lexical composto e depois foram transformadas em TXT para logo serem analisadas pelo Programa Stablex. Foram seguidas todas as etapas de análise exigidas pela metodologia do programa até chegar a Tabela dos Valores Lexicais. 


\section{RESULTADOS}

\subsection{Limitações da metodologia Stablex}

Verificamos que o Stablex identifica formas ortográficas, mas não lemas- parte de uma unidade lexical-, por exemplo, quando surge uma palavra não acentuada, que deveria tê-lo sido, o programa a assinala como palavra nova, sendo esta considerada duas vezes. Assim, todas as formas de inflexão da palavra (lema) são tratadas como itens diferentes, mesmo as inflexões verbais. Essa correção deve ser feita manualmente o que torna a tarefa de recontar cada palavra bastante trabalhosa. Além disso, o programa não seleciona as classes gramaticais, o que pode não ser relevante em interpretação literária de textos únicos, ou na interpretação da intenção do falante uma vez que o Stablex tem sido usado em estudos de interpretação dos vocabulários. Entretanto, essa função parece não ser bem adequada para uso clínico, além da interpretação não ser informativa sobre a neurocognição. Portanto, utilizamos a descrição básica semântica e sintática para interpretar a frequência e identificar os valores gerados pelo Stablex.

Nesse tópico, limitações também podem ser verificadas porque os itens lexicais das linhas da planilha EXCEL não determinam se essa mesma linha é necessariamente composta de uma palavra, pois em algumas linhas são apresentadas vários números que indicam quantas vezes cada individuo falou essa palavra. Apenas o item lexical hápax, palavra expressa uma única vez, é indicado com o número 1 nessas linhas. O hápax faz parte do vocabulário particular inserido no léxico preferencial.

\subsection{Levantamento dos dados demográficos e clínicos}

A seleção dos pacientes efetuada segundo os critérios de exclusão foi realizada após discussão com os respectivos médicos sobre o grau da doença, assim como a consulta aos prontuários para verificar o diagnóstico, o grau de desenvolvimento da doença e os sintomas clínicos. Antes da gravação foi aplicado o MEEM. Os pacientes do estudo foram 12 no estágio leve e 11 no estágio moderado. A Tabela 1 apresenta os dados demográficos e o estágio da doença de Alzheimer. 
Tabela 1- Dados Demográficos e clínicos do grupo DA, $n=23(\mathrm{M}=10, \mathrm{~F}=13)$

\begin{tabular}{|c|c|c|c|c|c|c|}
\hline Paciente & $\begin{array}{l}\text { Idade } \\
\text { (anos) }\end{array}$ & Gênero & Ocupação & MEEM & $\begin{array}{l}\text { Escolaridade } \\
\quad \text { (anos) }\end{array}$ & $\begin{array}{l}\text { Estágio na } \\
\text { doença de } \\
\text { Alzheimer }\end{array}$ \\
\hline 1 & 78 & $\mathrm{~F}$ & Costureira & 17 & 8 & Moderado \\
\hline 2 & 80 & M & Auxiliar administrativo & 14 & 8 & Moderado \\
\hline 3 & 83 & M & Motorista de Taxi & 26 & 4 & Leve \\
\hline 4 & 84 & $\mathrm{~F}$ & Professora de 2 grau & 16 & 15 & Moderado \\
\hline 5 & 77 & $\mathrm{M}$ & Médico & 28 & 25 & Leve \\
\hline 6 & 83 & M & Comerciante & 19 & 4 & Moderado \\
\hline 7 & 82 & $\mathrm{~F}$ & Dona de casa & 16 & 4 & Moderado \\
\hline 8 & 72 & $\mathrm{~F}$ & Dona de casa & 24 & 8 & Leve \\
\hline 9 & 77 & M & $\begin{array}{l}\text { Motorista de } \\
\text { caminhão }\end{array}$ & 26 & 4 & Leve \\
\hline 10 & 78 & $\mathrm{~F}$ & Costureira & 27 & 8 & Leve \\
\hline 11 & 77 & $\mathrm{~F}$ & $\begin{array}{l}\text { Funcionária de } \\
\text { creche }\end{array}$ & 19 & 11 & Moderado \\
\hline 12 & 78 & $\mathrm{~F}$ & $\begin{array}{l}\text { Técnica de } \\
\text { eletrocardiograma }\end{array}$ & 20 & 11 & Leve \\
\hline 13 & 76 & $\mathrm{~F}$ & Costureira & 21 & 4 & Leve \\
\hline 14 & 73 & $\mathrm{M}$ & Escriturário, & 25 & 11 & Leve \\
\hline 15 & 83 & M & $\begin{array}{l}\text { Auxiliar de } \\
\text { Almoxarifado }\end{array}$ & 19 & 11 & Moderado \\
\hline 16 & 80 & $\mathrm{M}$ & Advogado & 26 & 16 & Leve \\
\hline 17 & 82 & $\mathrm{~F}$ & $\begin{array}{l}\text { Professora } \\
\text { Universitária }\end{array}$ & 13 & 15 & Moderado \\
\hline 18 & 86 & $\mathrm{~F}$ & Dona de casa & 18 & 4 & Moderado \\
\hline 19 & 85 & M & Gráfico & 24 & 11 & Leve \\
\hline 20 & 84 & $\mathrm{~F}$ & Costureira & 19 & 6 & Moderado \\
\hline 21 & 82 & $\mathrm{~F}$ & Costureira & 16 & 6 & Moderado \\
\hline 22 & 80 & $\mathrm{M}$ & Comerciante & 25 & 11 & Leve \\
\hline 23 & 73 & $\mathrm{~F}$ & Professora de Yoga & 20 & 11 & Leve \\
\hline
\end{tabular}

A seleção do grupo controle foi realizada seguindo os critérios de exclusão do estudo. Antes da gravação para o estudo, foram aplicados os testes Mini Exame do Estado Mental e o Self-reporting Questionnaire-20,

A Tabela 2 apresenta os dados demográficos, Mini Exame do Estado Mental e Selfreporting Questionnaire-20 do grupo controle. 
Tabela 2 - Dados demográficos e exames do grupo Controle $n=23$ ( $M=8, F=15)$.

\begin{tabular}{ccccccc}
\hline Controle & $\begin{array}{c}\text { Idade } \\
\text { (anos) }\end{array}$ & \multicolumn{1}{c}{ Ocupação } & Gênero & MEEM & $\begin{array}{c}\text { Escolaridade } \\
\text { (anos) }\end{array}$ & SRQ20* \\
\hline 1 & 78 & Industriário & M & 30 & 4 & 0 \\
2 & 79 & Secretária & F & 30 & 13 & 0 \\
3 & 86 & $\begin{array}{l}\text { Auxiliar de } \\
\text { enfermagem }\end{array}$ & F & 28 & 8 & 1 \\
4 & 86 & Comerciante & M & 30 & 4 & 0 \\
5 & 69 & Comerciaria & F & 28 & 8 & 0 \\
6 & 79 & Dona de casa & F & 28 & 5 & 0 \\
7 & 83 & Comerciante & M & 27 & 4 & 0 \\
8 & 77 & Comerciante & M & 28 & 8 & 0 \\
9 & 89 & Funcionário público & M & 26 & 4 & 1 \\
10 & 76 & Funcionária de clube & F & 25 & 5 & 1 \\
11 & 65 & Professora, & F & 26 & 13 & 3 \\
& & bibliotecária & & & & \\
12 & 80 & Funcionária pública & F & 26 & 11 & 4 \\
13 & 72 & Mecânico de carros & M & 25 & 4 & 1 \\
14 & 71 & Dona de casa & F & 30 & 11 & 1 \\
15 & 71 & Biólogo & M & 30 & 18 & 0 \\
16 & 68 & Auxiliar de & F & 30 & 11 & 0 \\
& & escritório & & & & \\
17 & 84 & Costureira & F & 29 & 11 & 3 \\
18 & 79 & Nutricionista & F & 28 & 15 & 5 \\
19 & 66 & Economista & M & 30 & 18 & 0 \\
20 & 74 & Comerciante & F & 27 & 4 & 2 \\
21 & 71 & Comerciante & F & 29 & 4 & 2 \\
22 & 83 & Costureira & F & 29 & 8 & 1 \\
23 & 75 & Músico, empresário & F & 29 & 11 & 2 \\
\hline
\end{tabular}

*Self Reporting Questionnaire 20, pontuação de 1 a 20, ponto de corte 7 ou 8 para mulheres e 5ou 6 para homens

A tabela 3, construída a partir dos dados das tabelas 1 e 2, apresenta a frequência e a média, o desvio padrão, e mediana mínima e máxima dos dados demográficos dos grupos controle e dos pacientes nos estágios leve e moderado da doença de Alzheimer. Observou-se que $65 \%$ dos controles e $73 \%$ dos pacientes leves e dos moderados são do sexo feminino, o teste de Chi-Quadrado mostrou que o estágio da doença é independente do sexo $\mathrm{p}=0,261$.

A idade média dos indivíduos do grupo controle foi 76,6 $\pm 6,7$ anos e o valor médio de anos de escolaridade foi 8,8 $\pm 4,6$. O escores médios deste grupo no Mini Exame do Estado Mental foi $28,3 \pm 1,7$, por sua vez 4 controles tiveram estudo superior, dois do gênero masculino e dois do feminino. 
A idade média dos pacientes foi $81,9 \pm 2,7$ anos para os do estágio moderado e $77,7 \pm 4,0$ anos para os do estágio leve. O valor médio de anos de escolaridade dos pacientes leves foi $10,3 \pm 5,9$ e dos moderados $8,4 \pm 4,1$. Sendo que quatro pacientes apresentavam ensino superior, dois do gênero masculino no estágio leve da doença e dois do gênero feminino no estágio moderado da doença. Os pacientes tiveram uma pontuação média no Mini Exame do Estado Mental de $24,3 \pm 2,7$ no estágio leve e $16,9 \pm 2,1$ no estágio moderado. Esses pacientes desempenharam atividades profissionais variadas como revela a Tabela 1.

Os resultados do teste de Kruskal-Wallis utilizado na comparação dos grupos indicaram valores significativos quanto à idade $(\mathrm{p}=0,032)$ e MEEM $(\mathrm{p}<0,001)$. Os pacientes moderados apresentaram maior idade e menor MEEM do que os controles e do que os pacientes leves, $\mathrm{p}<0.05$. Os pacientes leves também apresentaram menor MEEM quando comparados aos controles, $\mathrm{p}<0.05$.

Não foi observada diferença significante no tempo de escolaridade entre os três grupos, $\mathrm{p}=0,750$.

Tabela 3- Perfil dos controles e dos pacientes nos estágios leve e moderado da DA.

\begin{tabular}{lcccc}
\hline & $\begin{array}{c}\text { Controle } \\
(\mathrm{n}=23)\end{array}$ & $\begin{array}{c}\text { Leve } \\
(\mathrm{n}=12)\end{array}$ & $\begin{array}{c}\text { Moderado } \\
(\mathrm{n}=11)\end{array}$ & $\mathrm{p}$ \\
\hline Feminino & $15(65 \%)$ & $5(73 \%)$ & $8(73 \%)$ & $\mathrm{p}=0,261^{1}$ \\
Masculino & $8(35 \%)$ & $7(27 \%)$ & $3(27 \%)$ & \\
Idade (anos) & $76,6 \pm 6,7$ & $77,7 \pm 4,0$ & $81,9 \pm 2,7$ & $\mathrm{p}=0,032^{2}$ \\
& $77[65 ; 89]$ & $77,5[72 ; 85]$ & $82[77 ; 86]^{\mathrm{ab}}$ & \\
Escolaridade (anos) & $8,8 \pm 4,6$ & $10,3 \pm 5,9$ & $8,4 \pm 4,1$ & $\mathrm{p}=0,750^{2}$ \\
& $8,0[4 ; 18]$ & $11,0[4 ; 25]$ & $8[4 ; 15]$ & \\
MEEM & $28,2 \pm 1,7$ & $24,3 \pm 2,7$ & $16,9 \pm 2,1$ & $\mathrm{p}<0.001^{2}$ \\
& $28[25 ; 30]$ & $25[20 ; 28]^{\mathrm{a}}$ & $17[13 ; 19]^{\mathrm{ab}}$ & \\
\hline
\end{tabular}

1: teste de Qui-Quadrado, 2: teste de Kruskal-Wallis, a: vs. Controle, b: vs. Leve, p<0.05 média \pm desvio padrão; mediana [mín; máx]

\subsection{Análise das entrevistas dos grupos}

A análise dos diálogos foi realizada em duas etapas. Na primeira etapa, os diálogos foram transcritos, inseridos no programa Word txt a seguir eles foram inseridos no programa Stablex. A segunda etapa foi efetuada a partir dos resultados obtidos com o Stablex, empregou-se o teste 
Kruskal-Wallis a fim de comparar as produções lexicais entre pacientes de estágios leve e moderado, controles versus pacientes de grau leve e controles versus pacientes de grau moderado.

\subsubsection{Análise da frequência e do valor dos itens lexicais}

Esta análise foi realizada com o programa Stablex a partir dos textos em formato txt. Depois de o programa realizar vários cálculos e com a ajuda manual de aplicação de fórmulas, o Stablex forneceu a Tabela dos Valores Lexicais (TVL). Essa Tabela mostra uma lista de todos os itens lexicais com seu respectivo valor. Camlong (1996) indica que se deve fazer uma divisão para a criação dos léxicos preferencial, básico e diferencial. Palavras com peso igual ou acima de 1,96 são consideradas palavras preferências, palavras com peso entre 1,96 e -1,96 são consideradas palavras básicas e aquelas com valor igual ou abaixo de -1,96 são denominadas diferencias. Dessa forma, foram obtidos os três vocabulários (léxicos). O vocabulário preferencial é constituído por itens lexicais temáticos; vocabulário básico constituído por itens lexicais comuns e finalmente o vocabulário diferencial que é constituído por itens lexicais de rejeição. Além disso, esse autor indica a existência do vocabulário particular, que é aquele constituído de itens lexicais expressos somente por um individuo. Esse vocabulário particular faz parte do léxico preferencial. Os vocabulários são constituídos de itens lexicais carregados de valor no discurso dos indivíduos.

As figuras 4, 5, 6 e 7 mostram as percentagens dos quatro léxicos preferencial, básico, diferencial e particular dos pacientes e controles. Utilizou-se a percentagem devido à diferença do número total de itens lexicais expressos por cada indivíduo. $\mathrm{Na}$ figura 4 , o léxico preferencial, mostra que tanto os pacientes quanto os controles têm altas percentagens de itens preferências, somente o paciente 17 e o controle 8 tiveram percentagens baixas, provavelmente isso seja pelo estágio moderado da doença e nível escolar e nível sócio cultural do controle. Somente o controle 19 teve percentagem lexical bem elevado. A figura 5 do léxico básico, de itens comuns, indica que quase todos os participantes têm léxico básico similar, em média $51 \%$ do seu léxico total, somente o controle 19 teve léxico baixo próximo de $20 \%$. Por outro lado, a figura 6 do léxico diferencial, constituído de itens lexicais deficitários, de abandono, apresenta a percentagem mais baixa dos participantes. O paciente 17 teve a maior percentagem de itens 
lexicais diferencias próximo de $40 \%$, e os controles 8 e 19 produziram $30 \%$ e $10 \%$ aproximadamente. Finalmente, a figura 7 mostra as percentagens do léxico particular, próprio, distintivo e exclusivo do individuo, em média foram expressos aproximadamente $18 \%$, exceto o controle 6 que expressou quase $5 \%$.

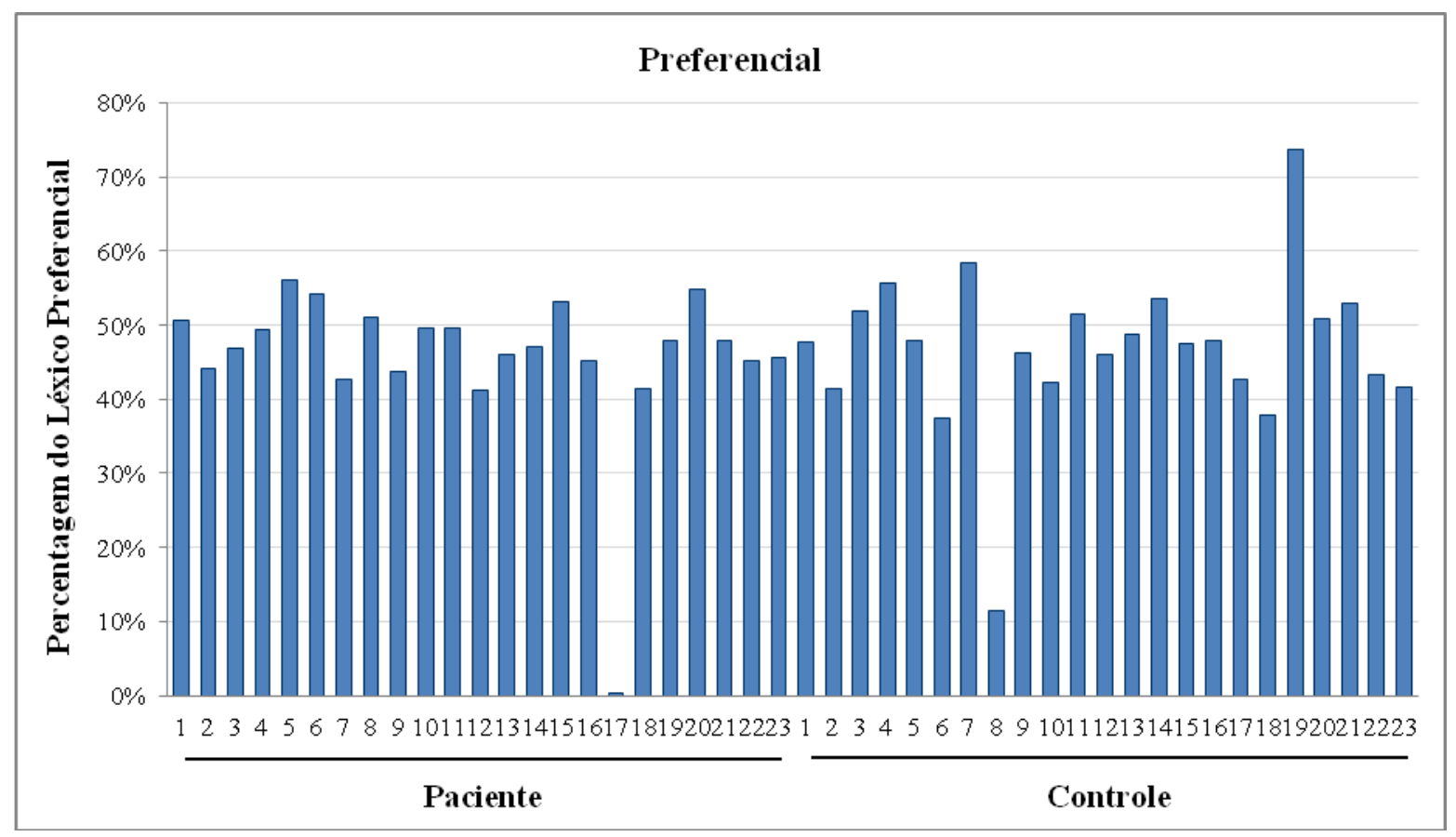

Figura 4. Percentagem do léxico preferencial dos pacientes e controles.

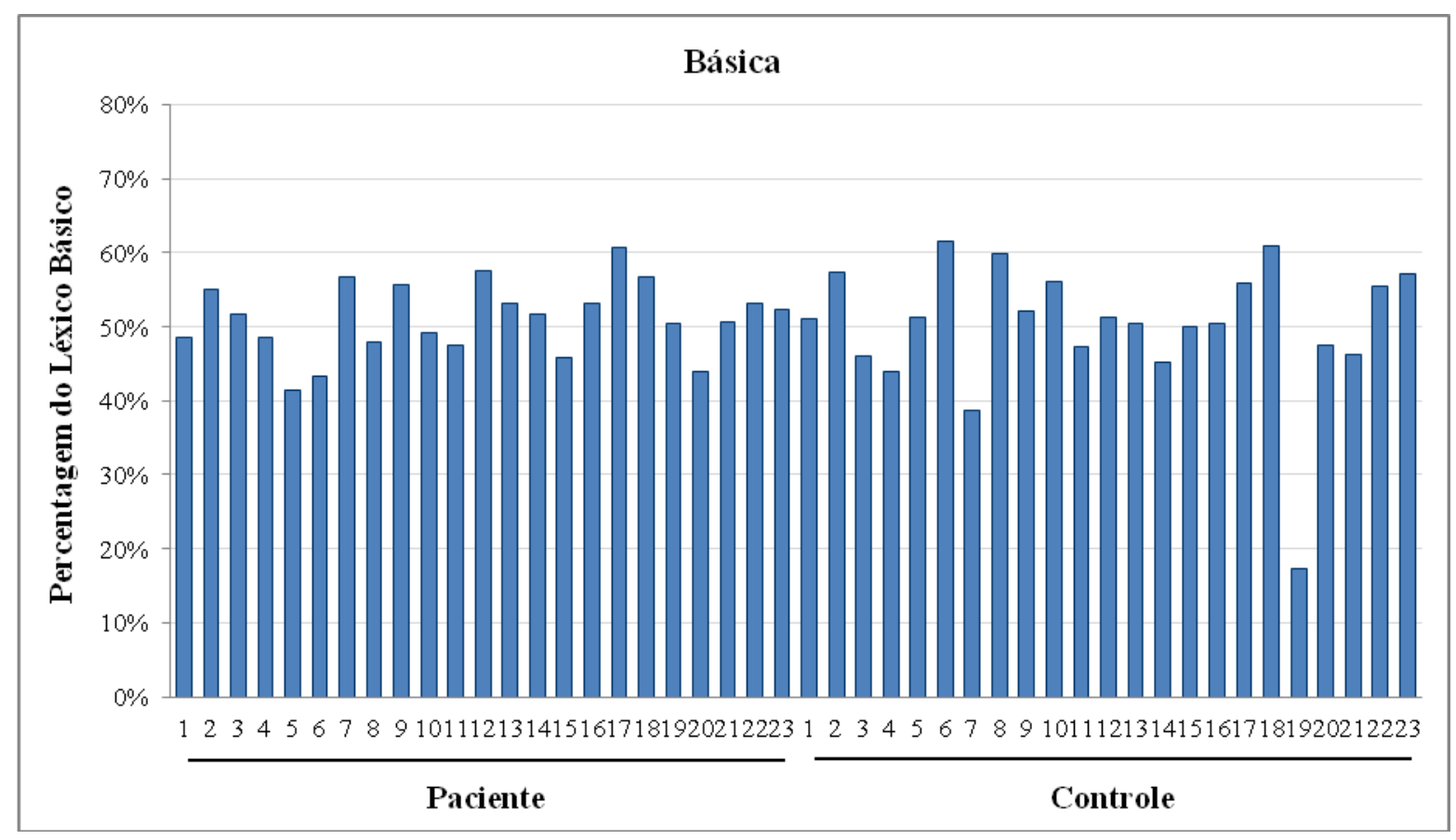

Figura 5. Percentagem do léxico básico dos pacientes e controles. 


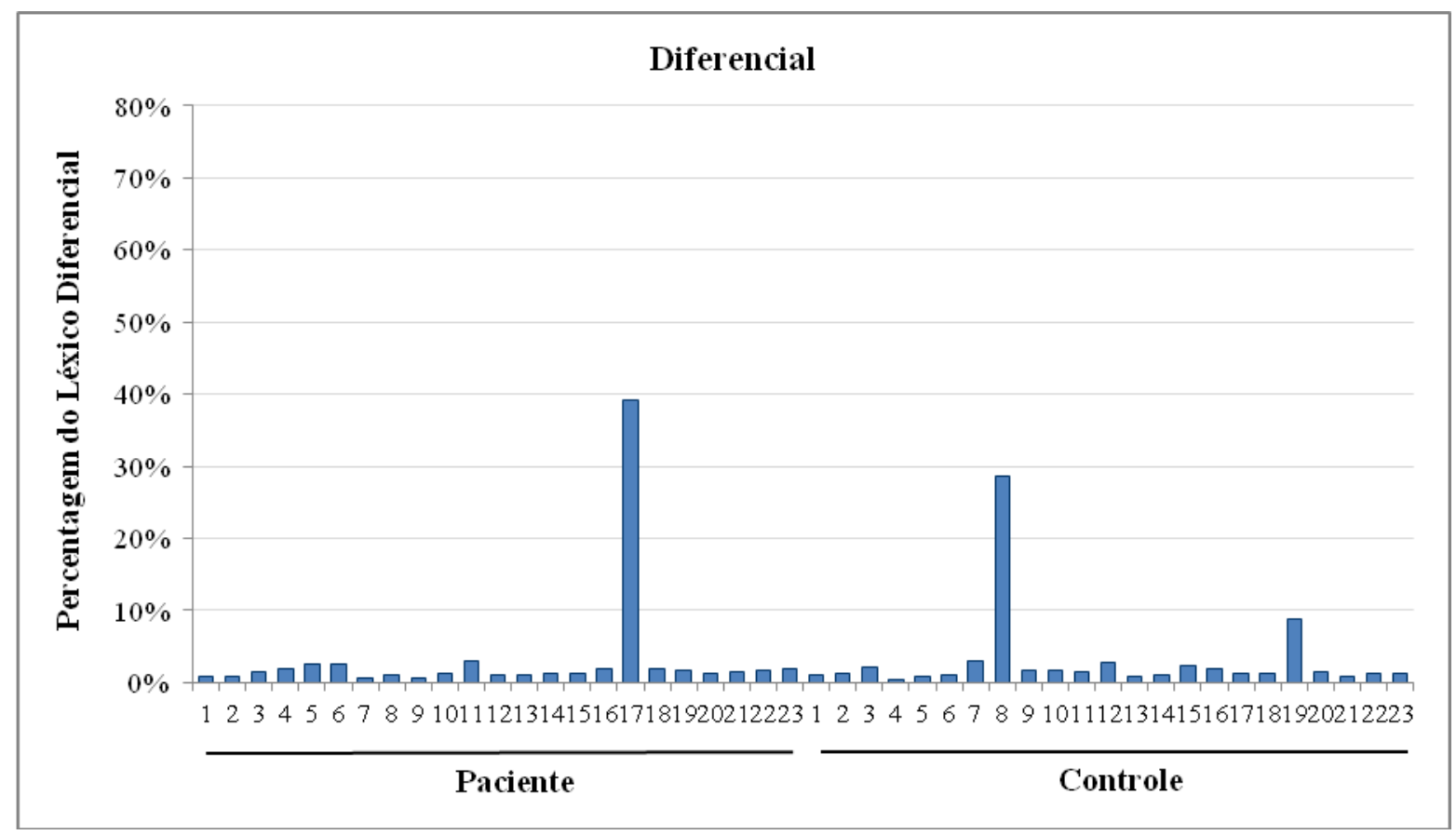

Figura 6. Percentagem do léxico diferencial dos pacientes e controles.

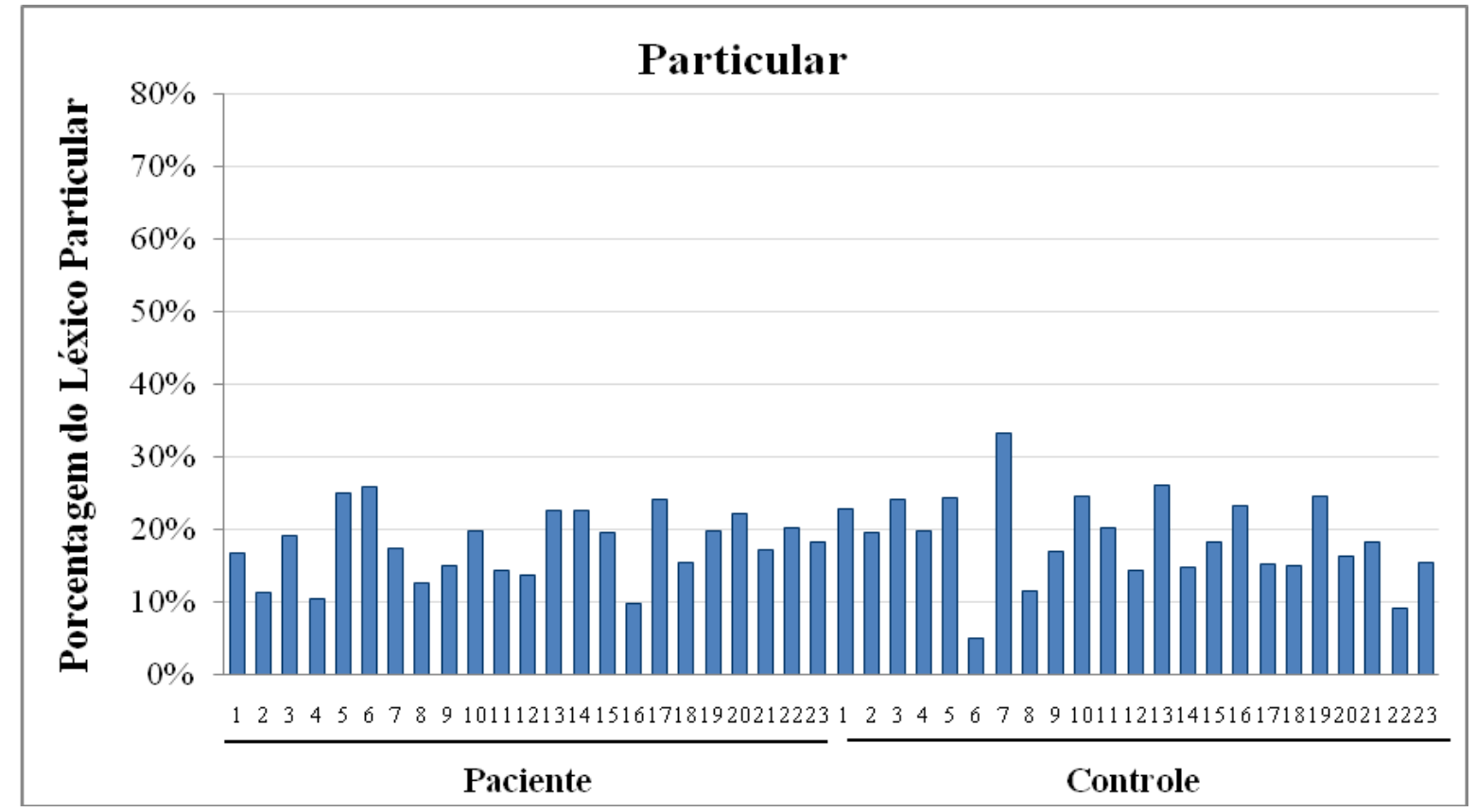

Figura 7. Percentagem do léxico particular dos pacientes e controles. 
A tabela 4 apresenta a análise descritiva da frequência e da percentagem dos léxicos particulares dos grupos controle, pacientes leves e pacientes moderados e do teste de KruskalWallis para comparação entre grupos.

Os pacientes moderados apresentaram menor número de itens lexicais particulares quando comparados aos controles e aos pacientes leves, $\mathrm{p}<0.05$. Os pacientes moderados apresentaram menor percentagem de itens lexicais particulares quando comparados aos pacientes leves, $\mathrm{p}<0,05$.

A tabela 5 apresenta a análise descritiva da frequência de léxicos preferenciais, básicos e diferenciais dos grupos controle, pacientes leves e pacientes moderados e do teste de KruskalWallis para comparação entre grupos.

Os pacientes leves e moderados e os controles não apresentaram diferença significante em relação ao número de itens lexicais preferenciais, $\mathrm{p}=0.209$.

Os pacientes moderados apresentaram menor número de itens lexicais básicos e totais quando comparados aos controles e aos pacientes leves, $\mathrm{p}<0.05$. Os pacientes moderados apresentaram menor número de itens lexicais diferenciais apenas quando comparados aos controles, $\mathrm{p}<0.05$. Os pacientes leves diferiram do controle nos itens lexicais básicos, diferenciais e totais, $\mathrm{p}<0,05$.

A tabela 6 apresenta a análise descritiva da percentagem dos léxicos preferenciais, básicos e diferenciais dos grupos controle, pacientes leves e pacientes moderados e do teste KruskalWallis para comparações entre grupos.

Não foi observada diferença significante entre os três grupos na percentagem dos léxicos preferenciais, básicos e diferenciais, $\mathrm{p}=0,257, \mathrm{p}=0,913$ e $\mathrm{p}=0,717$ respectivamente.

Tabela 4- Média e desvio padrão, mediana, valor mínimo e máximo da percentagem de itens lexicais particulares dos controles e dos pacientes nos estágios leve e moderado da DA.

\begin{tabular}{lcccc}
\hline & $\begin{array}{c}\text { Controle } \\
(\mathrm{n}=23)\end{array}$ & $\begin{array}{c}\text { Leve } \\
(\mathrm{n}=12)\end{array}$ & $\begin{array}{c}\text { Moderado } \\
(\mathrm{n}=11)\end{array}$ & $\mathrm{p}$ \\
\hline Particular & $113,3 \pm 47,7$ & $105,1 \pm 44,6$ & $56,1 \pm 35,6$ & $\mathrm{p}=0,006$ \\
& $109[44 ; 206]$ & $89,5[51 ; 192]$ & $53[9 ; 118]^{\mathrm{ab}}$ & \\
\% Particular & $17,9 \pm 4,6$ & $21,7 \pm 5,2$ & $15,7 \pm 5,9$ & $\mathrm{p}=0,042$ \\
& $18,3[9,7 ; 25,9]$ & $21,5[14,9 ; 33,3]$ & $15,1[5,0 ; 24,6]^{\mathrm{b}}$ & \\
\hline
\end{tabular}

Teste de Kruskal-Wallis, a: vs. Controle, b: vs. Leve média \pm desvio padrão; mediana [mín; máx] 
Tabela 5- Média e desvio padrão, mediana, valor mínimo e máximo do número de itens lexicais preferenciais, básicos, diferenciais e totais dos controles e dos pacientes nos estágios leve e moderado da DA

\begin{tabular}{|c|c|c|c|c|}
\hline & $\begin{array}{c}\text { Controle } \\
(n=23)\end{array}$ & $\begin{array}{c}\text { Leve } \\
(n=12)\end{array}$ & $\begin{array}{l}\text { Moderado } \\
(\mathrm{n}=11)\end{array}$ & $\mathrm{p}$ \\
\hline Preferencial & $\begin{array}{c}21,2 \pm 58,1 \\
9[3 ; 287]\end{array}$ & $\begin{array}{c}6,7 \pm 4,2 \\
5,5[1 ; 17]\end{array}$ & $\begin{array}{c}12,4 \pm 15,9 \\
7[2 ; 55]\end{array}$ & $\mathrm{p}=0,209$ \\
\hline Básico & $\begin{array}{c}310,9 \pm 74,1 \\
323[194 ; 445]\end{array}$ & $\begin{array}{c}239,3 \pm 64,3 \\
252[114 ; 331]^{\mathrm{a}}\end{array}$ & $\begin{array}{c}162,5 \pm 73,0 \\
150[55 ; 301]^{\mathrm{ab}}\end{array}$ & $\mathrm{p}<0,001$ \\
\hline Diferencial & $\begin{array}{l}275,6 \pm 88,1 \\
276[2 ; 431]\end{array}$ & $\begin{array}{c}225,8 \pm 55,6 \\
212[144 ; 337]^{\mathrm{a}}\end{array}$ & $\begin{array}{c}153,8 \pm 73,8 \\
164[22 ; 254]^{\mathrm{a}}\end{array}$ & $\mathrm{p}=0,001$ \\
\hline Total & $\begin{array}{c}607,7 \pm 127,6 \\
622[390 ; 799]\end{array}$ & $\begin{array}{c}471,8 \pm 107,8 \\
471[259 ; 609]^{\mathrm{a}}\end{array}$ & $\begin{array}{c}328,6 \pm 122,6 \\
317[182 ; 525]^{\mathrm{ab}}\end{array}$ & $\mathrm{p}<0.001$ \\
\hline
\end{tabular}

Teste de Kruskal-Wallis, a: vs. Controle, b: vs. Leve média \pm desvio padrão; mediana [mín; máx]

Tabela 6- Média e desvio padrão, mediana, valor mínimo e máximo da percentagem de itens lexicais preferenciais, básicos, diferenciais dos controles e dos pacientes nos estágios leve e moderado da DA.

\begin{tabular}{lcccc}
\hline & $\begin{array}{c}\text { Controle } \\
(\mathrm{n}=23)\end{array}$ & $\begin{array}{c}\text { Leve } \\
(\mathrm{n}=12)\end{array}$ & $\begin{array}{c}\text { Moderado } \\
(\mathrm{n}=11)\end{array}$ & $\mathrm{p}$ \\
\hline \multirow{3}{*}{ Preferencial } & $3,1 \pm 7,9$ & $1,3 \pm 0,7$ & $4,7 \pm 8,2$ & $\mathrm{p}=0,257$ \\
& $1,4[0,6 ; 39,1]$ & $1,3[0,4 ; 3,0]$ & $1,56[1,1 ; 28,7]$ & \\
Básico & $51,1 \pm 4,9$ & $50,4 \pm 6,0$ & $49,8 \pm 12,1$ & $\mathrm{p}=0,913$ \\
& $51,7[41,4 ; 60,6]$ & $50,8[38,7 ; 22,2]$ & $51,2[17,4 ; 61,5]$ & \\
Diferencial & $45,8 \pm 10,8$ & $48,2 \pm 5,9$ & $45,5 \pm 14,8$ & $\mathrm{p}=0,717$ \\
& $47,1[0,3 ; 56,0]$ & $47,9[37,9 ; 58,4]$ & $46,1[11,5 ; 73,8]$ &
\end{tabular}

Teste de Kruskal-Wallis, a: vs. Controle, b: vs. Leve média \pm desvio padrão; mediana [mín; máx] 


\subsubsection{Seleção das classes gramaticais e hápax dos léxicos}

Nesta etapa, foram selecionadas manualmente todas as classes gramaticais e subclasses dos itens lexicais da Tabela dos Valores Lexicais fornecidos pelo Stablex. Inicialmente essa seleção foi efetuada com os pacientes e depois com os controles. A decisão principal de selecionar os verbos e substantivos decorreu da indicação da literatura da dificuldade de uso dos mesmos no discurso pelos pacientes com doença de Alzheimer, mas os adjetivos, advérbios, pronomes, numerais, interjeições, conjunções, artigos, preposições da língua portuguesa do Brasil também foram selecionadas, assim como os hápax.

A análise da TVL mostra que foram expressas milhares de palavras nestes dois grupos. No total os pacientes produziram aproximadamente 9.277 palavras, enquanto os controles produziram 13.977 palavras, portanto eles expressaram $4.700(51 \%)$ palavras a mais que os pacientes.

As dez classes gramaticais e subclasses de verbos e substantivos da língua portuguesa foram selecionadas e categorizadas segundo critérios de Cunha \& Cintra, (2001), Jean Dubois et al., (1998), Scher (2003) e do site www.dicio.com.br, As subclasses de verbos e substantivos foram as subclasses mais analisadas. Os verbos selecionados foram: verbo lexical, verbo auxiliar, verbo leve, verbo mental (por exemplo, pensar, amar) e verbo de ação. Segundo critérios gramaticais e linguísticos, os verbos lexicais são definidos como verbos principais na sentença. Por sua vez, os verbos leves são verbos semanticamente vazios que se juntam a um substantivo para dar significado à sentença, no português são os verbos dar, fazer, ter, levar, por exemplo, dar uma olhada = olhar; fazer compras = comprar, ter dores = sentir, levar um susto = assustar (Scher, 2003). Além disso, os substantivos foram selecionados nas subclasses e categorias como: comum, próprio, abstrato, concreto, vivo e não-vivo. As outras categorias gramaticais foram selecionadas na sua forma simples sem subclasses.

\subsection{Análise dos itens lexicais verbos e substantivos}

Os itens lexicais selecionados manualmente foram analisados por testes estatísticos a fim de comparar os grupos controles e os grupos de pacientes leves e moderados. O teste Kruskal- 
Wallis foi utilizado na comparação do desempenho dos grupos quanto aos itens lexicais verbos e substantivos.

A Tabela 7 apresenta os resultados das análises estatísticas dos itens lexicais verbos e substantivos, esses resultados indicam valores significativos quanto à expressão de verbos, $\mathrm{p}=0,002$ e a de substantivos, $\mathrm{p}<0,001$. Os pacientes do grupo moderado tiveram menor expressão de verbos e substantivos em todas as subcategorias, exceto verbos leves e mentais. Os pacientes do grupo moderado produziram em média 106,2 $\pm 60,0$ verbos e $89,6 \pm 27,3$ substantivos enquanto

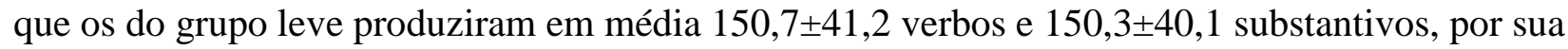
vez os controles produziram em média 190,3 $\pm 47,7$ verbos e 200,0 $\pm 53,8$ substantivos. Esses resultados estão consistentes e de acordo com resultados da literatura internacional que aponta a maior utilização de verbos e substantivos pelos falantes. Por outro lado, as subclasses de substantivos comuns, $\mathrm{p}<0,001$ e próprios, $\mathrm{p}=0,005$ também foram significativas, assim como os substantivos concretos, $\mathrm{p}<0,001$ e abstratos, $\mathrm{p}<0,001$; vivos, $\mathrm{p}=0,004$ e não-vivos, $\mathrm{p}<0,001$. Em relação aos verbos, somente os leves e mentais não foram significativos, $p=0,705$ e $p=0,264$ respectivamente, enquanto que os verbos lexicais, p=0,005, auxiliares, p<0,001 e de ação, $\mathrm{p}<0,001$ o foram. Os pacientes do grupo moderado quando comparados aos grupos controle e pacientes leves tiveram menor expressão de verbos e substantivos e nas subcategorias substantivo comum, próprio, concreto, não-vivo, verbo lexical e de ação, p <0,05.

Os pacientes leves e moderados quando comparados aos controles apresentaram menor expressão de substantivos e nas subcategorias substantivo comum, abstrato, concreto, não-vivo e verbo auxiliar, p<0,05. Quanto à expressão de substantivos vivos, somente os pacientes moderados apresentaram menor expressão em relação aos controles, $\mathrm{p}<0,05$.

Depois dos resultados da Tabela 7 apresentaremos as fig uras que mostram as medianas, os números e as percentagens dos itens lexicais verbos e substantivos, hápax e das outras oito classes gramaticais da língua portuguesa do Brasil realizada pelos participantes do estudo. Essas figuras são importantes para verificar o comportamento de uso dos itens lexicais. 
Tabela 7- Média e desvio padrão, mediana, valor mínimo e máximo dos valores lexicais dos verbos e substantivos dos controles e dos pacientes nos estágios leve e moderado da DA.

\begin{tabular}{|c|c|c|c|c|}
\hline & Controle & Leve & Moderado & $\mathrm{p}$ \\
\hline Verbo & $\begin{array}{c}190,3 \pm 47,7 \\
186[115 ; 279]\end{array}$ & $\begin{array}{c}150,7 \pm 41,2 \\
160,5[60 ; 200]\end{array}$ & $\begin{array}{c}106,2 \pm 60,0 \\
83[41 ; 208]^{\mathrm{ab}}\end{array}$ & $\mathrm{p}=0,002$ \\
\hline Substantivo & $\begin{array}{c}200,0 \pm 53,8 \\
196[121 ; 312]\end{array}$ & $\begin{array}{c}150,3 \pm 40,1 \\
137[94 ; 222]^{\mathrm{a}}\end{array}$ & $\begin{array}{c}89,6 \pm 27,3 \\
99[44 ; 127]^{\text {ab }}\end{array}$ & $\mathrm{p}<0,001$ \\
\hline Substantivo comum & $\begin{array}{c}176,0 \pm 44,4 \\
174[114 ; 260]\end{array}$ & $\begin{array}{c}129,8 \pm 35,6 \\
123,5[70 ; 179]^{\mathrm{a}}\end{array}$ & $\begin{array}{c}78,1 \pm 23,5 \\
87,0[38 ; 113]^{\mathrm{ab}}\end{array}$ & $\mathrm{p}<0,001$ \\
\hline Substantivo próprio & $\begin{array}{l}23,7 \pm 13,4 \\
22[5 ; 62]\end{array}$ & $\begin{array}{l}19,8 \pm 10,6 \\
17[8 ; 49]\end{array}$ & $\begin{array}{c}11,1 \pm 6,4 \\
9[3 ; 23]^{\mathrm{ab}}\end{array}$ & $\mathrm{p}=0,005$ \\
\hline Substantivo abstrato & $\begin{array}{c}60,5 \pm 18,8 \\
58[35 ; 105]\end{array}$ & $\begin{array}{c}44,8 \pm 14,5 \\
41,5[23 ; 69]^{\mathrm{a}}\end{array}$ & $\begin{array}{l}27,5 \pm 14,6 \\
27[6 ; 47]^{\mathrm{a}}\end{array}$ & $\mathrm{p}<0,001$ \\
\hline Substantivo concreto & $\begin{array}{c}115,5 \pm 31,9 \\
117[71 ; 183]\end{array}$ & $\begin{array}{c}83,0 \pm 23,5 \\
78[44 ; 118]^{\mathrm{a}}\end{array}$ & $\begin{array}{c}49,3 \pm 11,6 \\
49[32 ; 67]^{\mathrm{ab}}\end{array}$ & $\mathrm{p}<0,001$ \\
\hline Substantivo vivo & $\begin{array}{c}34,3 \pm 11,7 \\
33[17 ; 62]\end{array}$ & $\begin{array}{c}29,8 \pm 7,6 \\
30[17 ; 39]\end{array}$ & $\begin{array}{c}21,2 \pm 7,3 \\
23[8 ; 30]^{\mathrm{a}}\end{array}$ & $\mathrm{p}=0.004$ \\
\hline Substantivo não vivo & $\begin{array}{c}140,9 \pm 38,0 \\
139[93 ; 225]\end{array}$ & $\begin{array}{c}98,2 \pm 30,9 \\
94[49 ; 142]^{\mathrm{a}}\end{array}$ & $\begin{array}{c}56,2 \pm 19,9 \\
66[20 ; 87]^{\mathrm{ab}}\end{array}$ & $\mathrm{p}<0,001$ \\
\hline Verbo lexical & $\begin{array}{c}168,8 \pm 41,3 \\
163[105 ; 244]\end{array}$ & $\begin{array}{c}139,5 \pm 40,3 \\
150[49 ; 188]\end{array}$ & $\begin{array}{c}96,2 \pm 57,1 \\
75[34 ; 191]^{\mathrm{ab}}\end{array}$ & $\mathrm{p}=0,005$ \\
\hline Verbo auxiliar & $\begin{array}{c}17,8 \pm 9,6 \\
16[3 ; 41]\end{array}$ & $\begin{array}{c}7,3 \pm 3,3 \\
6,5[4 ; 16]^{\mathrm{a}}\end{array}$ & $\begin{array}{c}6,5 \pm 3,4 \\
6[3 ; 14]^{\mathrm{a}}\end{array}$ & $\mathrm{p}<0,001$ \\
\hline Verbo leve & $\begin{array}{l}2,8 \pm 2,2 \\
2[0 ; 9]\end{array}$ & $\begin{array}{l}3,0 \pm 1,8 \\
2[1 ; 6]\end{array}$ & $\begin{array}{l}2,5 \pm 1,9 \\
2[1 ; 6]\end{array}$ & $\mathrm{p}=0,705$ \\
\hline Verbo mental & $\begin{array}{c}30,8 \pm 12,9 \\
30[13 ; 61]\end{array}$ & $\begin{array}{c}29,9 \pm 14,3 \\
29,5[5 ; 64]\end{array}$ & $\begin{array}{l}23,5 \pm 18,6 \\
17[5 ; 57]\end{array}$ & $\mathrm{p}=0,264$ \\
\hline Verbo de ação & $\begin{array}{c}118,5 \pm 32,3 \\
110[69 ; 180]\end{array}$ & $\begin{array}{c}90,5 \pm 25,1 \\
97,5[39 ; 122]\end{array}$ & $\begin{array}{c}57,9 \pm 38,7 \\
45[19 ; 134]^{\mathrm{ab}}\end{array}$ & $\mathrm{p}<0,001$ \\
\hline
\end{tabular}

Teste de Kruskal-Wallis, a: vs. Controle, b: vs. Leve média \pm desvio padrão; mediana [mín; máx] 
As figuras 8 e 9 mostram os valores dos verbos e substantivos dos participantes do estudo. Pode- se notar que os pacientes moderados apresentam valores menores do que os outros participantes.

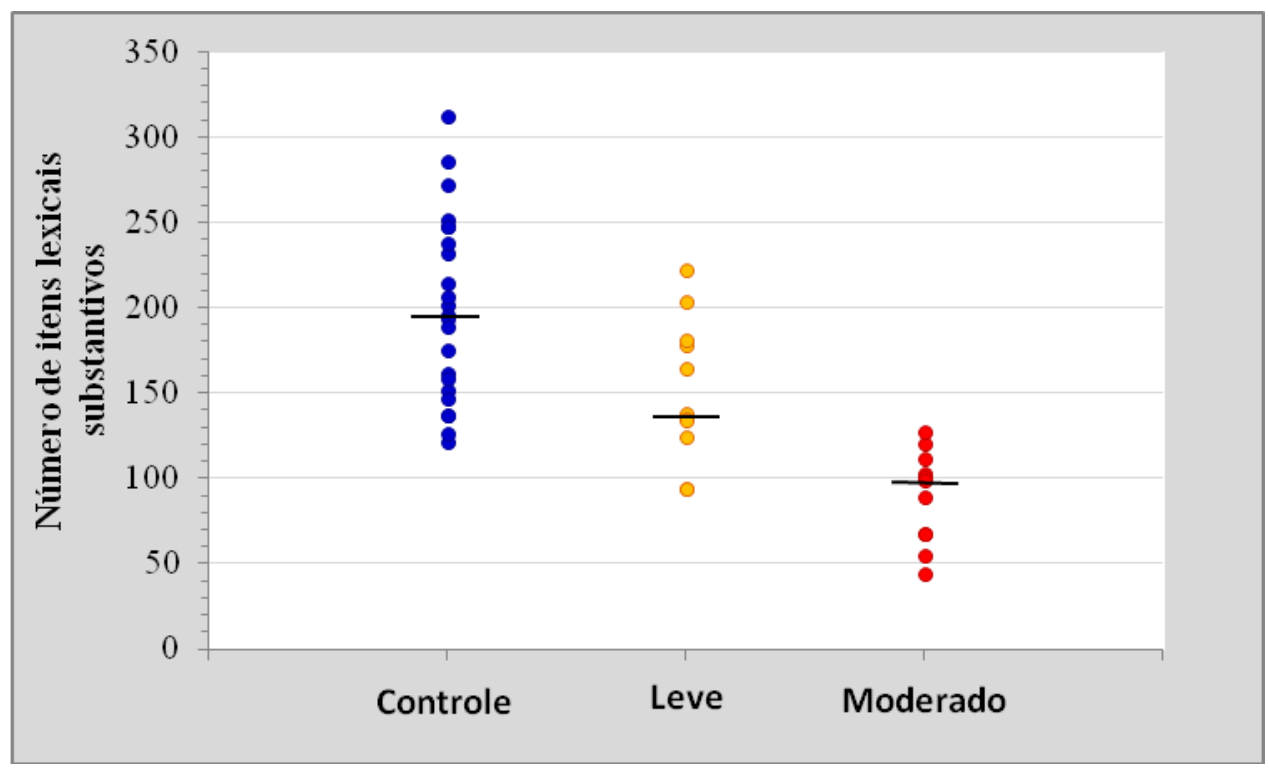

Figura 8. Valores lexicais e mediana dos substantivos dos controles e dos pacientes nos estágios leve e moderado da doença de Alzheimer.

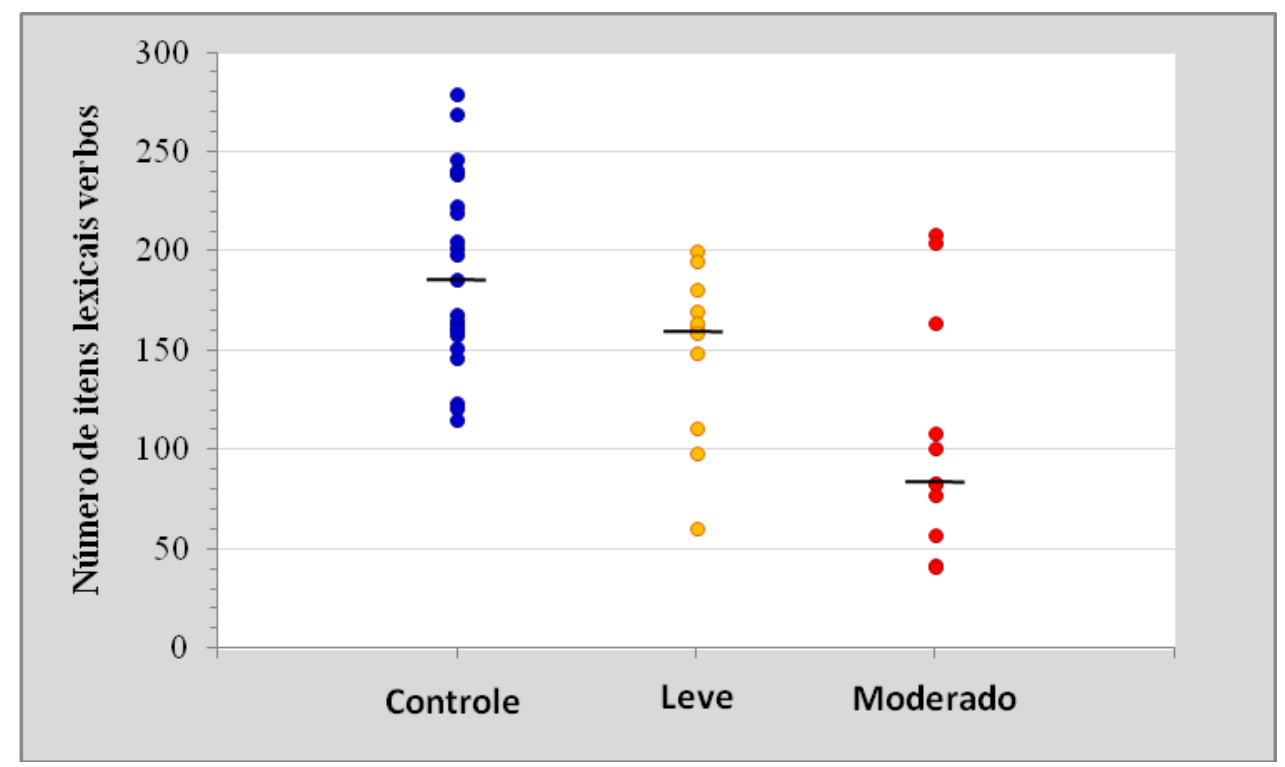

Figura 9. Valores lexicais e mediana dos verbos dos controles e dos pacientes nos estágios leve e moderado da doença de Alzheimer. 
O teste Kruskal-Wallis foi utilizado na comparação da percentagem dos itens lexicais verbos e substantivos e suas subclasses entre os grupos controle, pacientes leves e moderados, os resultados são mostrados na Tabela 8. Os resultados não indicaram valores significantes quanto à expressão da percentagem de verbos ou substantivos, $\mathrm{p}=0,626$. Os pacientes do grupo moderado apresentaram em média $51,8 \pm 9,6 \%$ de verbos e 48,2 $\pm 9,6 \%$ de substantivos. Os pacientes do

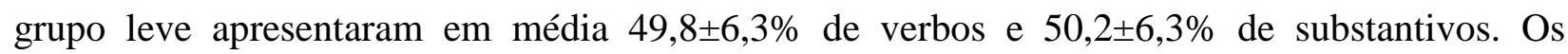
controles apresentaram em média $48,9 \pm 4,4 \%$ de verbos e $51,1 \pm 4,4 \%$ de substantivos.

Não foi observada diferença significante entre os grupos nas subclasses de substantivos

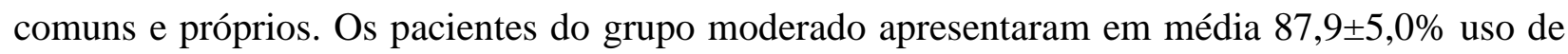
substantivos comuns e $12,1 \pm 5,0 \%$ de substantivos próprios. Os pacientes do grupo leve apresentaram em média $86,5 \pm 5,8 \%$ de substantivos comuns e 13,5 $\pm 5,8 \%$ de substantivos

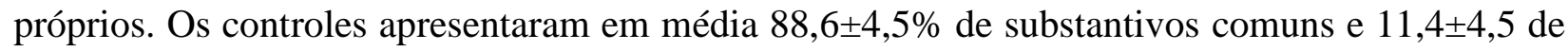
substantivos próprios.

O mesmo resultado foi observado nas subclasses de substantivos abstratos e concretos, $\mathrm{p}=0,941$. Os pacientes do grupo moderado apresentaram em média 66,3 $\pm 11,8 \%$ de substantivos abstratos e $33,7 \pm 11,8 \%$. de substantivos concretos Os pacientes do grupo leve apresentaram em

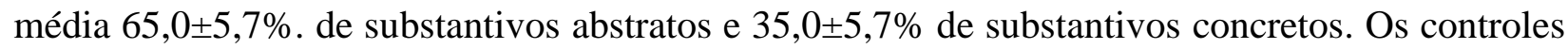
apresentaram em média $65,6 \pm 6,2 \%$ de substantivos abstratos e 34,4 $\pm 6,2 \%$ de substantivos concretos.

Por outro lado, foi observada diferença significante dos grupos moderado e leve em relação ao controle nas subclasses de substantivos relativos a seres vivos e objetos não-vivos, $\mathrm{p}<0.05$. Os pacientes do grupo moderado apresentaram em média 28,3 $\pm 9,1 \%$ de substantivos

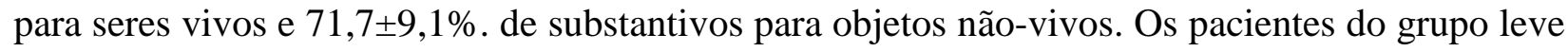
apresentaram em média $24,0 \pm 6,1 \%$ de substantivos para seres vivos e 76,0 $06,1 \%$. de substantivos

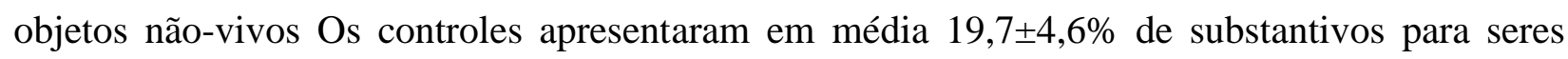
vivos e $80,3 \pm 4,6 \%$ de substantivos para objetos não-vivos.

Em relação ao uso de verbos lexicais, houve indicação de diferença entre os pacientes leves e os controles, $\mathrm{p}=0.053$. Os pacientes do grupo moderado apresentaram em média $90,3 \pm 3,9 \%$ de verbos lexicais, os pacientes do grupo leve apresentaram em média 92,4 $43,8 \%$ enquanto os controles apresentaram em média de $89,3 \pm 4,4 \%$. 
Quanto ao uso de verbos auxiliares, houve diferença significante entre os pacientes leves e os controles, $\mathrm{p}<0.05$. Os pacientes do grupo moderado apresentaram uso, em média 6,9 $\pm 2,5 \%$, de

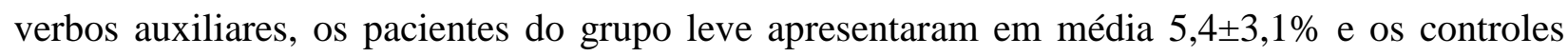
apresentaram em média 9,2 $\pm 4,1 \%$.

Não foi observada diferença significante entre os grupos na subclasse de verbos leves, $\mathrm{p}=0,146$. Os pacientes do grupo moderado apresentaram em média $2,7 \pm 2,1 \%$ de verbos leves, os pacientes do grupo leve apresentaram em média 2,2 $\pm 1,6 \%$ e os controles apresentaram em média $1,5 \pm 1,2 \%$. Não foi observada diferença significante entre os grupos na subclasse de verbos

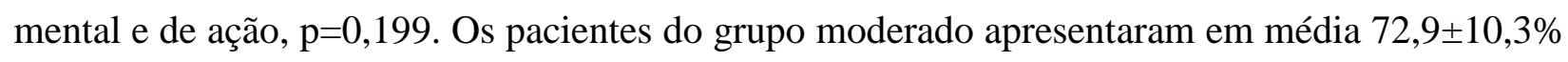
de verbos de ação e $27,1 \pm 10,3 \%$ de verbos mentais. Os pacientes do grupo leve apresentaram em média 76,2 $\pm 6,5 \%$ de verbos de ação e $23,8 \pm 6,5 \%$ de verbos mentais. Os controles apresentaram em média $79,5 \pm 5,8 \%$ de verbos de ação e $20,5 \pm 5,8 \%$ de verbos mentais. 
Tabela 8- Média e desvio padrão, mediana, valor mínimo e máximo da percentagem dos valores lexicais dos verbos e substantivos dos controles e dos pacientes nos estágios leve e moderado da DA

\begin{tabular}{|c|c|c|c|c|}
\hline & Controle & Leve & Moderado & $\mathrm{p}$ \\
\hline Verbo & $\begin{array}{c}48,9 \pm 4,4 \\
50,1[34,6 ; 54,0]\end{array}$ & $\begin{array}{c}49,8 \pm 6,3 \\
51,0[39,0 ; 57,8]\end{array}$ & $\begin{array}{c}51,8 \pm 9,6 \\
50,5[37,6 ; 66,5]\end{array}$ & \multirow[b]{2}{*}{$\mathrm{p}=0,626^{*}$} \\
\hline Substantivo & $\begin{array}{c}51,1 \pm 4,4 \\
49,9[46,1 ; 65,5]\end{array}$ & $\begin{array}{c}50,2 \pm 6,3 \\
49,0[42,2 ; 61,0]\end{array}$ & $\begin{array}{c}48,2 \pm 9,6 \\
49,5[33,6 ; 62,4]\end{array}$ & \\
\hline Substantivo comum & $\begin{array}{c}88,6 \pm 4,5 \\
89,4[78,2 ; 95,8]\end{array}$ & $\begin{array}{c}86,5 \pm 5,8 \\
88,2[75,3 ; 94,0]\end{array}$ & $\begin{array}{c}87,9 \pm 5,0 \\
87,0[80,7 ; 94,6]\end{array}$ & \multirow{2}{*}{$\mathrm{p}=0,629^{*}$} \\
\hline Substantivo próprio & $\begin{array}{c}11,4 \pm 4,5 \\
10,6[4,2 ; 21,8]\end{array}$ & $\begin{array}{c}13,5 \pm 5,8 \\
11,8[6,0 ; 24,7]\end{array}$ & $\begin{array}{c}12,1 \pm 5,0 \\
13,0[5,5 ; 19,3]\end{array}$ & \\
\hline Substantivo concreto & $\begin{array}{c}65,6 \pm 6,2 \\
65,9[55,2 ; 77,0]\end{array}$ & $\begin{array}{c}65,0 \pm 5,7 \\
66,2[49,6 ; 70,9]\end{array}$ & $\begin{array}{c}66,3 \pm 11,8 \\
61,4[50,0 ; 84,2]\end{array}$ & \multirow{2}{*}{$\mathrm{p}=0,941^{*}$} \\
\hline Substantivo abstrato & $\begin{array}{c}34,4 \pm 6,2 \\
34,1[23,0 ; 44,8]\end{array}$ & $\begin{array}{c}35,0 \pm 5,7 \\
33,8[29,1 ; 50,4]\end{array}$ & $\begin{array}{c}33,7 \pm 11,8 \\
38,6[15,8 ; 50,0]\end{array}$ & \\
\hline Substantivo vivo & $\begin{array}{c}19,7 \pm 4,6 \\
19,1[11,1 ; 28,7]\end{array}$ & $\begin{array}{c}24,0 \pm 6,1 \\
22,4[15,2 ; 36,1]^{\mathrm{a}}\end{array}$ & $\begin{array}{c}28,3 \pm 9,1 \\
25,8[13,8 ; 44,4]^{\mathrm{a}}\end{array}$ & \multirow{2}{*}{$\mathrm{p}=0.005^{*}$} \\
\hline Substantivo não vivo & $\begin{array}{c}80,3 \pm 4,6 \\
81,0[71,3 ; 88,9]\end{array}$ & $\begin{array}{c}76,0 \pm 6,1 \\
77,6[63,9 ; 84,8]^{\mathrm{a}}\end{array}$ & $\begin{array}{c}71,7 \pm 9,1 \\
74,2[55,6 ; 86,2]^{\mathrm{a}}\end{array}$ & \\
\hline Verbo lexical & $\begin{array}{c}89,3 \pm 4,4 \\
89,8[81,1 ; 97,4]\end{array}$ & $\begin{array}{c}92,4 \pm 3,8 \\
93,6[81,7 ; 96,0]\end{array}$ & $\begin{array}{c}90,3 \pm 3,9 \\
90,4[82,7 ; 96,0]\end{array}$ & $\mathrm{p}=0,053$ \\
\hline Verbo auxiliar & $\begin{array}{c}9,2 \pm 4,1 \\
8,8[2,6 ; 17,4]\end{array}$ & $\begin{array}{c}5,4 \pm 3,1 \\
4,7[2,5 ; 13,3]^{\mathrm{a}}\end{array}$ & $\begin{array}{c}6,9 \pm 2,5 \\
7,0[3,0 ; 9,8]\end{array}$ & $\mathrm{p}=0,010$ \\
\hline Verbo leve & $\begin{array}{c}1,5 \pm 1,2 \\
1,2[0,0 ; 4,1]\end{array}$ & $\begin{array}{c}2,2 \pm 1,6 \\
1,6[0,6 ; 5,2]\end{array}$ & $\begin{array}{c}2,7 \pm 2,1 \\
2,4[0,9 ; 8,0]\end{array}$ & $\mathrm{p}=0,146$ \\
\hline Verbo mental & $\begin{array}{c}20,5 \pm 5,8 \\
19,9[8,7 ; 31,3]\end{array}$ & $\begin{array}{c}23,8 \pm 6,5 \\
23,0[11,4 ; 40,0]\end{array}$ & $\begin{array}{c}27,1 \pm 10,3 \\
23,9[15,8 ; 44,2]\end{array}$ & \multirow{2}{*}{$\mathrm{p}=0,199^{*}$} \\
\hline Verbo de ação & $\begin{array}{c}79,5 \pm 5,8 \\
80,1[68,8 ; 91,3]\end{array}$ & $\begin{array}{c}76,2 \pm 6,5 \\
77,0[60,0 ; 88,6]\end{array}$ & $\begin{array}{c}72,9 \pm 10,3 \\
76,1[55,8 ; 84,2]\end{array}$ & \\
\hline
\end{tabular}

Teste de Kruskal-Wallis, a: vs. Controle, b: vs. Leve média \pm desvio padrão; mediana [mín; máx]

*Nesses casos o valor de p é o mesmo nas duas análises. 


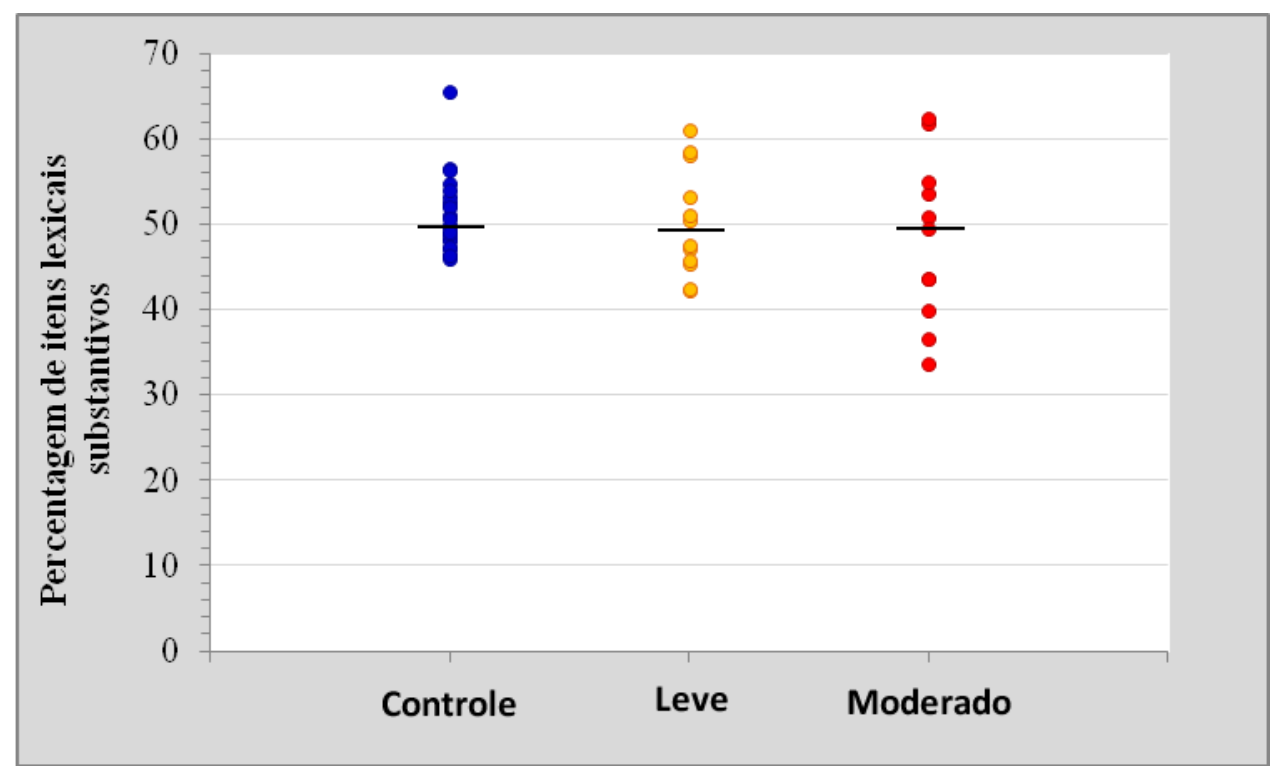

Figura 10. Percentagem e mediana dos valores lexicais dos substantivos dos controles e dos pacientes nos estágios leve e moderado da doença de Alzheimer.

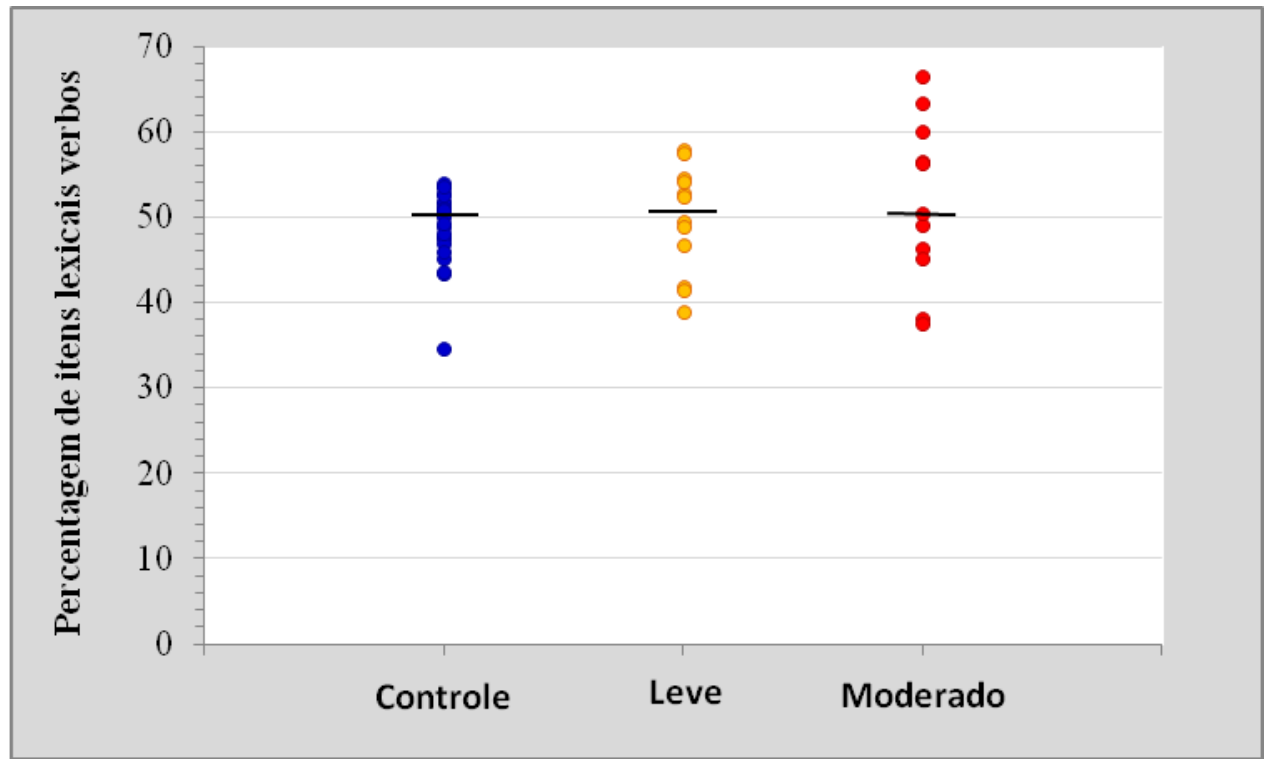

Figura 11. Percentagem e mediana dos valores lexicais dos verbos dos controles e dos pacientes nos estágios leve e moderado da doença de Alzheimer.

As figuras 10 e 11 apresentam as percentagens e medianas dos itens lexicais substantivos e verbos que têm distribuição semelhante. 


\subsection{Análise da comparação dos hápax}

Para analisar e comparar os hápax, item lexical expresso somente uma vez, foi usado o teste Kruskal-Wallis. Essa análise de comparação entre os grupos controles e pacientes leves e moderados indicou diferença significante, $\mathrm{p}<0,001$. Os pacientes leves e moderados mantêm menor número de palavras de uso próprio do que os controles, $\mathrm{p}<0,05$. Os pacientes moderados mantêm menor número de palavras de uso próprio do que os pacientes leves, p<0,05. Em relação à porcentagem dos hápax não foi detectada diferença significante entre os grupos, $\mathrm{p}=0,387$. A Tabela 9 mostra os resultados das analises estatísticas dos hápax. Enquanto que as Figuras 12 e 13 apresentam a distribuições de números e percentagem dos hápax, pode-se destacar que um paciente apresenta um item hápax e $0,5 \%$, por outro lado, as figuras mostram que as distribuições dos controles com os pacientes leves são semelhantes ou próximas.

Tabela 9- Média e desvio padrão, mediana, valor mínimo e máximo do número e percentagem dos hápax dos controles e dos pacientes nos estágios leve e moderado da DA.

\begin{tabular}{lcccc}
\hline & $\begin{array}{c}\text { Controle } \\
(n=23)\end{array}$ & $\begin{array}{c}\text { Leve } \\
(n=12)\end{array}$ & $\begin{array}{c}\text { Moderado } \\
(n=11)\end{array}$ & $p$ \\
\hline No. Hápax & $334,9 \pm 82,3$ & $257,2 \pm 60,8^{a}$ & $162,7 \pm 75,5^{\text {ab }}$ & $p<0,001$ \\
& $341[220 ; 495]$ & $251,5[156 ; 356]$ & $172[1 ; 282]$ & \\
\% Hápax & $54,9 \pm 4,2$ & $54,7 \pm 4,7$ & $48,5 \pm 17,3$ & $p=0,387$ \\
\hline
\end{tabular}

Teste de Kruskal-Wallis, a: vs. Controle, b: vs. Leve média \pm desvio padrão; mediana [mín; máx] 


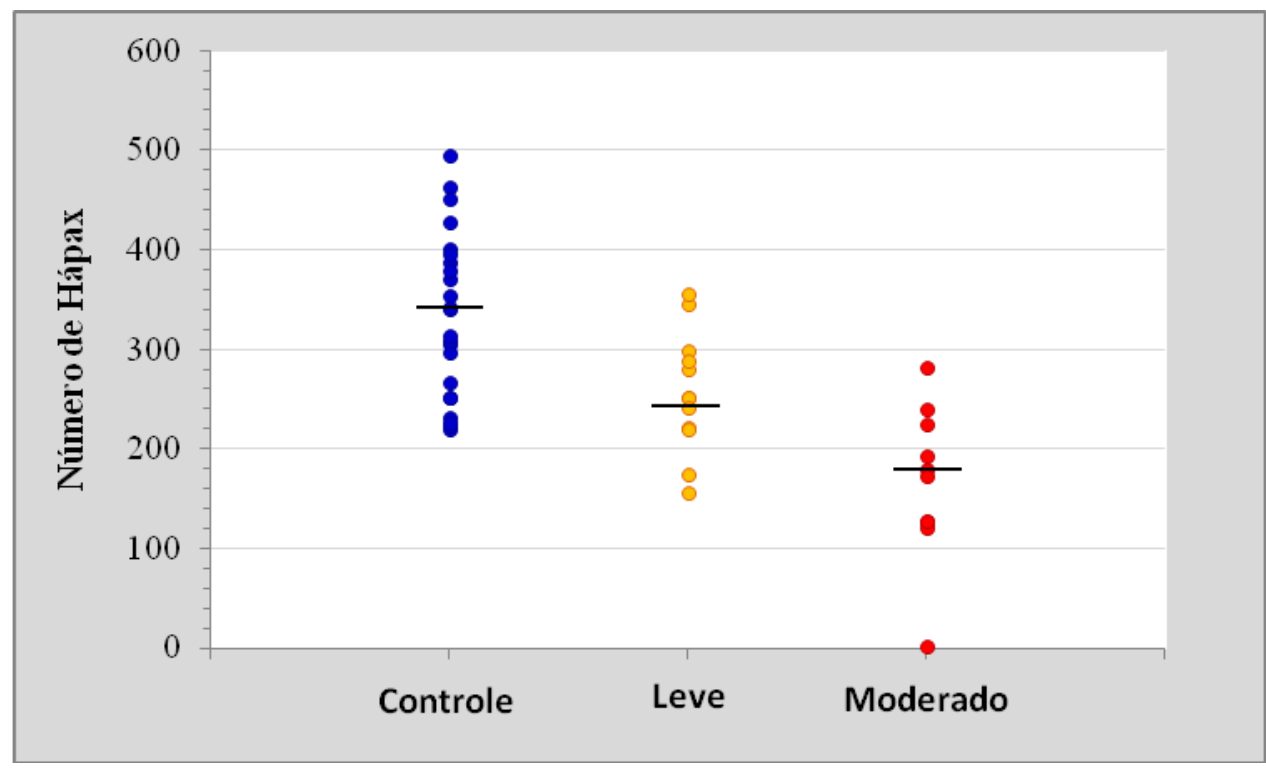

Figura 12- Número e mediana dos hápax dos controles e dos pacientes nos estágios leve e moderado da doença de Alzheimer.

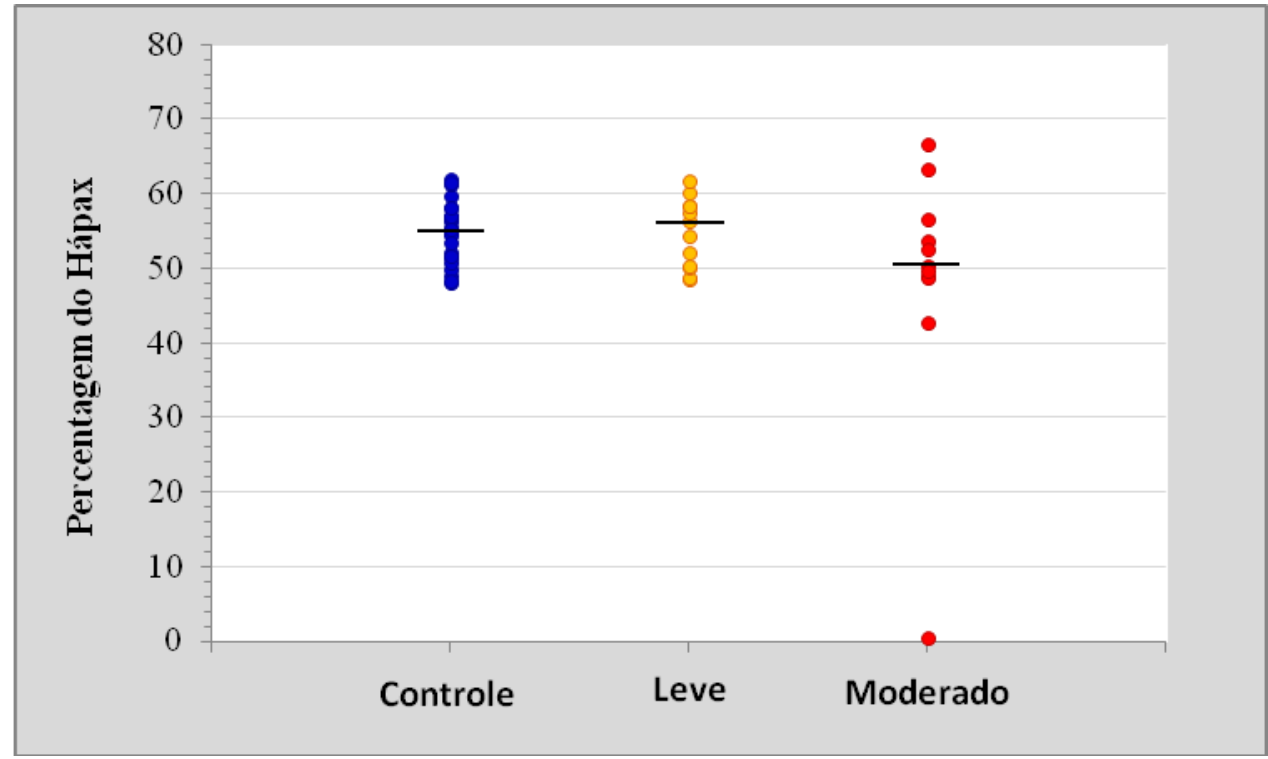

Figura 13- Percentagem e mediana dos hápax dos controles e dos pacientes nos estágios leve e moderado da doença de Alzheimer.

Foi importante verificar os resultados dos hápax provavelmente por ser resultado do uso cultural, profissional ou outros motivos que induzam o individuo usar essa palavra. 


\subsection{Análise da comparação dos adjetivos}

Para analisar e comparar os adjetivos foi usado o teste Kruskal-Wallis. Essa análise de comparação entre os grupos controles e pacientes leves e moderados indicou diferença significante, $\mathrm{p}<0,001$. Os pacientes leves e moderados mantêm menos adjetivos do que os controles, $\mathrm{p}<0,05$. Em relação à percentagem de adjetivos não foi detectada diferença significante entre os grupos, $\mathrm{p}=0,515$. Esses resultados são mostrados na Tabela 10.

Exemplos de adjetivos dos controles, pacientes de graus leve e moderado

Controle: eu nunca precisei viver doente

Paciente de grau leve: minha saúde esta equilibrada

Paciente de grau moderado: estou ficando velha

Tabela 10- Média e desvio padrão, mediana, valor mínimo e máximo do número e percentagem dos adjetivos dos controles e dos pacientes nos estágios leve e moderado da DA.

\begin{tabular}{lcccc}
\hline & $\begin{array}{c}\text { Controle } \\
(n=23)\end{array}$ & $\begin{array}{c}\text { Leve } \\
(n=12)\end{array}$ & $\begin{array}{c}\text { Moderado } \\
(n=11)\end{array}$ & $p$ \\
\hline No. Adjetivos & $61,2 \pm 17,5$ & $43,7 \pm 15,2$ & $33,0 \pm 18,4$ & $p<0,001$ \\
& $63[34 ; 100]$ & $41[18 ; 66]^{a}$ & $32[5 ; 59]^{a}$ & \\
\% Adjetivos & $10,0 \pm 1,5$ & $9,1 \pm 2,0$ & $9,4 \pm 3,1$ & $p=0,515$ \\
& $9,9[7,7 ; 13,2]$ & $9,2[6,5 ; 11,9]$ & $9,8[2,8 ; 13,3]$ & \\
\hline
\end{tabular}

Teste de Kruskal-Wallis, a: vs. Controle, b: vs. Leve média \pm desvio padrão; mediana [mín; máx] 
As Figuras 14 e 15 mostram as distribuições, a primeira dos adjetivos em número e a segunda da percentagem, essa figura da percentagem apresenta distribuição similar entre os grupos.

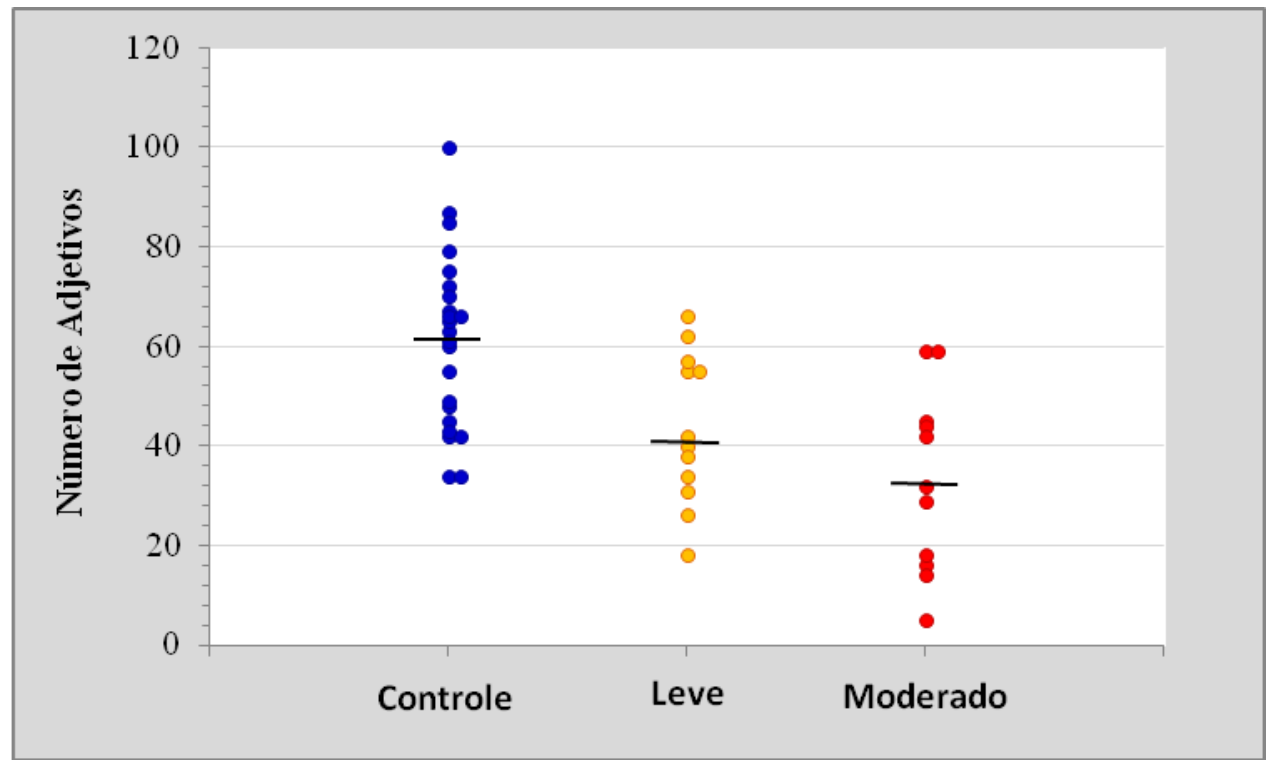

Figura 14 - Número e mediana dos adjetivos dos controles e dos pacientes nos estágios leve e moderado da doença de Alzheimer.

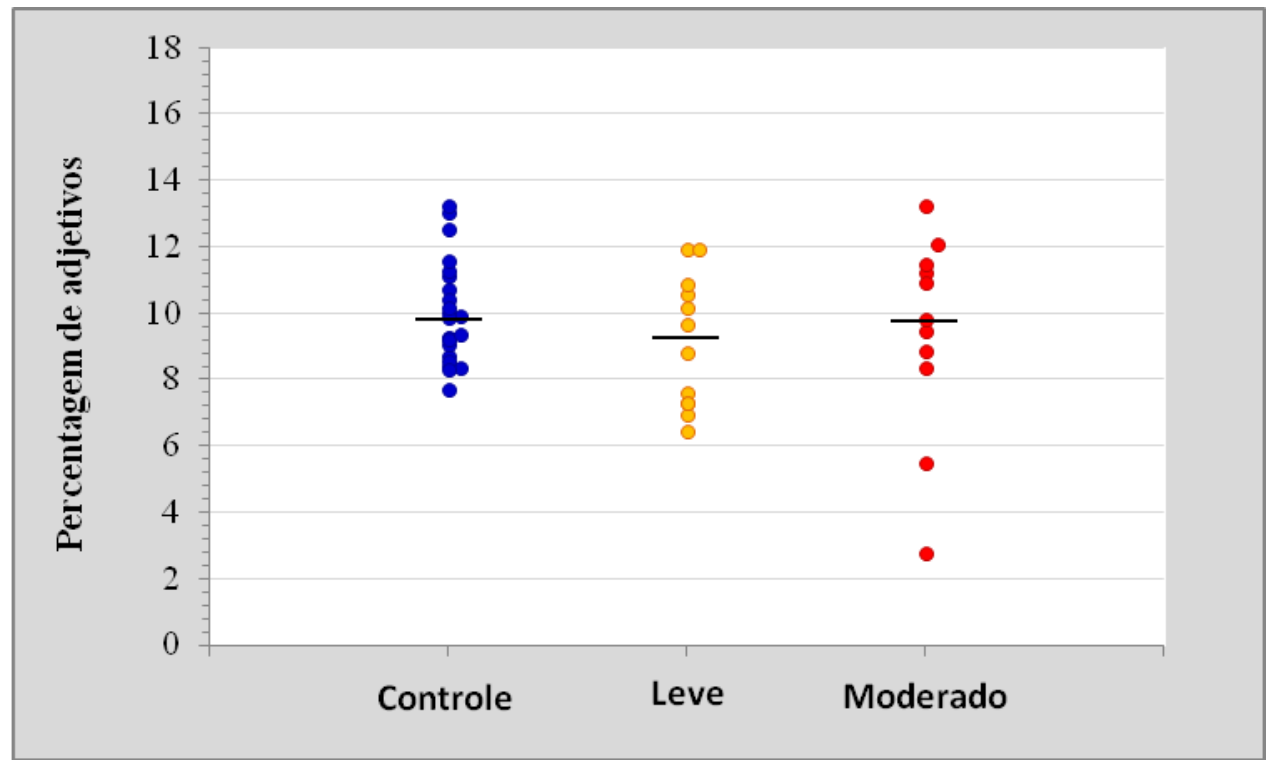

Figura 15- Percentagem e mediana dos adjetivos dos controles e dos pacientes nos estágios leve e moderado da doença de Alzheimer. 


\subsection{Análise da comparação dos advérbios}

Para analisar e comparar o número e percentagem dos advérbios foi usado o teste Kruskal-Wallis. A Tabela 11 mostra a análise de comparação entre os grupos. Observa-se diferença significante tanto em relação ao número, $\mathrm{p}=0,004$, quanto em relação a percentagem, $\mathrm{p}=0,008$. Os pacientes moderados mantêm menor número de advérbios do que os controles, $\mathrm{p}<0,05$, porém maior percentagem de advérbios do que os controles, $\mathrm{p}<0,05$. Os pacientes leves também apresentaram menor percentagem de advérbios quando comparados aos controles, $\mathrm{p}<0,05$.

As Figuras 16 e 17 mostram suas distribuições.

Tabela 11- Média e desvio padrão, mediana, valor mínimo e máximo do número e percentagem dos advérbios dos controles e dos pacientes nos estágios leve e moderado da DA.

\begin{tabular}{lcccc}
\hline & $\begin{array}{c}\text { Controle } \\
(\mathrm{n}=23)\end{array}$ & $\begin{array}{c}\text { Leve } \\
(\mathrm{n}=12)\end{array}$ & $\begin{array}{c}\text { Moderado } \\
(\mathrm{n}=11)\end{array}$ & $\mathrm{p}$ \\
\hline No. Advérbios & $33,7 \pm 7,9$ & $30,5 \pm 6,0$ & $24,4 \pm 8,6$ & $\mathrm{p}=0,004$ \\
& $34[8 ; 44]$ & $32[21 ; 39]$ & $27[4 ; 18]^{\mathrm{a}}$ & \\
\% Advérbios & $5,7 \pm 1,4$ & $6,6 \pm 1,1$ & $7,7 \pm 2,8$ & $\mathrm{p}=0,008$ \\
\hline
\end{tabular}

Teste de Kruskal-Wallis, a: vs. Controle, b: vs. Leve média \pm desvio padrão; mediana [mín; máx] 


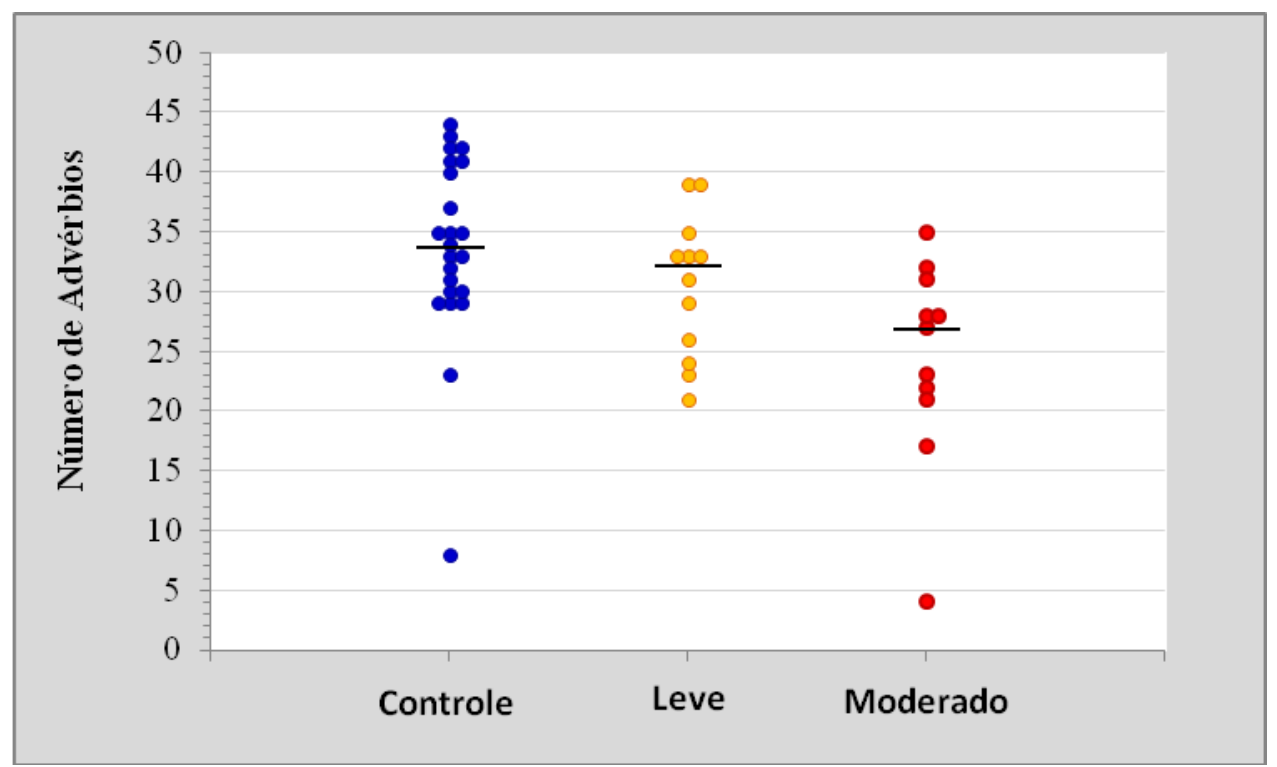

Figura 16 - Número e mediana dos advérbios dos controles e dos pacientes nos estágios leve e moderado da doença de Alzheimer.

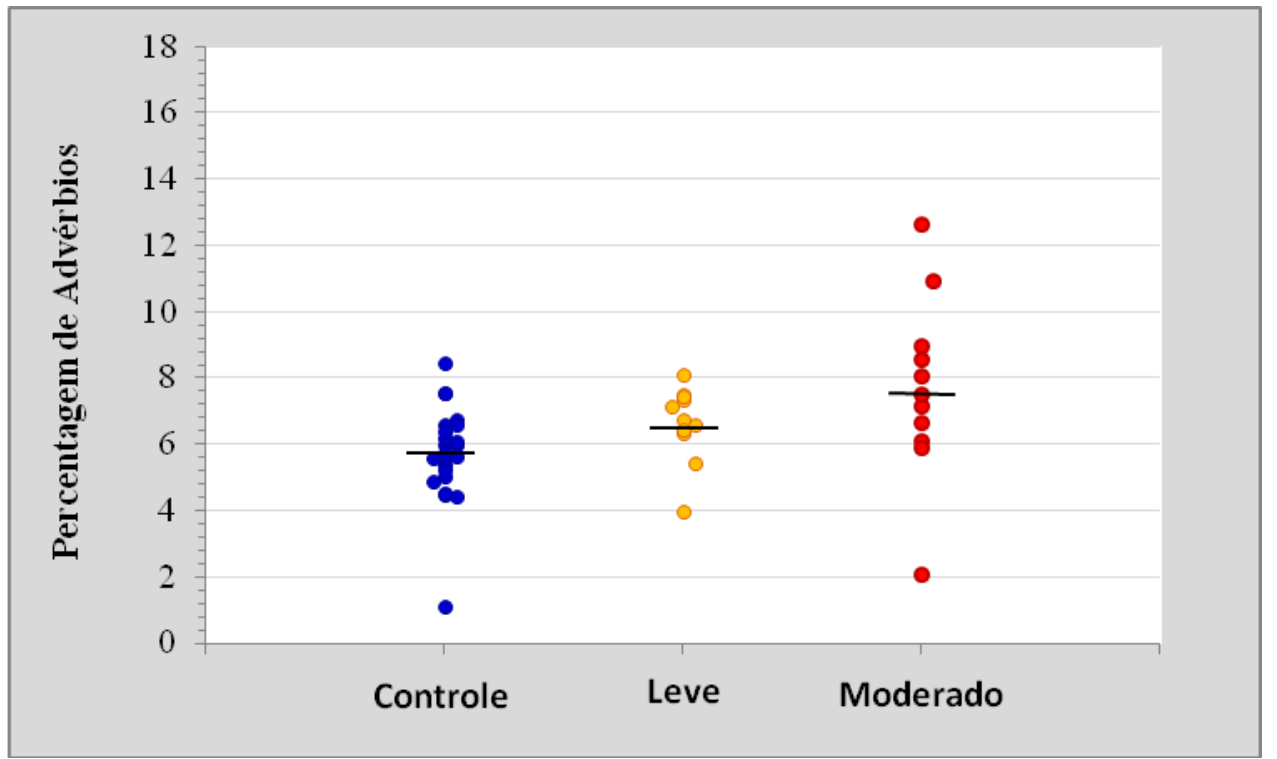

Figura 17 - Percentagem e mediana dos advérbios dos controles e dos pacientes nos estágios leve e moderado da doença de Alzheimer.

Exemplos de advérbios dos controles, pacientes de graus leve e moderado. Controle: de subida eu sempre pego o ônibus

Paciente de grau leve: estamos juntos até hoje

Paciente de grau moderado: me falou não coma mais 


\subsection{Análise da comparação dos pronomes}

Para analisar e comparar o número e percentagem dos pronomes foi usado o teste Kruskal-Wallis. Essa análise de comparação entre os grupos não foi detectada diferença significante, $p=0,107$. Houve diferença significante entre os grupos na percentagem de pronomes $\mathrm{p}=0,002$. O grupo moderado apresentou maior percentagem de pronomes do que o grupo controle, $\mathrm{p}<0,05$. A Tabela 12 mostra os resultados dessas análises e as Figuras 18 e 19 mostram as distribuições dos números e percentagens dos pronomes.

Tabela 12 - Média e desvio padrão, mediana, valor mínimo e máximo do número e percentagem dos pronomes dos controles e dos pacientes nos estágios leve e moderado da DA.

\begin{tabular}{lcccc}
\hline & $\begin{array}{c}\text { Controle } \\
(n=23)\end{array}$ & $\begin{array}{c}\text { Leve } \\
(n=12)\end{array}$ & $\begin{array}{c}\text { Moderado } \\
(n=11)\end{array}$ & $p$ \\
\hline No. Pronomes & $35,9 \pm 9,5$ & $34,9 \pm 8,8$ & $28,0 \pm 12,3$ & $p=0,107$ \\
& $37,0[10 ; 47]$ & $35,5[19 ; 50]$ & $26,0[8 ; 52]$ & \\
$\%$ Pronomes & $6,0 \pm 1,4$ & $7,5 \pm 1,6$ & $8,5 \pm 2,1$ & $p=0,002$ \\
& $6,2[1,4 ; 8,3]$ & $7,3[5,3 ; 10,0]$ & $9,2[4,2 ; 11,0]^{\mathrm{a}}$ & $\mathrm{p}$
\end{tabular}

Teste de Kruskal-Wallis, a: vs. Controle, b: vs. Leve média \pm desvio padrão; mediana [mín; máx] 


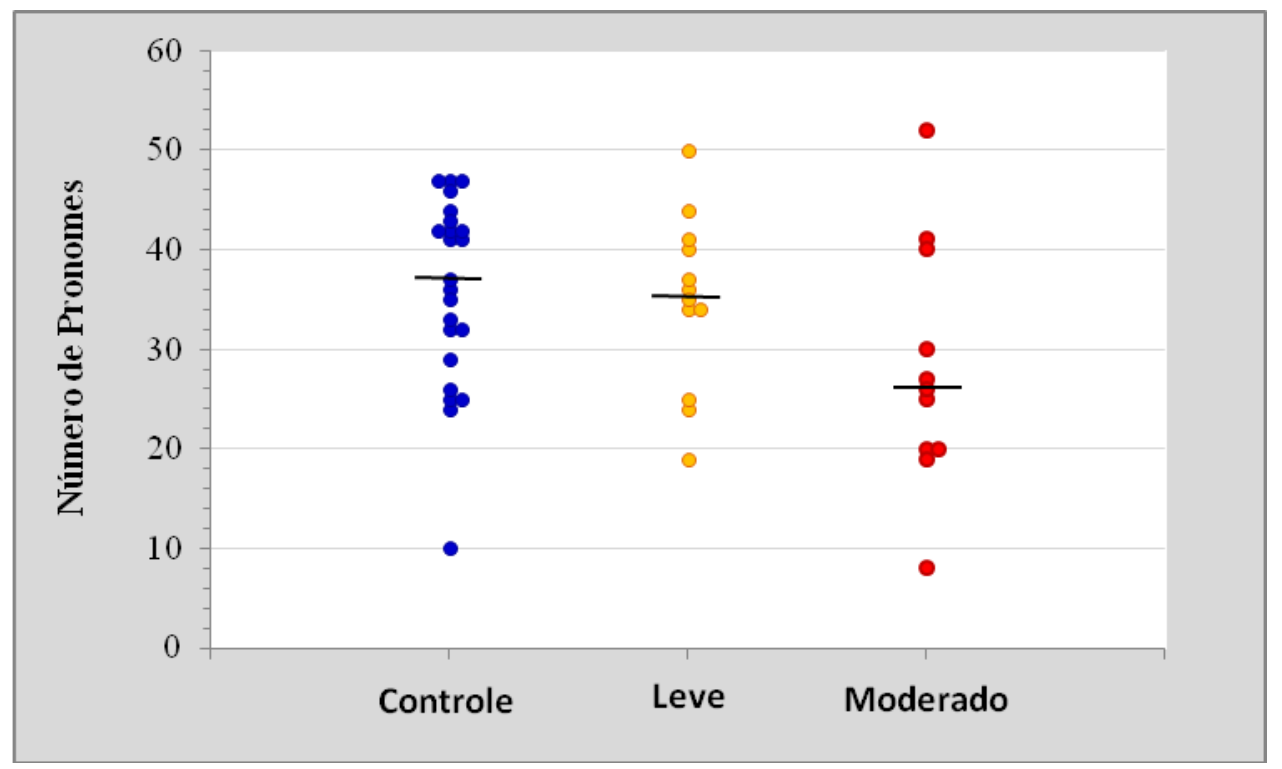

Figura 18. Número e mediana dos pronomes dos controles e dos pacientes nos estágios leve e moderado da doença de Alzheimer.

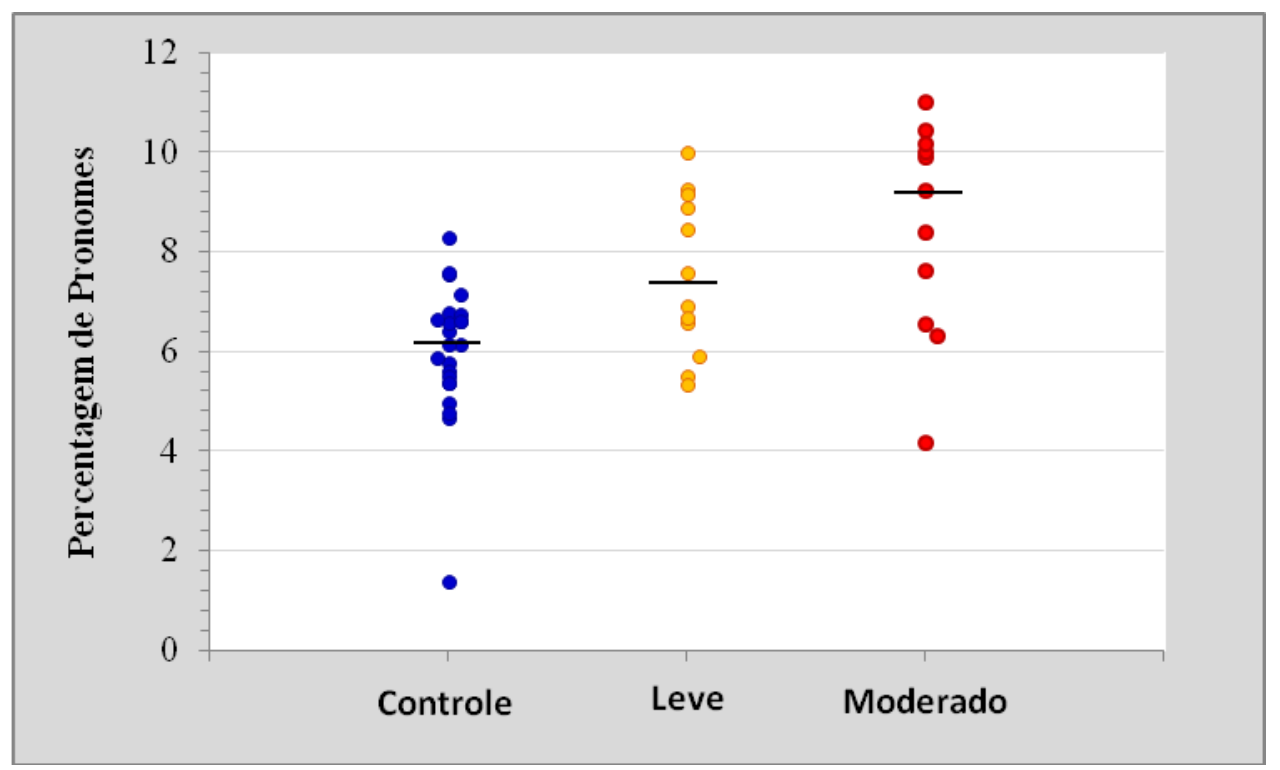

Figura 19. Percentagem e mediana dos pronomes dos controles e dos pacientes nos estágios leve e moderado da doença de Alzheimer.

Exemplos de pronomes dos controles, pacientes de graus leve e moderado.

Controle: $e u$ nunca precisei viver doente

Paciente de grau leve: eu tava lá encontrei ela

Paciente de grau moderado: ainda me deu vontade 


\subsection{Análise da comparação dos numerais}

Para analisar e comparar o número e percentagem dos numerais foi usado o teste KruskalWallis. Essa análise de comparação entre os grupos controles e pacientes leves e moderados indicou diferença significante, $p<0,001$. Os pacientes moderados e leves apresentam menor número de numerais do que os controles, $\mathrm{p}<0,05$ e os pacientes moderados apresentam menor número de numerais do que os pacientes leves, $\mathrm{p}<0,05$. Em relação à percentagem de numerais não foi detectada diferença significante entre os grupos, $p=0,078$. A Tabela 13 mostra os resultados dessa análise enquanto que as Figuras 20 e 21 mostram as distribuições dos números e percentagem dos numerais respectivamente.

Tabela 13- Média e desvio padrão, mediana, valor mínimo e máximo do número e percentagem dos numerais dos controles e dos pacientes nos estágios leve e moderado da DA.

\begin{tabular}{lcccc}
\hline & $\begin{array}{c}\text { Controle } \\
(\mathrm{n}=23)\end{array}$ & $\begin{array}{c}\text { Leve } \\
(\mathrm{n}=12)\end{array}$ & $\begin{array}{c}\text { Moderado } \\
(\mathrm{n}=11)\end{array}$ & $\mathrm{p}$ \\
\hline \multirow{2}{*}{ No. Numerais } & $23,7 \pm 9,2$ & $18,3 \pm 11,6$ & $8,3 \pm 4,1$ & $\mathrm{p}<0,001$ \\
& $24[5 ; 43]$ & $19[6 ; 49]^{\mathrm{a}}$ & $7[3 ; 16]^{\mathrm{ab}}$ & \\
\% Numerais & $4,0 \pm 1,8$ & $3,7 \pm 1,8$ & $2,8 \pm 1,6$ & $\mathrm{p}=0,078$ \\
\hline
\end{tabular}

Teste de Kruskal-Wallis, a: vs. Controle, b: vs. Leve média \pm desvio padrão; mediana [mín; máx] 


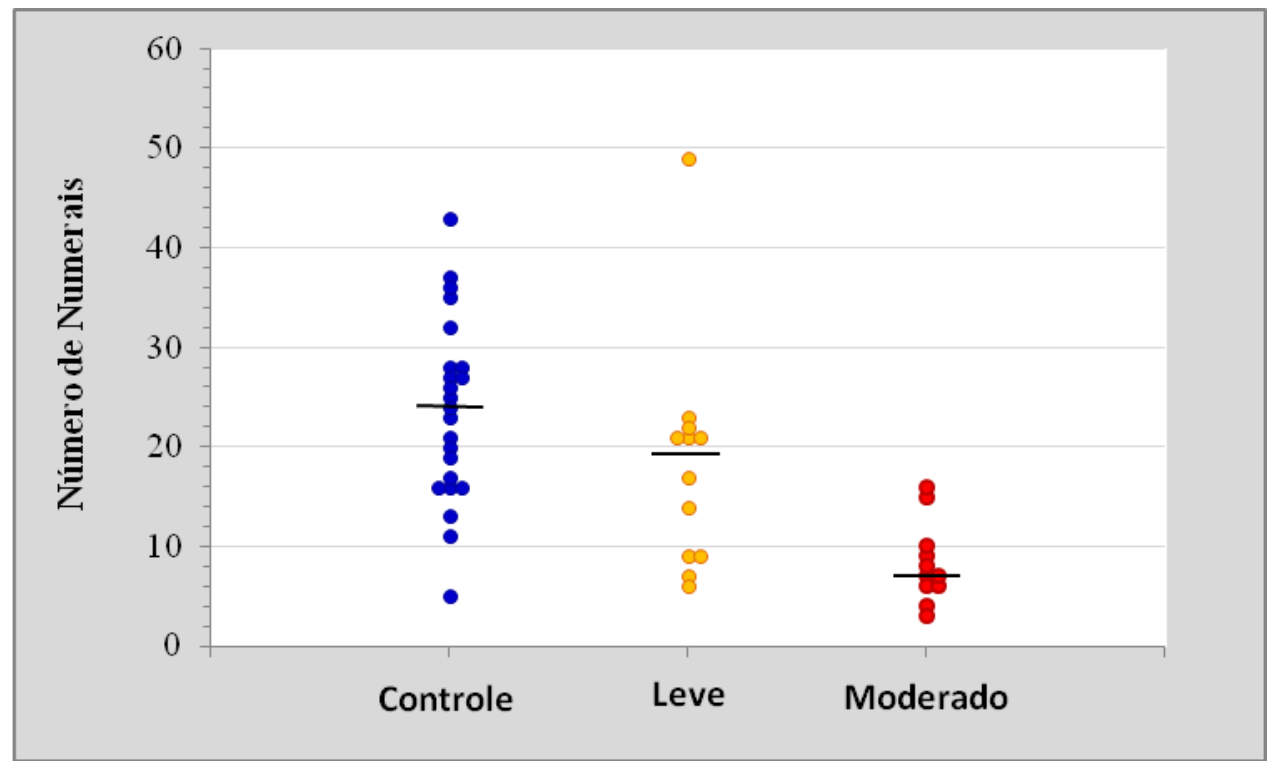

Figura 20. Número e mediana dos numerais dos controles e dos pacientes nos estágios leve e moderado da doença de Alzheimer.

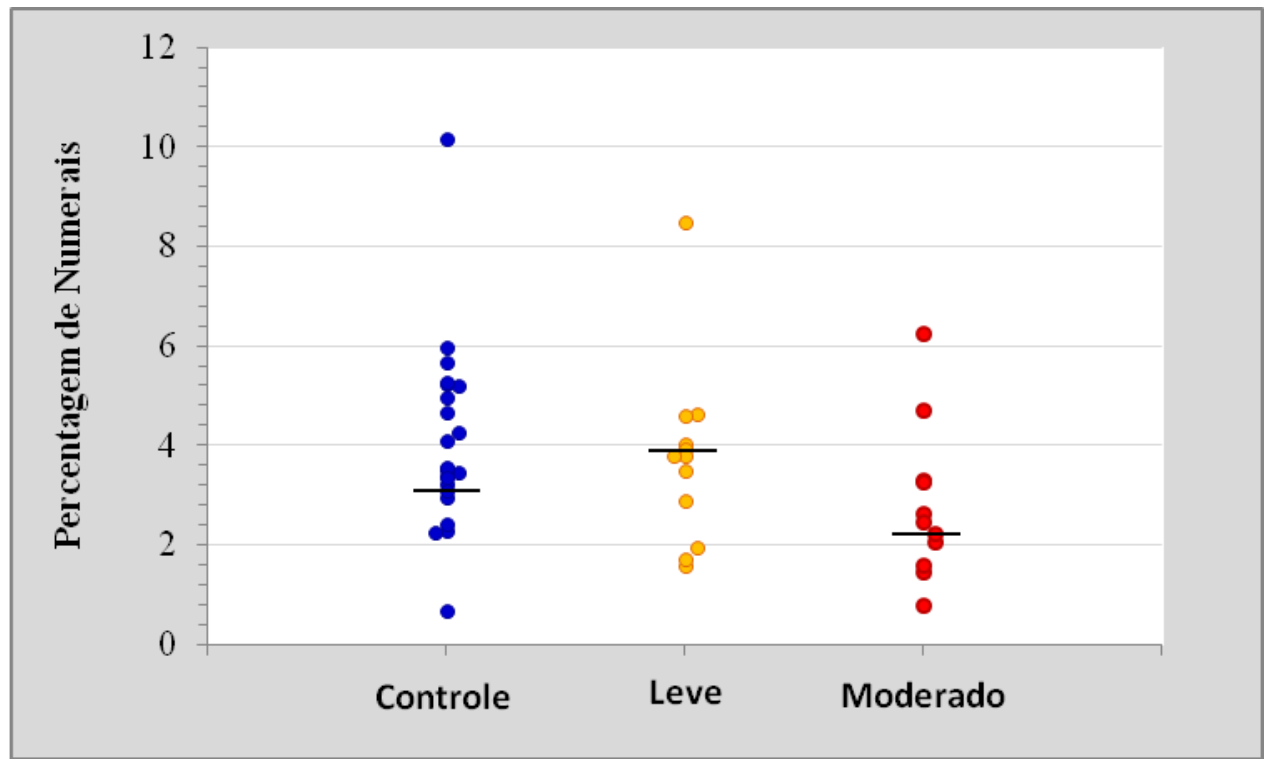

Figura 21. Percentagem e mediana dos numerais dos controles e dos pacientes nos estágios leve e moderado da doença de Alzheimer.

Exemplos dos numerais dos controles, pacientes de graus leve e moderado.

Controle: ela já com o terceiro filho

Paciente de grau leve: tenho cinco filhos

Paciente de grau moderado: eu sai do terceiro ano do grupo 


\subsection{Análise da comparação das interjeições}

Para analisar e comparar o número e percentagem das interjeiçõos foi usado o teste Kruskal-Wallis. Essa análise de comparação entre os grupos controles e pacientes leves e moderados não indicou diferença significante no número de interjeições, $p=0,421$. Em relação à percentagem das interjeições foi detectada diferença significante entre os grupos, $\mathrm{p}<0,001$ Os pacientes leves e moderados mantém maior número de interjeições do que os controles, $\mathrm{p}<0,05$.

Os resultados são mostrados na Tabela 14. As Figuras 22 e 23 mostram as distribuições dos números e percentagens das interjeições respectivamente. Em relação ao número, as distribuições são bem próximas, por sua vez a figura da percentagem mostra a maior distribuição das interjeições dos pacientes.

Tabela 14- Média e desvio padrão, mediana, valor mínimo e máximo do número e percentagem das interjeições dos controles e dos pacientes nos estágios leve e moderado da DA.

\begin{tabular}{lcccc}
\hline & $\begin{array}{c}\text { Controle } \\
(\mathrm{n}=23)\end{array}$ & $\begin{array}{c}\text { Leve } \\
(\mathrm{n}=12)\end{array}$ & $\begin{array}{c}\text { Moderado } \\
(\mathrm{n}=11)\end{array}$ & $\mathrm{p}$ \\
\hline \multirow{2}{*}{ No. Interjeições } & $4,5 \pm 2,2$ & $6,2 \pm 3,0$ & $5,7 \pm 3,8$ & $\mathrm{p}=0,421$ \\
& $4,0[0 ; 9]$ & $5,5[2 ; 12]$ & $4,0[1 ; 12]$ & \\
\% Interjeições & $0,8 \pm 0,4$ & $1,4 \pm 0,5$ & $1,7 \pm 1,0$ & $\mathrm{p}<0,001$ \\
\hline
\end{tabular}

Teste de Kruskal-Wallis, a: vs. Controle, b: vs. Leve média \pm desvio padrão; mediana [mín; máx] 


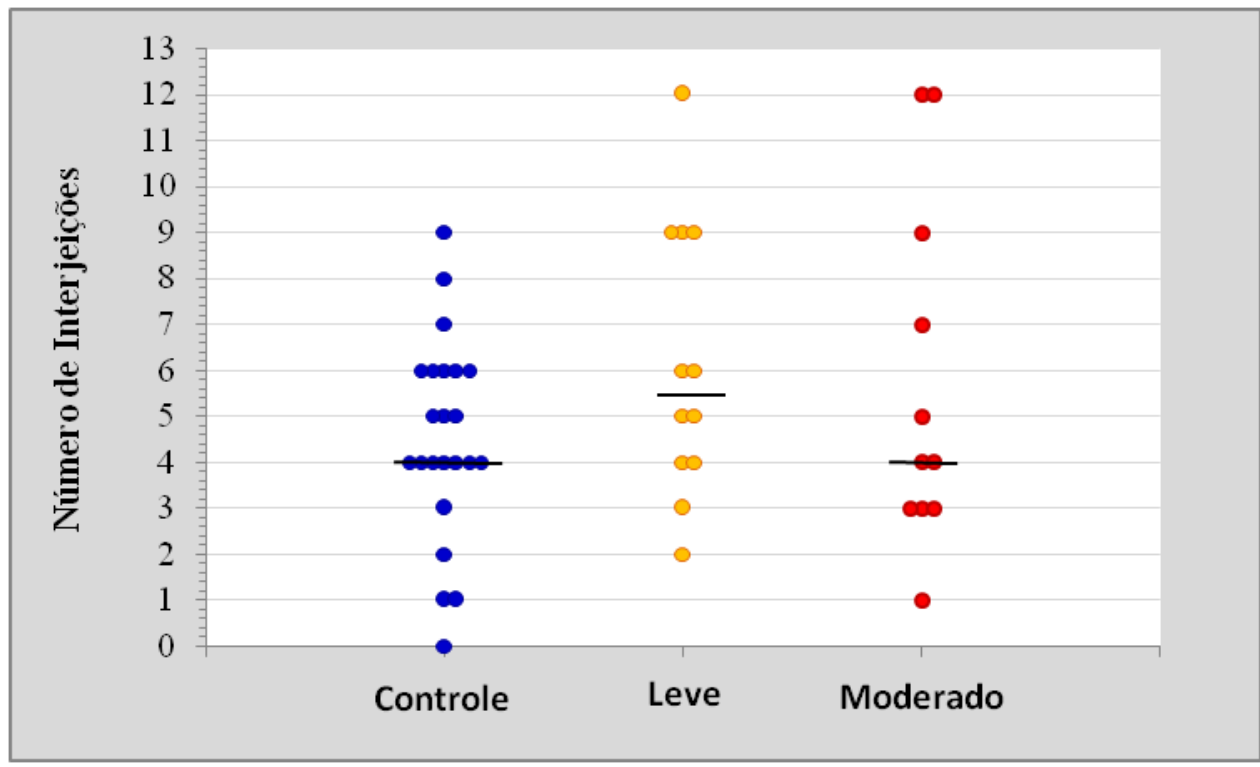

Figura 22. Número e mediana das interjeições dos controles e dos pacientes nos estágios leve e moderado da doença de Alzheimer.

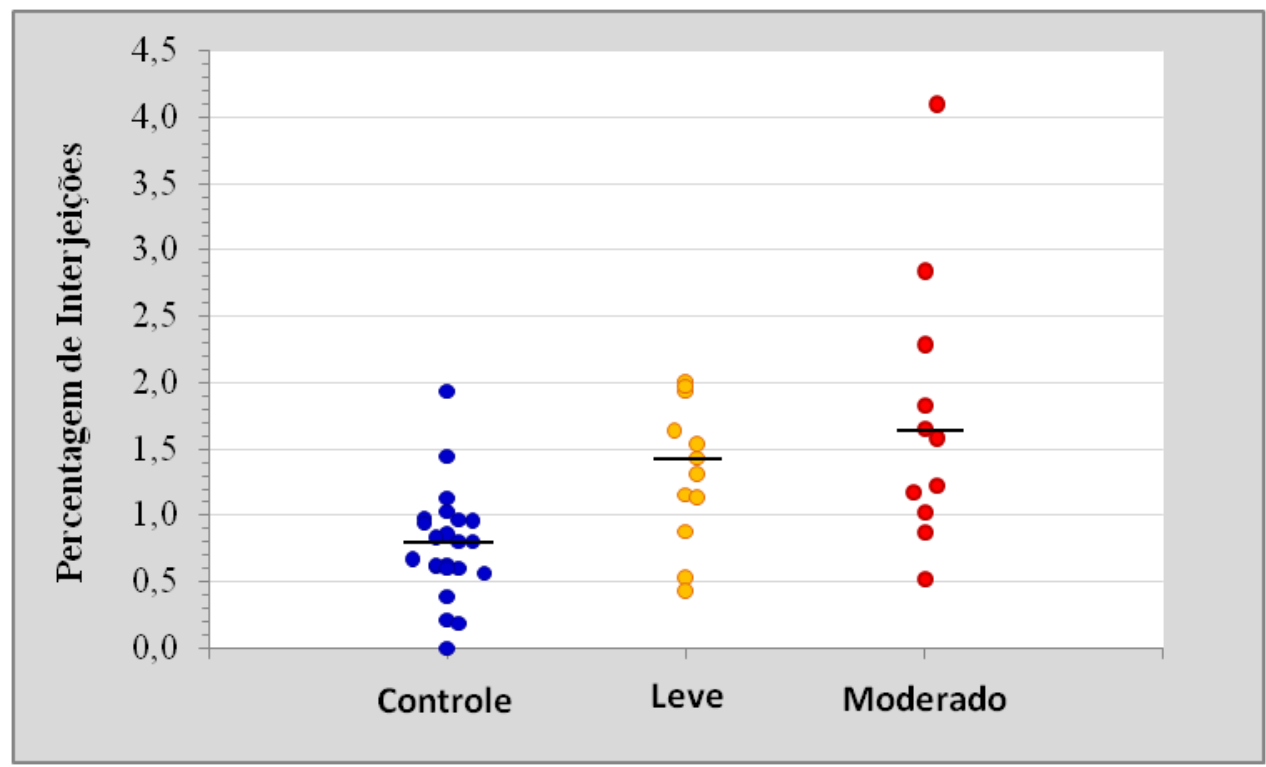

Figura 23. Percentagem e mediana das interjeições dos controles e dos pacientes nos estágios leve e moderado da doença de Alzheimer.

Exemplos das interjeições dos controles e pacientes de graus leve e moderado.

Controle: nossa!, fiquei bom

Paciente de grau leve: $a h$ ! não meu avô

Paciente de grau moderado: $e h$ ! por lá 


\subsection{1 - Análise da comparação das conjunções}

Para analisar e comparar o número e percentagem das conjunções foi usado o teste Kruskal-Wallis. Essa análise de comparação entre os grupos controles e pacientes leves e moderados não detectou diferença significante no número de conjunções, $p=0,063$. Em relação à percentagem de conjunções também não foi detectada diferença significante entre os grupos, $\mathrm{p}=0,794$. Os resultados são mostrados na Tabela 15 e as Figuras 24 e 25 mostram as distribuições dos números e percentagem das conjunções respectivamente.

Tabela 15- Média e desvio padrão, mediana, valor mínimo e máximo do número e percentagem das conjunções dos controles e dos pacientes nos estágios leve e moderado da DA.

\begin{tabular}{lcccc}
\hline & $\begin{array}{c}\text { Controle } \\
(\mathrm{n}=23)\end{array}$ & $\begin{array}{c}\text { Leve } \\
(\mathrm{n}=12)\end{array}$ & $\begin{array}{c}\text { Moderado } \\
(\mathrm{n}=11)\end{array}$ & $\mathrm{P}$ \\
\hline No. Conjunções & $5,4 \pm 2,4$ & $4,3 \pm 0,9$ & $3,5 \pm 1,9$ & $\mathrm{p}=0,063$ \\
& $5[1 ; 9]$ & $4[3 ; 6]$ & $3[1 ; 6]$ & \\
\% Conjunções & $0,9 \pm 0,4$ & $1,0 \pm 0,3$ & $1,0 \pm 0,4$ & $\mathrm{p}=0,794$ \\
& $0,9[0,1 ; 1,5]$ & $0,9[0,5 ; 1,4]$ & $1,0[0,3 ; 2,0]$ & \\
\hline
\end{tabular}

Teste de Kruskal-Wallis, a: vs. Controle, b: vs. Leve média \pm desvio padrão; mediana [mín; máx] 


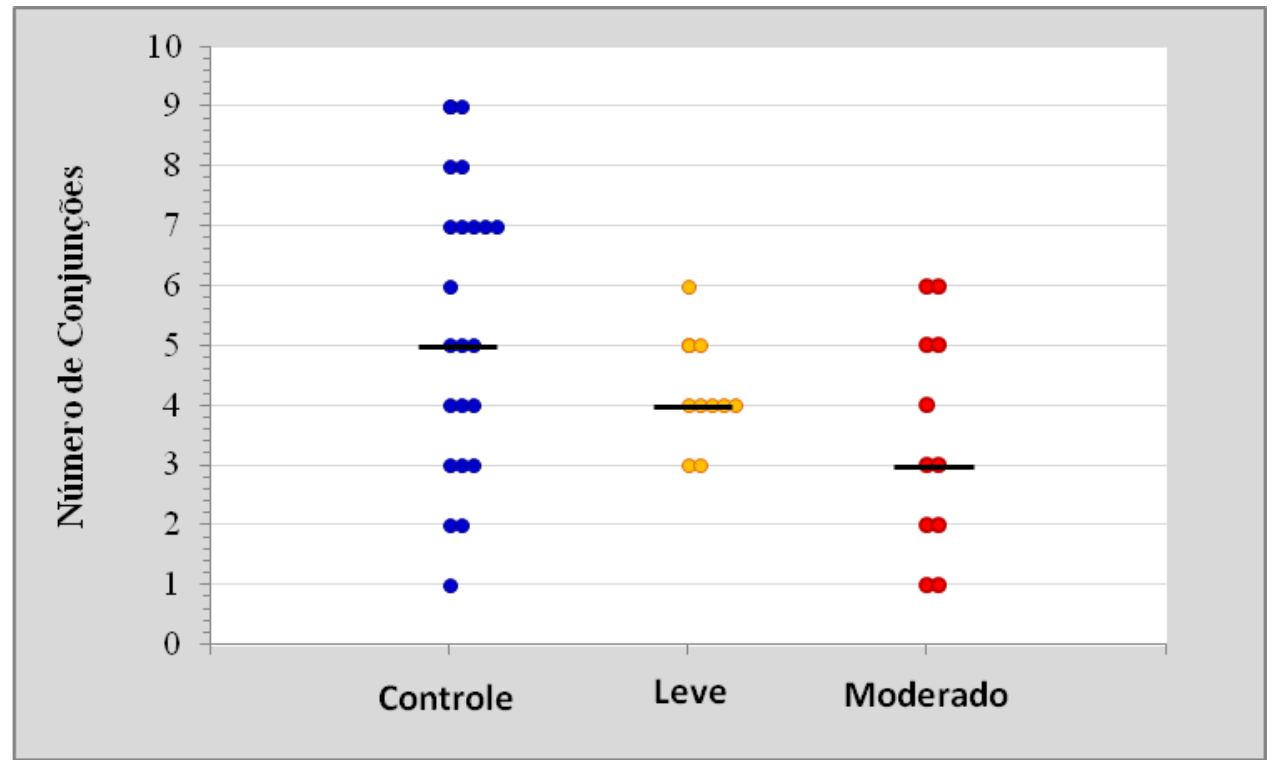

Figura 24. Número e mediana das conjunções dos controles e dos pacientes nos estágios leve e moderado da doença de Alzheimer.

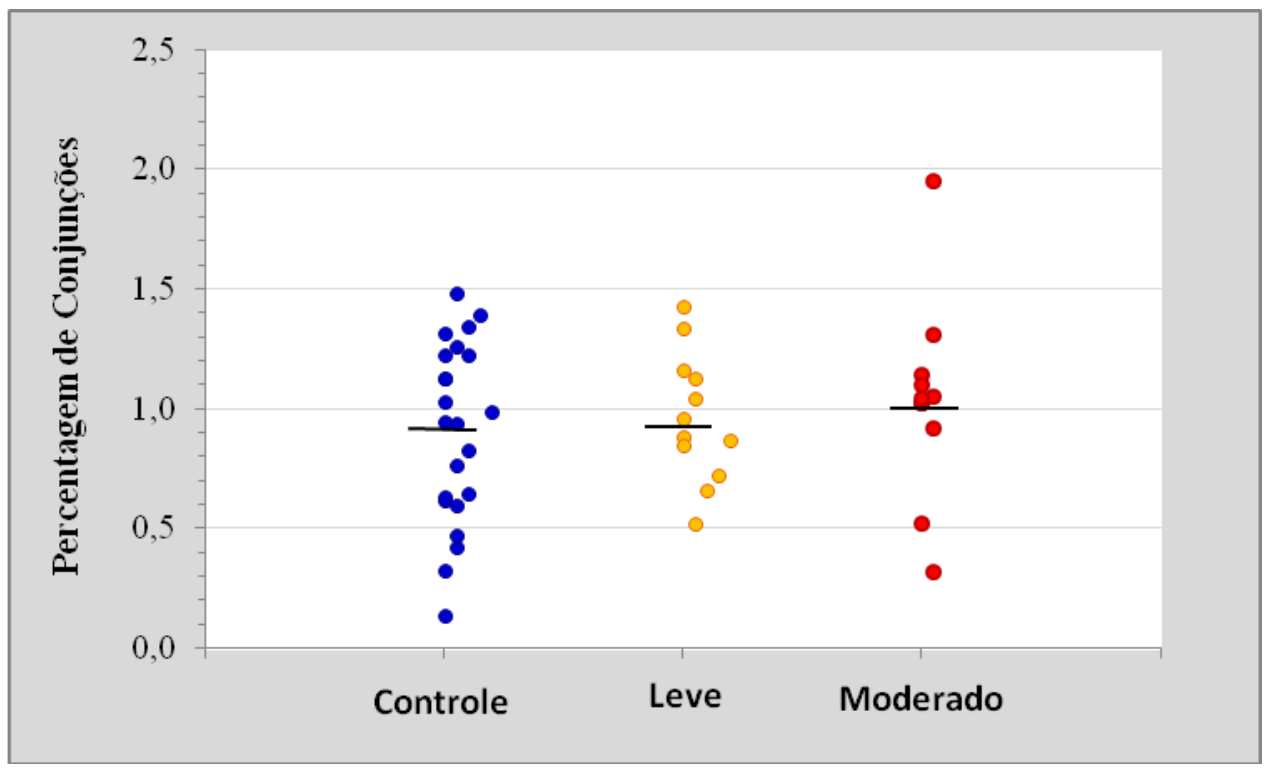

Figura 25. Percentagem e mediana das conjunções dos controles e dos pacientes nos estágios leve e moderado da doença de Alzheimer.

Exemplos das conjunções dos controles e pacientes de graus leve e moderado.

Controle: eu vou porque eu quero

Paciente de grau leve: então quando ele chegou

Paciente de grau moderado: quando era moço 


\subsection{2 - Análise da comparação dos artigos}

Para analisar e comparar o número e percentagem do artigo foi usado o teste KruskalWallis. Essa análise de comparação entre os grupos controles e pacientes leves e moderados indicou diferença significante, $p<0,001$. Os pacientes leves e moderados mantêm menor número de artigos do que os controles, $\mathrm{p}<0,05$, e os pacientes moderados apresentaram menor número de artigos do que os pacientes leves, $\mathrm{p}<0,05$. Em relação à percentagem de artigos não foi detectada diferença significante entre os grupos, $\mathrm{p}=0,566$. A Tabela 16 mostra os resultados das análises, enquanto que as Figuras 26 e 27 mostram as distribuições dos números e percentagem dos artigos respectivamente.

Tabela 16 - Média e desvio padrão, mediana,valor mínimo e máximo do número e percentagem dos artigos dos controles e dos pacientes nos estágios leve e moderado da DA

\begin{tabular}{lcccc}
\hline & $\begin{array}{c}\text { Controle } \\
(\mathrm{n}=23)\end{array}$ & $\begin{array}{c}\text { Leve } \\
(\mathrm{n}=12)\end{array}$ & $\begin{array}{c}\text { Moderado } \\
(\mathrm{n}=11)\end{array}$ & $\mathrm{P}$ \\
\hline No. Artigos & $16,7 \pm 4,7$ & $14,3 \pm 2,5$ & $10,9 \pm 3,6$ & $\mathrm{p}<0,001$ \\
& $18[1 ; 23]$ & $14[12 ; 21]^{\mathrm{a}}$ & $11[4 ; 17]^{\mathrm{ab}}$ & \\
\% Artigos & $2,8 \pm 0,8$ & $3,2 \pm 0,8$ & $3,7 \pm 1,7$ & $\mathrm{p}=0,566$ \\
& $2,8[0,1 ; 4,1]$ & $2,9[2,4 ; 5,0]$ & $3,3[1,7 ; 6,3]$ & \\
\hline
\end{tabular}

Teste de Kruskal-Wallis, a: vs. Controle, b: vs. Leve média \pm desvio padrão; mediana [mín; máx] 


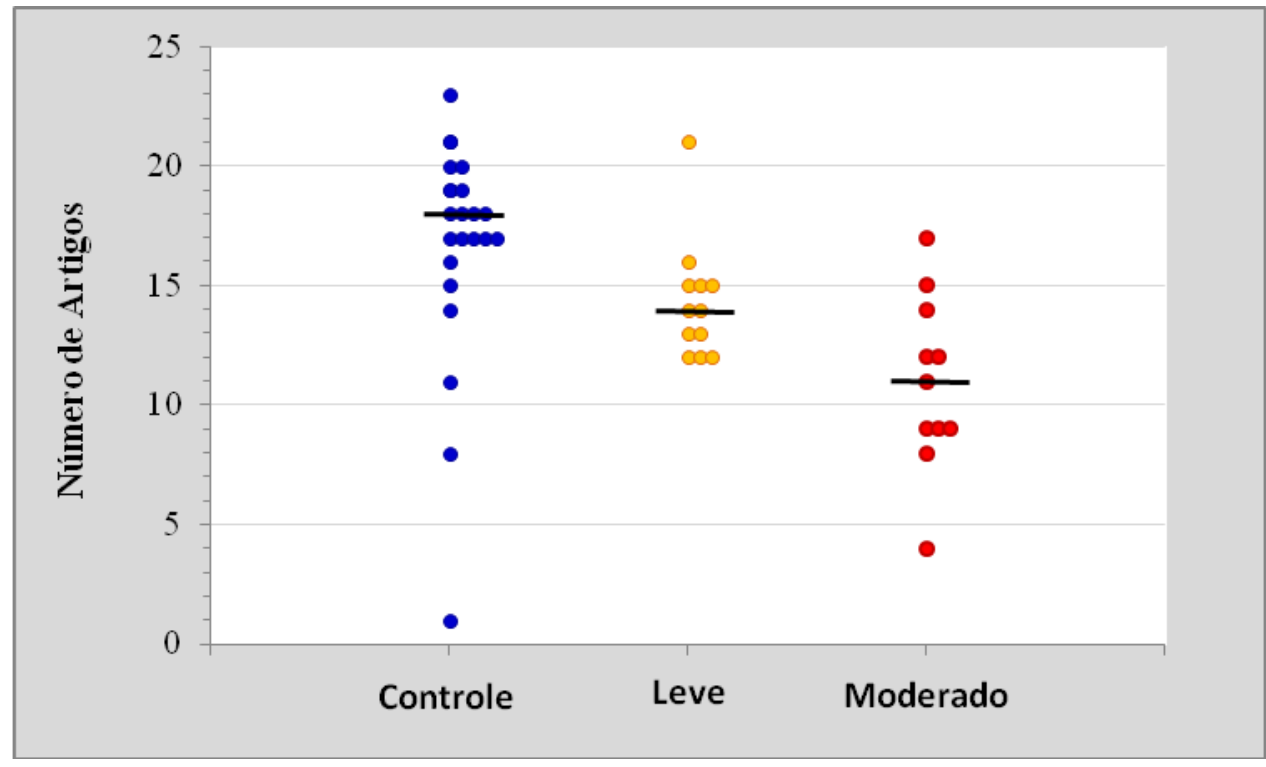

Figura 26. Número e mediana de artigos dos controles e dos pacientes nos estágios leve e moderado da doença de Alzheimer

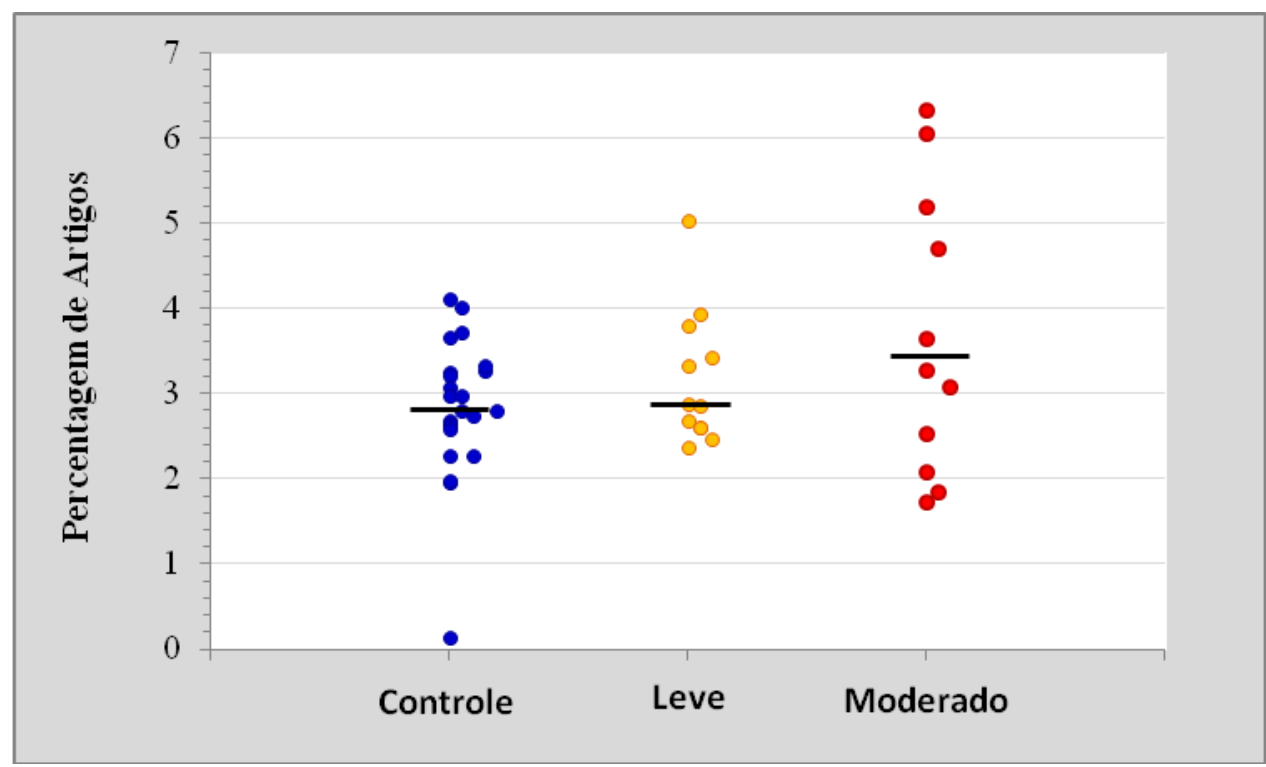

Figura 27. Percentagem e mediana de artigos dos controles e dos pacientes nos estágios leve e moderado da doença de Alzheimer

Exemplos dos artigos dos controles e pacientes de graus leve e moderado.

Controle: passar $a$ outra fase

Paciente de grau leve: tem um neto e uma neta

Paciente de grau moderado: $o$ meu marido faleceu 


\subsection{3 - Análise da comparação das preposições}

Para analisar e comparar o número e percentagem do item lexical preposição foi usado o teste Kruskal-Wallis. A análise de comparação entre os grupos controles e pacientes leves e moderados não detectou diferença significante no número de preposições, $p=0,120$. Em relação à percentagem de preposições foi detectada diferença significante entre os grupos, $p<0,001$. Os pacientes moderados e leves mantêm maior número de preposições do que os controles, $\mathrm{p}<0,05$, e os pacientes moderados apresentaram maior número de preposições do que os pacientes leves, $\mathrm{p}<0,05$. A Tabela 17 mostra os resultados das analises, enquanto que as Figuras 28 e 29 mostram as distribuições dos números e percentagem das preposições respectivamente.

Tabela 17- Média e desvio padrão, mediana, valor mínimo e máximo do número e percentagem das preposições dos controles e dos pacientes nos estágios leve e moderado da DA.

\begin{tabular}{lcccc}
\hline & $\begin{array}{c}\text { Controle } \\
(\mathrm{n}=23)\end{array}$ & $\begin{array}{c}\text { Leve } \\
(\mathrm{n}=12)\end{array}$ & $\begin{array}{c}\text { Moderado } \\
(\mathrm{n}=11)\end{array}$ & $\mathrm{P}$ \\
\hline \multirow{2}{*}{ No. Preposições } & $15,3 \pm 5,2$ & $19,2 \pm 3,1$ & $17,1 \pm 4,9$ & $\mathrm{p}=0,120$ \\
& $15[5 ; 23]$ & $18[14 ; 26]$ & $16[10 ; 25]$ & \\
\% Preposições & $2,8 \pm 1,5$ & $4,3 \pm 1,5$ & $5,7 \pm 2,1$ & $\mathrm{p}<0,001$ \\
\hline
\end{tabular}

Teste de Kruskal-Wallis, a: vs. Controle, b: vs. Leve média \pm desvio padrão; mediana [mín; máx] 


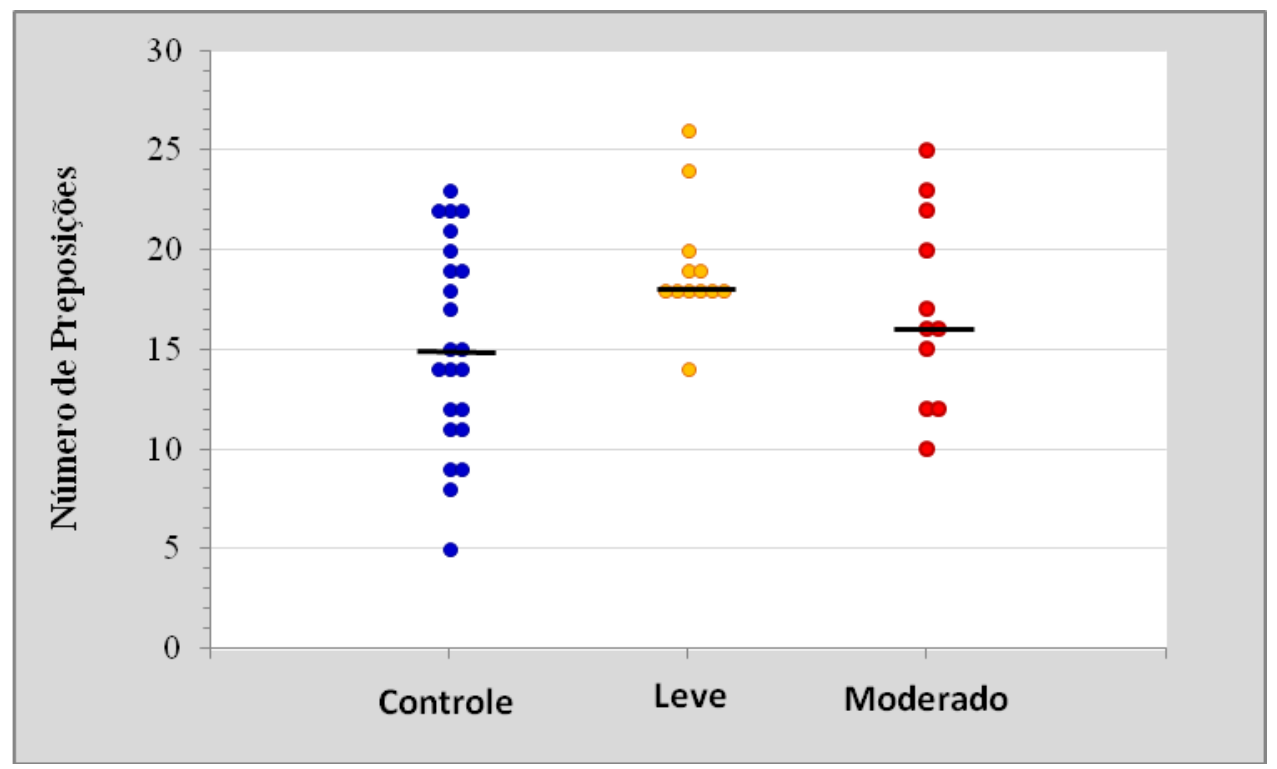

Figura 28.Número e mediana das preposições dos controles e dos pacientes nos estágios leve e moderado da doença de Alzheimer

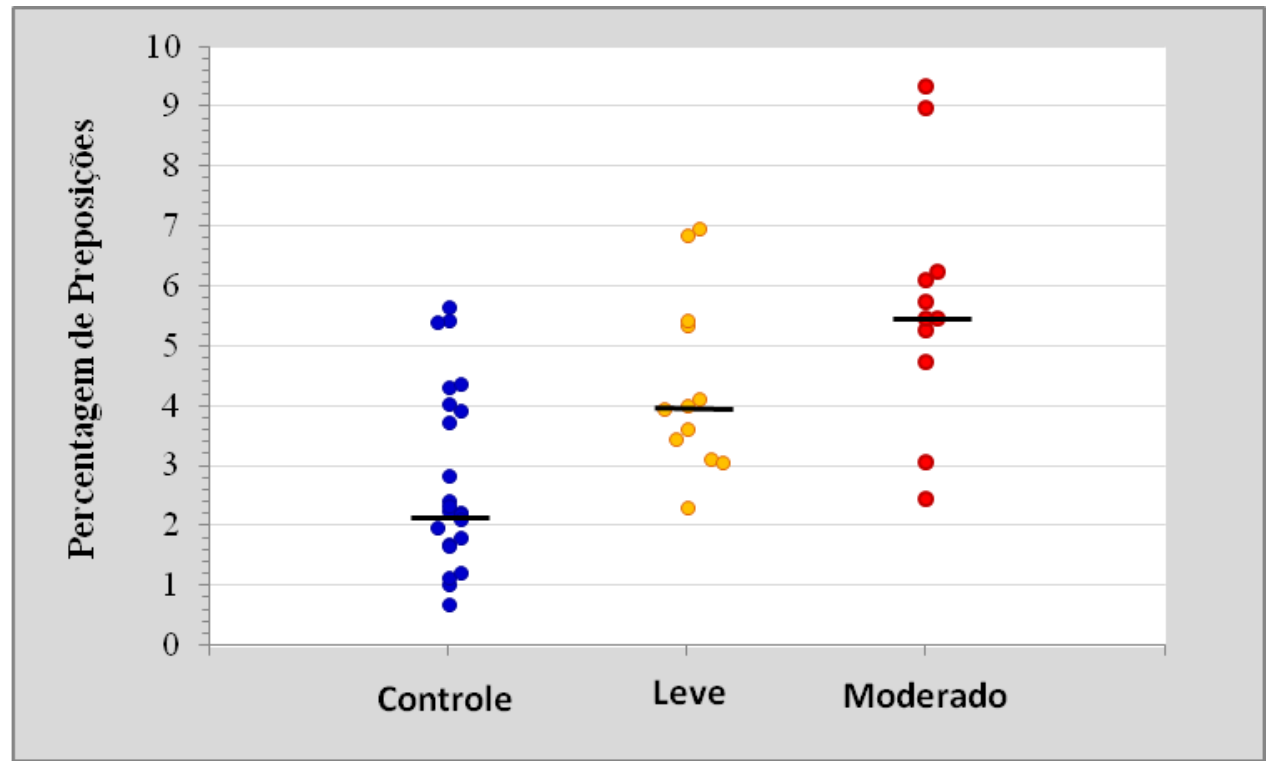

Figura 29. Percentagem e mediana das preposições dos controles e dos pacientes nos estágios leve e moderado da doença de Alzheimer

Exemplos das preposições dos controles e pacientes de graus leve e moderado.

Controle: eu comprei pra ela

Paciente de grau leve: aí ficamos para lá

Paciente de grau moderado: vi passagem dele por aqui 
As Tabelas 18 e 19 mostram os dez primeiros itens lexicais pela frequência e os dez primeiros itens lexicais verbos e dez primeiros substantivos respectivamente expressos pelos participantes do estudo.

Tabela 18- Dez primeiras palavras pela frequência

\begin{tabular}{lll}
\hline Grupo DA leve & Pacientes moderados & Grupo Controle \\
\hline Eu & Não & Eu \\
Não & Eu & Não \\
Que & Que & Que \\
E & E & E \\
De & De & De \\
A & É & A \\
É & A & O \\
O & Ele & É \\
Né & O & Né \\
Lá & Eh & Ele \\
\hline
\end{tabular}

Nesses dez primeiras palavras pode se verificar semelhanças, sendo os itens lexicais mais frequentes eu e não, provavelmente pelos indivíduos estarem centrados em si mesmos.

Tabela 19- Dez primeiros verbos e dez primeiros substantivos

\begin{tabular}{llllll}
\hline \multicolumn{2}{c}{ Grupo DA leve (V e S) } & \multicolumn{3}{c}{ Grupo DA moderado (V e S) } & Grupo \\
\hline É & Anos & É & Casa & É & Anos \\
Tem & Casa & Era & Mãe & Tem & Gente \\
Tinha & Coisa & Tem & São-Paulo & Era & Casa \\
Tenho & São-Paulo & Tenho & Filho & Tinha & Pai \\
Era & Mãe & Como & Coisa & Foi & São-Paulo \\
Faz & Filho & Tinha & Tempo & Como & Coisa \\
Foi & Tempo & Faz & Pai & Tenho & Mãe \\
Vou & Dia & Sei & Anos & Vai & Dia \\
Sei & Filha & Foi & Marido & Fui & Tempo \\
Acho & pai & gosto & Igreja & acho & Ano \\
\hline
\end{tabular}

Esses dez primeiros itens lexicais estão bem semelhantes entre os grupos. Ainda, esses itens lexicais verbos e substantivos estão em concordância com os resultados obtidos das comparações estatísticas que apesar da doença estar em processo de degeneração, existem itens lexicais que estão preservados e podem ser decodificados quando os indivíduos são estimulados. 


\subsection{Análise da influência dos dados sócio-demográficos nos itens lexicais}

Empregou-se o Modelo Linear Generalizado para avaliar a influência dos dados demográficos: gênero, idade, MEEM e escolaridade nos itens lexicais verbos e substantivos.

A análise mostrou influência significante do gênero nos verbos, $p=0,011$, indicando que nesse estudo, as mulheres apresentaram preferência por uso de verbos. Em média os homens falam 40 verbos a menos que as mulheres.

A influência do gênero nos verbos lexicais foi significante, $p=0,008$. Os homens falam em média 39 verbos lexicais a menos do que as mulheres.

Além disso, houve influência significante do gênero nos verbos de ação, $p=0,025$, indicando que neste estudo os homens falam em média 24 verbos de ação a menos do que as mulheres.

Também, houve influência significante do gênero nos verbos mentais, $p=0,009$, o que indica neste estudo os homens falam em média 12,5 verbos mentais a menos do que as mulheres.

Houve influência significante do gênero nos substantivos vivos, $\mathrm{p}=0,010$, indicando que neste estudo os homens falam em média 8,3 substantivos vivos a menos do que as mulheres.

Além disso, houve influência da idade para substantivos concretos e para substantivos não-vivos, $\mathrm{p}=0,027$ e $\mathrm{p}=0,015$ respectivamente. A cada ano há uma diminuição em média de 1,7 substantivos concretos falados e 2,3 substantivos não-vivos falados.

Em relação às palavras básicas houve influência significante de gênero, p=0,001. Em média, os homens falam 73 palavras básicas a menos do que as mulheres.

Além disso, empregou-se o Modelo Linear Generalizado para avaliar a influência dos dados demográficos: gênero, idade, MEEM e escolaridade na influência de itens lexicais adjetivo, advérbio, pronome, numeral, interjeição, conjunção e artigo.

A análise mostrou influência significante do gênero nos adjetivos, $p=0,013$, indicando que nesse estudo, as mulheres apresentaram preferência por uso dos adjetivos. Em média os homens falam 12,6 adjetivos a menos que as mulheres.

Houve influência significante do estágio da doença nos advérbios, $p=0,041$. Controles falam, em média, 19 advérbios a mais do que os pacientes e os pacientes leves falam em média 12 advérbios a mais do que os pacientes moderados.

Em relação à interjeição, houve influência significante do MEEM, p=0,014. A cada ponto a menos no MEEM há uma diminuição em média de 0,5 no número de interjeições. 


\section{DISCUSSÃO}

O uso da linguagem em situações reais como diálogos, entrevistas, conversações e situações corriqueiras do dia a dia e fatos culturais são importantes para o estudo da linguagem na doença de Alzheimer. A análise da linguagem na conversação com pacientes com DA mostra mais eficácia, pois é nela que os pacientes têm que ter mais atenção e concentração para poderem interagir. É importante destacar que são necessários estudos onde os pacientes com essa doença ao sentirem-se estimulados com situações reais possam se expressar melhor e provavelmente evitar o estresse ao serem solicitados a fazer atividades que nunca antes eram expostos nas suas relações sociais e culturais. Além disso, alguns pacientes, nas aplicações de testes, referem já saber as respostas, outros afirmam que não são crianças para fazer esse tipo de testes e prefeririam conversar.

Estudo sobre a qualidade de vida feita no Reino Unido pela Alzheimer's Society (2010) conclui que de dez resultados a primeira era que os pacientes com DA desejam ter um relacionamento e alguém para conversar e a habilidade para se comunicarem ficou em sexto lugar. É interessante observar que os pacientes com DA em várias sociedades ainda tem habilidades da linguagem muitas vezes de acordo com o estágio da doença usam mecanismos compensatórios que precisam ser estimuladas. Esses pacientes podem codificar e decodificar os enunciados linguísticos como mostram nossos resultados.

Pode-se ressaltar que nas interações comunicativas em situações reais ou mais próximas do real como sugerida por Bucks et al., (2000) é possível verificar interações verbais muitas vezes coerentes, como por exemplo ao ser questionado: $O$ Sr nasceu em São Paulo? A maioria dos pacientes responde: nasci. Essa resposta afirmativa pode ser identificada como sendo um discurso com enunciado que tem várias informações: a pessoa (eu) inserida, o tempo no pretérito, o local ou espaço: São Paulo, a decência do verbo na vogal (i), muitas repostas requerem interpretação das informações semânticas ou de acessos lexicais e também devido à língua portuguesa do Brasil, que tem marcas e desinências verbais e de substantivos marcantes, específicos, que muitas vezes estão preservados na doença, como demonstrado neste estudo. Dessa forma, pode-se verificar que pelo fato cultural as respostas de muitos pacientes não usam o advérbio sim ou não nas respostas, mas repetem os verbos que foram perguntados, por exemplo quando perguntados : O senhor tem filhos? Muitas vezes as respostas eram na terceira pessoas do 
verbo ter, tem. Uma análise breve indicaria que o indivíduo estava errado, mas é comum no português brasileiro as pessoas responderem com o sujeito em terceira pessoa mesmo se o referente for a primeira. Ainda ao organizar os itens lexicais substantivo, pode-se verificar que muitos substantivos foram expressos no singular, por exemplo, eu tenho duas irmã, meus filho moram em Minas ou meus avôs eram espanhol.

Em relação as nossas análises preferimos dar ênfase às percentagens devido a que todos os indivíduos têm diferença no número total de itens lexicais expressos nas conversações ou discursos, pode-se verificar que os cálculos das percentagens dos léxicos são mais adequados para comparar os itens lexicais preservados e em uso. Essas análises mostraram que tanto os pacientes quanto os controles têm altas percentagens de itens lexicais preferenciais, os índices proporcionais menores foram de um indivíduo de estágio moderado e outro do grupo controle, talvez isso seja devido ao estágio da doença e ao nível sócio-cultural do individuo controle. Por sua vez, as percentagens dos itens lexicais básicos indicaram que todos os participantes têm em média $51 \%$ do léxico total, provavelmente isso indique que o léxico básico é comum a todos. As percentagens mais baixas foram nos léxicos diferenciais. Em relação ao léxico particular que é próprio, distintivo do individuo, em média foram expressos $18 \%$ dos itens lexicais. Assim, não foi observada diferença significante entre os grupos na percentagem dos léxicos, mas os pacientes moderados apresentaram menor percentagem de itens lexicais particulares do que os leves, o que pode indicar quanto maior o estágio menor expressão ou preservação de itens lexicais. Quanto ao número de itens lexicais não houve diferença significativa entre os três grupos, ao pacientes moderados apresentaram menor número de itens lexicais básicos, diferenciais, particulares e totais quando comparado aos controles.

Os resultados das análises estatísticas do número de verbos e substantivos mostraram valores significantes, pois os pacientes do grupo moderado tiveram menor expressão de verbos e substantivos. Nas subcategorias substantivo comum, próprio, abstrato, concreto, vivo, não-vivo foram significativas, por sua vez os verbos lexicais, auxiliares e de ação analisadas foram significativos, exceto nos verbos leves e mentais. Os pacientes do grupo moderado ao serem comparados com os leves e controles tiveram menor expressão de esses itens e subitens. Somente os pacientes moderados apresentaram menor expressão em relação aos controles quanto aos substantivos vivos. Nosso estudo está de acordo com os resultados da literatura, que afirmam que os pacientes com DA têm mais dificuldades com os substantivos porque eles têm dificuldades de 
nomeação provavelmente esses pacientes tem memória semântica comprometida ou deteriorada além de apresentar prejuízo na memória operacional (Almor et al., 1999; Balthazar, 2008; Apostolova et al., 2008; Astell \& Harley, 2002; Chiarelli et al., 2005; Gonnerman et al., 2003; Joubert at al., 2010). Em todas as categorias de verbos e substantivos os pacientes moderados tiveram menor número de expressão desses itens. Além disso, em relação aos verbos, foi argumentado que a complexidade dessas classes gramaticais é afetada na doença e está associada à ruptura do léxico dos substantivos (Kim \& Thompson, 2004), provavelmente isso indicaria o prejuízo nos verbos derivados dos substantivos. Ademais, há evidências de que os verbos são mais difíceis de serem acessados do que os substantivos pelas ações que expressam e suas localizações frontais no encéfalo (Grossmann, 2008).

Estudos indicam que no começo da doença, existem dificuldades em nomeação de animais e preservação de nomes de ferramentas devido a erros na nomeação se observa prejuízo entre várias categorias no domínio objetos, enquanto que nas categorias seres vivos ficam um pouco poupadas. Ainda, os nomes próprios, nomes de pessoas famosas mais do que objetos fixos são afetados também, sugerindo diferentes exigências no sistema da linguagem (Chan et al., 2001; Cornil \& Pillon, 2003; Drucks et al., 2006; Gonnermann et al.,2003; Joubert et al., 2010). Isso poderia indicar prejuízo na atenção e déficit na memória operacional, é possível que nossos resultados sejam coerentes, pois em relação aos nomes próprios os pacientes moderados tem maior preservação quando comparados aos leves.

Esses resultados na literatura internacional também estão em concordância com nosso que foi possível verificar que existe mais dificuldade de nomeação de substantivos que representam seres vivos, do não-vivos. Por outro lado, estudos mais recentes, afirmam que existe degradação dos conceitos vivos e distintivos e preservação das características partilhadas (Apostolova et al., 2008; Astell \& Harley, 2002; Chiarelli et al., 2005; Gonnerman et al., 2003; Joubert at al., 2010).

Ademais, outros autores relatam controvérsias entre os verbos e substantivos pela rapidez que os substantivos são acessados, diferentemente dos verbos (Masterson et al.,2007).. Outros estudos sobre a diferença no uso de verbos e substantivos indicam que a quantidade de substantivos nas línguas são maiores do que a dos verbos, pois os verbos são adquiridos depois dos substantivos e por isso se perdem primeiro (Mätzig et al., (2009). 
Ainda, estudos relatam que os pacientes manifestam uma categoria de efeito de reconhecimento, mas tem dificuldades na nomeação de seres vivos e nomes abstratos (Taler \& Jarena, 2005; Cherkow et al., 2008.

Por outro lado, nas analises estatísticas das percentagens de itens lexicais do nosso estudo mostrou valores significantes quanto à expressão de verbos e substantivos, não foi observada diferença significante entre os três grupos nos substantivos comuns e próprios, abstratos e concretos, mas foi encontrada diferença significativa entre os substantivos vivos e não vivos, com maior prejuízo nos pacientes moderados. Em relação aos verbos lexicais, auxiliares, houve diferença significante entre os pacientes leves, os moderados expressam mais verbos auxiliares devido à preservação de memória de longo prazo, mas não foi observada diferença significativa entre os grupos nos verbos mentais e de ação, talvez porque os pacientes também tenham esses itens preservados na memória de longa duração e a doença ainda não afetou as áreas e conexões envolvidas. Não foi possível verificar a categorização de hipônimos e hiperônimos preservados pelos participantes pelo fato de o estudo ter sido feito com os temas de conversações livres.

Comparando os hápax, verificou-se que existe diferença significativa entre os grupos, os moderados mantém menor numero de hápax do que os controles, mas na percentagem dos hápax não houve diferença significante, isso seria provável porque a doença não interfere na percentagem de hápax preservados devido também que as palavras únicas são próprias de cada individuo.

Ao comparar os itens lexicais adjetivos, observou-se que a doença não interfere na percentagem dos itens expressos, mas existe diferença significante no número de adjetivos expressos entre os grupos. Além dos verbos e substantivos, mostra-se importante o uso de adjetivos na interação verbal com os pacientes. Por sua vez, a percentagem de os artigos também não é interferida com a doença, mas no número, talvez isso seja o fato do bastante uso de artigos na língua portuguesa. Os pacientes moderados expressam menor número de advérbios, porque o moderado fala menos, mas o moderado expressa maior percentagem de advérbios do que o controle, da mesma forma a percentagem de pronomes expressos pelos pacientes moderados é maior dos grupos, mas não existe diferença significativa no numero de esses itens, como destaca Almor et al.(1999), que isso seja devido ao déficit da memória operacional

Além disso, os itens lexicais numerais, as análises mostraram que existe diferença significativa nos numerais, porém a percentagem de numerais é igual entre os grupos. 
As interjeições são expressas em maior percentagem pelos pacientes moderados, talvez isso seja pelo fato de os pacientes moderados terem menor número de outras categorias preservadas e eles repetem muitas interjeições, os pacientes moderados expressam quantidades similares de interjeições que os outros indivíduos.

As conjunções foram os itens lexicais que não apresentaram diferenças significantes no número nem na percentagem expressas pelos membros dos grupos, provavelmente pelo pouco uso de conjunções na língua portuguesa.

Foram também comparados os itens lexicais preposições, os quais mostram que não há diferença no número de preposições faladas, mas os pacientes moderados apresentam maior percentagem de preposições, provavelmente os pacientes se apoiam nesses itens lexicais para formar as frases.

Os controles e os pacientes podem expressar várias quantidades de palavras com diferentes categorias gramaticais, mas usá-las somente para manter os enunciados o que pode ser que as outras categorias gramaticais são constituintes de formação de discursos ou talvez esses itens por serem adquiridos posteriormente possam ser facilmente esquecidos.

Estes resultados também demonstram a importância das alterações semânticas e compensações pragmáticas quando os itens lexicais são usados de forma compensatória a fim de ajudar no uso contextual e de atos de fala nos diálogos. Ainda, se verificou as diferenças na preservação de palavras concretas e abstratas, algumas vezes quando o tópico do diálogo era mais abstrato como religião e educação, os indivíduos controles do estudo produziram mais itens abstratos, enquanto os do grupo DA produziram menos, por exemplo, foi possível constatar várias vezes ao dizer que Deus é tudo.

Assim, essa análise enfoca as diferenças significativas em algumas variáveis da produção de verbos e substantivos e buscou identificar a preservação ou perda de itens lexicais em todas as classes gramaticais. É importante indicar, que os resultados significativos dos itens lexicais verbos e substantivos que foram mais analisados nesse estudo se deve à abordagem da literatura que destaca estudos da linguagem com verbos e substantivos, provavelmente porque foi constatado que esses itens lexicais sofrem mais alterações nessa doença.

Essa análise também sugere que na interação verbal com os pacientes com DA é necessário considerar as dificuldades nos domínios linguísticos dos substantivos e verbos 
principalmente, assim como evitar o uso de verbos e substantivos que tenham baixa frequência na língua portuguesa.

Além disso, os resultados também sugerem que embora os pacientes tenham perda lexical progressiva, suas habilidades comunicativas, semântico-pragmáticas não estão muito alteradas nos estágios leves e moderadas, sendo que adequadamente estimulados podem apresentar algumas melhoras. Os itens lexicais substantivos desse estudo, indicaram na análise destaque em marcas ideológicas, culturais e sócio-históricas. (A Tabela da lista das 150 palavras mais expressas está no Anexo).

O conhecimento e uso dos itens lexicais mais preservados pode contribuir para aprimorar a comunicação, em especial se acoplados ao uso de "auxílios" para memória, que em geral consistem de referências biográficas, ou seja, fotos da família, endereços, número de telefone, etc, que agregam valor semântico às frases, palavras e imagens por propiciarem o acesso a outras informações semânticas guardadas na memória de longo prazo (Bourgeois, 1990; Egan et al., 2010).

Contudo, a fim de verificar alterações nas outras categorias gramaticais, os resultados sugerem mais pesquisa nesses itens lexicais, dessa forma ajudar nas elaborações de guias de comunicação com os pacientes com DA.

É importante indicar que não se tem conhecimento de trabalhos semelhantes a este, que tenham avaliado vários tipos e subclasses de verbos e substantivos, hápax e as outras categorias gramaticais da língua portuguesa com pacientes com doença de Alzheimer, pois a maioria dos trabalhos mencionados foi realizada com substantivos de categorias vivas, objetos, ferramentas e com confrontação visual utilizando pouco recurso dialógico.

Portanto, a análise dos itens lexicais nos discursos dos pacientes com doença de Alzheimer não só contribui para nosso entendimento dos déficits da linguagem, mas também sugere formas de melhor entender e aprimorar a comunicação entre os pacientes e seus cuidadores. Além disso, como os pacientes, aqui considerados, são medicados e os cuidadores frequentam aulas psicoeducionais seria importante num primeiro estágio de abordagem, comunicar os resultados desse estudo, que poderiam contribuir para minimizar a sobrecarga de estresse nos envolvidos na interação, bem como futuramente divulgar esses resultados para outros grupos de interações entre cuidadores e pacientes. 


\section{CONCLUSÕES}

Este estudo, inédito na literatura da análise de itens lexicais no doente com Alzheimer em estágios leve e moderado, evidencia que apesar do estigma de que o doente de Alzheimer seja uma pessoa passiva, irresponsiva, deve-se considerar que essa doença varia entre os diversos pacientes, quanto ao grau de severidade e manifestações linguísticas e comportamentais e que é possível pela adoção de terapias linguístico-comunicativas, aliadas à abordagem clinica e terapias não medicamentosas, estabelecer interação socio-cultural efetiva.

Este estudo, nas condições em que foi realizado, permite concluir que:

1. Dos itens lexicais substantivos, verbos, hápax, adjetivos, advérbios, pronomes, numerais, interjeições, conjunções, artigos e preposições, foi observado que há prejuízo em quase todos os itens lexicais expressos no paciente com doença de Alzheimer em relação aos controles. Sendo que nos pacientes do estágio moderado esse prejuízo é mais acentuado.

2. O prejuízo é maior nos itens lexicais substantivos abstratos e aqueles que denominam seres vivos.

3. Os verbos, em geral, estão mais preservados do que as demais categorias gramaticais.

4. Esses pacientes apresentam itens lexicais preservados quando são estimulados com enunciados que abordem temas da sua cultura e de seu ambiente social, além de preservam vários nomes próprios de locais e pessoas.

5. Há grande influência do nível socio-econômico e cultural na preservação de itens lexicais, sendo que quanto maior a escolaridade há vocabulário mais fluido.

6. Os resultados dessa pesquisa evidenciam que é possível criar estratégias linguisticodiscursivas adequadas para melhorar a interação pacientes e cuidadores.

7. Essas perdas mostram que ao contrário do conhecimento corrente de que os pacientes da doença de Alzheimer apresentam discurso vazio e incoerente, contudo, apesar da perda quantidade de itens lexicais, eles apresentam uma percentagem de léxico similar aos dos controles. Técnicas de estimulo linguístico, aliados à uma interação adequada podem minimizar essas perdas de comunicação, melhorando a qualidade de vida dos envolvidos antes dos pacientes chegarem ao estágio grave. 


\section{REFERÊNCIAS}

Abott, A. (2001). A problem for our age. Nature, 475, 7355, 82-84.

Asp, E. D. \& Villiers, J. (2010). When Language Breaks down. Analyzing Discourse in Clinical Contexts. New York: Cambridge University Press.

Almor, A., Kempler, D., MacDonald, M.C., Andersen, E S., \& Tyler L.K. (1999). Why do Alzheimer Patients Have difficulty with Pronouns? Working Memory, Semantics, and Reference in Comprehension and Production in Alzheimer's Disease. Brain and Language, 67, 202-227.

Almor, A., Aronoff, J. M., MacDonald, M.C., Gonnerman, L. M., Kempler, D.,Hintiryan, H. et al. (2009). A common mechanism in verb and noun naming deficits in Alzheimer's patients. Brain and Language, 111, 8-19.

Alzheimer`s Association. Communication: Best ways to interact with the person with dementia.(Publicado on line). Recuperado em 12 de julho de 2009. Disponível em: http://www.alz.org/

Alzheimer's Association. Alzheimer's Disease facts and figures. (2012). Alzheimer's \& Dementia. The journal of the Alzheimer's Association, 80, 131-168.

Alzheimer's Society. (2010). My name is not dementia. People with dementia discuss quality of life indicators, London. Fishbooks.

American Psychiatry Association Committee on Nomenclature and Statistics. Diagnostic and Statistical Manual of Mental Disorders. (1999). (4 ${ }^{\text {th }}$ Ed.)Washington, D.C: American Psychiatric Association.

Annaert W, De Strooper B.(2002). A cell biological perspective on Alzheimer's disease. Annual Review of Cell Developmental Biology, 18, 25-51.

Apostolova, L. G., Lu., P. Rogers, S., Dutton, R. A., Hayashy, K. M. , Toga, A. W., Cummings, J. L.,et al. (2008). 3D mapping of Language networks in clinical and pre-clinical Alzheimer's disease. Brain and Language, 104, 33-41.

Araújo UI. (2002). Análise do Sujeito numa abordagem léxico-discursivo-computacional sobre o discurso do trabalho. Tese de doutorado. Departamento de Linguística. Faculdade de Filosofia, Letras e Ciências Humanas, Universidade de São Paulo. São Paulo.

Aronoff, J. M., Gonnerman, L.M., Almor, A., Kempler, D., \&Andersen, S. E. (2004).The role of similarity structure in category specific deficits in Alzheimer's disease. Brain and Language, 91,154-155. 
Astell, A. J. \& Harley T. A. (2002). Accessing semantic knowledge in dementia: evidence from a word definition task. Brain and Language, 82, 312-326.

Balthazar, M. L. F. (2008). Memória léxico-semântica no comprometimento cognitivo leve amnéstico e doença de Alzheimer leve: aspectos neuropsicológicos, de neuroimagem estrutural e modelo de organização cerebral. Tese de doutorado. Departamento de Linguística, Faculdade de Ciências medicas da Universidade Estadual de Campinas, Campinas, SP.

Barbosa, M A. (2001). A construção do conceito nos discursos técnico-científicos, nos discursos literários e nos discursos sociais não-literários. In Revista Brasileira de linguística, São Paulo, 11, (27), 31-60.

Bear, M. F., Connors, B. W., Paradiso, M. A. (2001). Neuroscience: Exploring the Brain, (2nd ed). Baltimore, MA: Lippincott Williams \& Wilkins.

Bennet, D.A., Schneider, J.A., Tang, Y., Arnold, S.E., \& Wilson, R.S.(2006).The effect of social networks on the relation between Alzheimer's disease pathology and level of cognitive function in older people: a longitudinal cohort study. Lancet Neurology, 5, 406-412.

Binder, J. R., Frost, J. A., Hammeke, T. A., Bellgowan, P. S. F., Rao, S. M.,\& Cox, R. W. (1999).Conceptual Processing during the Conscious Resting State: A Functional MRI Study. Journal of Cognitive Neuroscience, 11, 80-93.

Binder, J. R.\& Price ,C.J. (2001). Functional neuroimaging of Language. In R. Cabeza \& A. Kingstone (Eds), Handbook of Functional Neuroimaging of Cognition. Cambridge, MA: MIT Press, 187-251.

Bottino, C.M.C., Carvalho, I.A., Alvarez, A.M., Ávila, R., Zukauskas, P.R, Bustamante, S.E, et al. (2002). Cognitive rehabilitation in Alzheimer's disease patients: multidisciplinary team report. Arquivos de Neuropsiquiatria, 60, 1, 70-79.

Bourgeois, M. S. (1990). Enhancing conversation skills in patients with Alzheimer`s disease using a prosthetic memory aid. Journal of Applied Behavior Analysis, 23, 1, 29-42.

Bownds, D.M. (1999). The Biology of Mind: origins and structures of mind, brain and consciousness. Bethesda, NY: Fitzgerald Science Press, Inc.

Bragazza, D.F. (2005). Sublimes Pormenores: escolhas lexicais na produção das personagens e das temáticas em contos de Machado de Assis. Tese de doutorado. Departamento de Linguística, Faculdade de Filosofia, Letras e Ciências Humanas, Universidade de São Paulo. São Paulo.

Bucks, R.S., Singh, S., Cuerden, J. N., \& Wilcock, G. K. (2000). Analysis of spontaneous, conversational speech in dementia of Alzheimer's type: Evaluation of an objective technique for analyzing lexical performance, Aphasiology, 14, 1-35. 
Camlong, A. (1996). Méthode d'analyse textuelle et discursive. Paris. Editions Ophrys.

Camlong, A., \&Beltran, T. (2004). Stablex.[CD]. São Paulo Tec Art Editora Ltda.

Carthery-Goulart, M.T.(2005). Memória operacional e linguagem no envelhecimento normal e na doença de Alzheimer. Tese de doutorado. Faculdade de Medicina, Universidade de São Paulo. São Paulo.

Carvalho, I. A.(2006). Avaliação funcional das habilidades de comunicação - ASHA FACS para população com doença de Alzheimer. Tese de doutorado. Programa de Pós-graduação em Fisiopatologia experimental da Faculdade de Medicina da Universidade de São Paulo, São Paulo.

Catani, M \& Mesulam, M. (2008). The arcuate fasciculus and the disconnection theme in language and aphasia: History and current state. Cortex, 44, 953 - 961.

Chan, A. S., Salmon, D. P., \& De la Pena, J. (2001). Abnormal semantic network for "animals" but not "tools" in Patients with Alzheimer's disease, Cortex, 37, 197-217.

Chertkow, H., Whatmough, C., Saumier D.\& Duong, A.(2008). Cognitive Neuroscience studies of semantic memory in Alzheimer's disease. Progress in Brain Research, 169, 25, 395-405.

Chiarelli, V., Menichelli, A., \& Semenza, C. (2005). Naming compounds in aphasia and in Alzheimer's disease. Brain and Language, 95, 137-138.

Cornil, V., \& Pillon, A. (2003). Longitudinal pattern of knowledge loss for plants and manufactured objects in a patient with Alzheimer's disease. Brain and Language, 87, 105106.

Cummings, J.L.\& Cole, G. (2002). Alzheimer's Disease. Journal of American Medical Association. JAMA,18, 2335-2338.

Cunha, C., \& Cintra L. (2001). Nova gramática do Português Contemporâneo. (3a ed). Rio de Janeiro. Nova Fronteira,

Damasceno, B. P. (2000). Avaliação da Linguagem no Sujeito Idoso.In ). V. Forlenza \& P. Caramelli, P. (Eds), Neuropsiquiatria Geriátrica. Rio de Janeiro. Atheneu, 527-530.

Démonet, J. F., Thierry, G. , Cardebat, D. (2005). Renewal of the Neurophysiology of Language; Functional Neuroimaging. Physiology Review, 85, 40-95.

Den Dunnen, W. F.Brouwer, W.H. Bijlard, E., Kamphuis, J., van Linschote, K. Eggens-Meijer, E., Holtege, G. (2008). No disease in the brain of a 115-year-old woman. Neurobiology of Aging, 29,8, 1127-1132. 
Dicionário online de Português. Recuperado em 12 de novembro de 2010. Disponível em: http://www.dicio.com.br/

Dronkers, N. F., Pinker, S., \& Damasio, A. R. (2000). Language and the aphasias. In E. R. Kandel, J. H. Schwartz, \& T. M. Jessell (Eds), Principles of Neural Science, (4th ed.), New York, Elsevier, 1170-1186.

Drucks, J., Masterson, J., Kopelman, M.,Clare, L.,Rose, A., Rai, G. (2006), Is action naming better preserved (than object naming) in Alzheimer's disease and why should I ask?. Brain and Language, 98, 332-340

Dubois, J., Giacomo, M., Guespin, L., Marcellesi, C., Marcellesi, J.B., \& Mevel, J.P. (1998). Dicionário de linguística. ( F. P. Barros, G. T. Ferretti, J. R. Scmitz, L. S. Cabral, M. E. L. Salum e V. Khedi, trads.,, São Paulo. Editora Clutrix Lta.

Egan, M., Bérubé, D., Racine, G., Leonard, C., \& Rochon, E.(2010). Methods to Enhance Verbal Communication between individuals with Alzheimer's Disease and their Formal and Informal Caregivers: A Systematic Review. International Journal of Alzheimer's Disease, $1-12$.

Fiorin, J. S. (2005). Pragmática. In .J. L. Fiorin. Introdução à Linguística II. Princípios de análise. São Paulo. Contexto.

Folstein, M. F., Folstein, S. E. \& Mchugh, P. R. (1975). Mini-Mental State: A practical Method for grading the cognitive state for the clinician. Journal of Psychiatric Research, 12, 189198.

Garrard, P., Maloney, L. M., Hodges, J. R., \& Patterson, K. (2005).The effects of early Alzheimer's disease on the characteristics of writing by a renewal author. Brain, 128, 250260.

Gentry, R. A. \& Fisher, J. E. (2007).Facilitating conversation in elderly persons with Alzheimer's disease. Clinical Gerontolgist, 31, 2, 77-98.

Gonnerman, L.M., Aronoff, J.M., Andersen, E. S. Kempler, D.,\& Almor, A. (2003). The relationship between naming performance and underlying category structure in Alzheimer Disease. Brain and Language, 87, 29-30.

Giffard, B., Laisney, M., Mézengge, F., de la Sayette, V., Eustache, F., Desgranges, B. (2008). The neural substrates of semantic memory deficits in early Alzheimer's disease: Clues from semantic priming effects and FDG-PET. Neuropsychologia, 46, 1657-1666

Grossman, F. (2008). Language in Dementia. In B. Stemmer \& H. S. Whitaker (Eds), Handbook of the Neuroscience of Language. San Diego, CA: Academic Press, 279-287 
Hellice, J. B. (2008). Interhemispheric Interaction in the Lateralized Brain. In B. Stemmer \& H. S. Whitaker (Eds), Handbook of Neuroscience of Language. San Diego, CA: Academic Press. 257-265.

Instituto Brasileiro de Geografia e Estatística (IBGE). (2011). Perfil dos idosos responsáveis pelos domicílios no Brasil. Recuperado em 20 de janeiro de 2011. Disponível em: http://www.ibge.gov.br/home/estatistica/perfilidoso

Jerdziewsky, M. K., Ewbank, D. C., Wang, H.. Tojanowski, J. Q. (2010). Exercise and cognition: Results from the national Long Term Care Survey. Alzheimer's \& Dementia. The journal of the Alzheimer's Association, 6, 448-455.

Joubert, S., Brambati, S. M., Ansado, J., Barbeau, E. J., Felician, O., Didic, M., Lacombe, J. et al. (2010). The cognitive and neural expression of semantic memory impairment in mild cognitive impairment and early Alzheimer's disease. Neuropsychologia, 48, 978-988.

Kandel, E. R., Schwartz, J.H., \& Jessell, T. M.(Eds).(2000). Principles of Neural Science, (4th ed.), New York, Elsevier,

Kim, M., Thompson, C. K. (2004). Verb deficits in Alzheimer's disease and agrammatism: Implication for Lexical organization. Brain and Language, 88, 1-20.

Kolb, B; Whishaw, I.Q.(2002). Neurociência do Comportamento. São Paulo, Manole,

Kovic, V., Plunkett, K. \& Westermann, G. (2010). The shape of words in the brain. Cognition, $114,19-28$.

MacDonald, M. C., Almor, A., Henderson, V. W., Kempler, D., \& Andersen, E. S. (2001). Assessing Working memory and Language Comprehension in Alzheimer's disease. Brain and Language, 78, 17-42.

McDonald, S. (2008). Frontal Lobes and Language. In B. Stemmer \& H. S. Whitaker (Eds), Handbook of the Neuroscience of Language. San Diego. CA: Academic Press, 289-297

Mansur, L. L (1996). Formulações e reformulações: contribuição ao estudo da produção da linguagem oral de indivíduos com demências de tipo Alzheimer. Tese de doutorado. Departamento de Linguística, Faculdade de Filosofia, Letras e Ciências Humanas Universidade de São Paulo, São Paulo.

Mansur L. L \& Radanovic, M. (2004). Neurolinguística: princípios para a prática clínica. São Paulo, Edições Inteligentes,

Mari, J. J.\& Williams, P.(1986). A validity study of a psychiatry screening questionnaire (SRQ20) in primary care in the city of São Paulo. Brazilian Journal of Psychiatry, 148, 23-26. 
Martin, C. R., Newsome, M. R., \& Vu, H. (2002). Language and Lexical Processing, In V. S. Ramachandran (Ed), Encyclopedia of the Human Brain, (2), San Diego.CA: Academic Press, 631-643.

Masterson, J., Druks, J., Kopelman, M. Clare, L., Garley, C., \& Hayes, M. (2007). Selective naming (and comprehension) deficits in Alzheimer's disease?. Cortex. 48, 921-934.

McMillan, P. Moore, P., Gee. J.,\& Grossman, M. (2003).Neural basis for confrontation naming difficulty in semantic dementia and Alzheimer's disease. Brain and Language, 87, 197-205.

Mätzig, S, Druks, J., Masterson J., \&Vigliocco, G. (2009). Noun and verbs differences in picture naming: Past studies and new evidence. Cortex, 45, 738-758.

Mckhann G, Drachman D, Folstein M, Katzman R, Price D, Stadlan EM. (1984).Clinical diagnosis of Alzheimer's disease: report of the NINCDS-ADRDA work group under the auspices of Department of Health and Human Services Task Force on Alzheimer's disease. Neurology, 34, 939-944.

Mesulam, M. (2001).Principles of Behavior and Cognitive Neurology, Oxford University Press.

Obler, K. L \& Pekkala, S. (2008). Language and Communication in Aging. In B. Stemmer \& H. S. Whitaker (Eds), Handbook of the Neuroscience of Language. San Diego.CA: Academic Press, 351-358.

Orange, J. B., \& Kertesz, J. (2000). Discourse Analyses and Dementia. Brain and Language, 71, 172-174.

Orlandi, E. P. (1996). Discurso e Leitura. 2. São Paulo. Cortez/EDUNICAMP.

Ortiz, K. Z., \& Bertolucci, P. H. F. (2005). Language Impairment in the early stages of Alzheimer's disease. Arquivo de Neuropsiquiatria, 63, 2, 311-317.

Petersen, R. C., Parisi, J.E., Dickson, D. W., Kris, A., Johnson, K. A., Knopman, D. S., et al. (2006). Neuropathologic Features of Amnestic Mild Cognitive Impairment. Archives of Neurology, 63, 665-672

Pinker, S. (1994). The language instinct. Boston, MIT Press,

Preti, D. (1991). A linguagem dos idosos. São Paulo. Contexto.

Querfurth, H. W., \& Laferla, F. M. (2010). Mechanisms of Disease. Alzheimer's Disease. The New England Journal of Medicine. 362, 4, 329-344.

Pulvemuller, F. (1999).Words in the Brain's Language. Behavioral and Brain Sciences, 22, 253336 
Reilly, J., Antonucci, S. M., Peelle, J. E., \& Grosman, M. (2011). Anomia as a marker of distinct Semantic Memory Impairments in Alzheimer's Disease and Semantic Dementia. Neuropsychology, 25,4, 413-426.

Rico Duarte, L. Marquié, L., Marquié, J. C., Terrier, P., \& Ouset, P.J.(2009). Analyzing feature distinctiveness in the processing of living and non-living concepts in Alzheimer's disease. Brain and Cognition,71, 108-117.

Robio, S., Kareholt, I., Helkala, E.L., Viitanen, M., Winblad, B., \& Tuomilehto, J. (2005).Leisure-time physical activity at midlife and the risk of dementia and Alzhiemer's disease. Lancet Neurology, 4, 705-711.

Rockwood, K. \& Macknight, C. (2001). Understanding Dementia: a Primer of Diagnosis and Management. Halifax, NS, Canada. Pottersfield Press Ltd.

Sabat, S. R. (2001).The experience of Alzheimer's Disease. Life Through a Tangled Veil. Oxford. Blackwell Publishers Ltd.

Senhorini, M. C. T. (2010). Fluência Verbal fonológica avaliada através da ressonância magnética funcional com análise de variáveis demográficas. Tese de doutorado. Faculdade de Medicina da Universidade de São Paulo,

Scher, A. P. (2003). Quais são as propriedades lexicais de uma construção de um verbo leve? In A. I. Müller \& E. Negrão, E. (Orgs), Semântica Formal. São Paulo. Contexto,

Shapiro, K., \& Caramazza, A. (2004). The organization of Lexical Knowledge in the Brain: the Grammatical Dimension. In M. S. Gazzaniga (Ed), The Cognitive Neuroscience III, (3rd ed.,pp. 803-814). Cambridge, MA: MIT Press,

Snowdon, D. A., Kemper, S. J., Mortimer, J. A., Greimener, L. H., Markesbery, D.R. (1996). Linguistic Ability in Early Life and Cognitive Function and Alzheimer's Disease in Late Life: Findings from the Nun Study, Journal of the American Medical Association. JAMA, 7. 275-290.

Souza, M. G. C. (2005). Interfaces do Texto e a Informática. Recife. Editora Universitária da UFPE.

Stemmer, B. (2008). Neuropragmatics: Disorders and Neural Systems. In B. Stemmer \& H. S. Whitaker (Eds), Handbook of Neuroscience of Language. San Diego. CA: Academic Press, 175-187.

Swerdlow, R. H. (2007). Is aging part of Alzheimer's disease, or is Alzheimer's disease part of aging? Neurobiology of Aging, 28, 1465-1480.

Taler, V.\& Jarema, G. (2005). A dissociation between semantic and syntactic processing of mass/count information in Alzheimer's disease. Brain and Language, 95, 92-93. 
Tager-Flusberg, H. (2002).Language and Lexical Processing. In V. S Ramachandran (Ed), Encyclopedia of the Human Brain, (2), San Diego.CA: Academic Press, 617-629.

Turgeon, Y, \& Macoir, J. (2008).Classical and Contemporary Assessment of Aphasia and Acquired Disorders of Language. In B. Stemmer \& H. S. Whitaker (Eds), Handbook of Neuroscience of Language. San Diego.CA: Academic Press, 3-11.

Ullman, M.T. (2004). Contribution of memory circuits to language: the declarative/procedural model. Cognition, 92, 231-270.

Ullman, M.T. (2008). The role of Memory Systems in Disorders of Language. In B. Stemmer \& H. S. Whitaker (Eds), Handbook of Neuroscience of Language.San Diego. CA: Academic Press. 189-198.

Van den Heuvel, M. P. \& Hulshoff Pol, E. H. (2010). Exploring the brain network: A review on resting-state fMRI functional connectivity. European Psychopharmacology, 20, 519-534.

Van Lancker, D. \& Pachana, N. (1998).The influence of emotion and language end communication disorders. In B. Stemmer \& H. S. Whitaker (Eds), Handbook of Neurolinguistics, San Diego. CA: Academic Press, 302-310.

Venneri, A., McGeown, W. J., Hietanen H. M., Guerrini, C., Ellis, A. W., Shanks, M. F. (2008). The anatomical bases of semantic retrieval deficits in early Alzheimer's disease. Neuropsychologia, 46, 497-510

Verghese, J., Lipton, R. B., Katz, M. J., Hall, C.B., Derby, C. A., Kuslansky, G. (2003). Leisure activities and the risk of dementia in the elderly. New England Journal of Medicine, 348, 2508-2516.

Walsh, D. M. \& Selkoe, D. J. (2004). Deciphering the molecular basis of memory failure in Alzheimer's disease. Neuron, 44, 181-193

Wierenga, C. E., Stricker N. H., McCauley, A., Simmons, A., Jack, A. J., Chang, Y. L, et al. (2011). Altered Brain responses for semantic knowledge in Alzheimer's disease. Neuropsychologia, 49, 392-404.

Zapparoli, Z. M.,\& Camlong, A. (2002). Do Léxico ao Discurso pela Informática. São Paulo. Edusp/Fapesp.

Zurif, B. E. (2000). Syntactic and Semantic Composition. Brain and Language, 71, 261-263 


\begin{abstract}
ANEXOS
Anexo A: Ficha de Consentimento do controle da pesquisa

HOSPITAL DAS CLÍNICAS DA FACULDADE DE MEDICINA DA UNIVERSIDADE DE SÃO PAULO-HCFMUSP
\end{abstract}

\title{
TERMO DE CONSENTIMENTO LIVRE E ESCLARECIDO
}

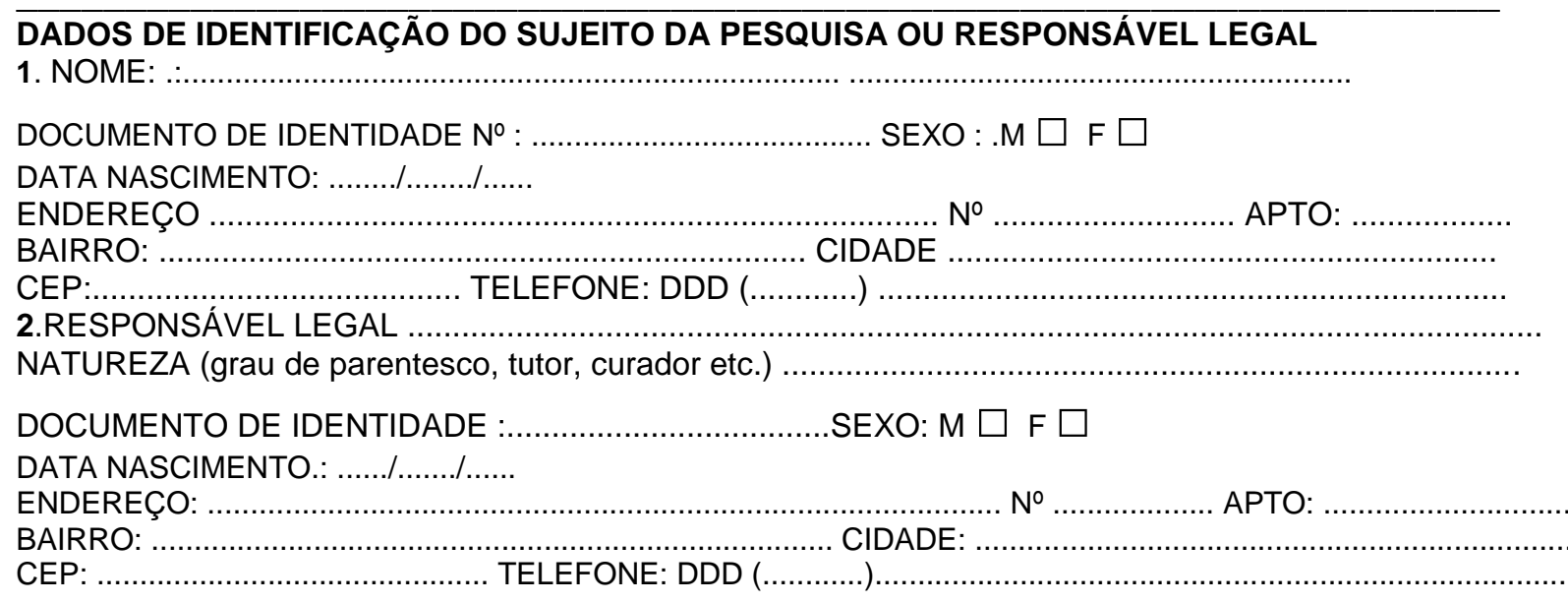

\section{DADOS SOBRE A PESQUISA}

1. TÍTULO DO PROTOCOLO DE PESQUISA .

Análise dos aspectos lexicais do discurso oral dos pacientes com doença de Alzheimer.

PESQUISADOR: Cássio Machado de Campos Bottino

CARGO/FUNÇÃO: médico assistente INSCRIÇÃO CONSELHO REGIONAL № 61025

UNIDADE DO HCFMUSP: Instituto de Psiquiatria

3. AVALIAÇÃO DO RISCO DA PESQUISA:

$\begin{array}{lll}\text { RISCO MÍNIMO } & X & \text { RISCO MÉDIO } \\ \text { RISCO BAIXO } & \square & \text { RISCO MAIOR }\end{array}$

4.DURAÇÃO DA PESQUISA : 2 anos 


\section{HOSPITAL DAS CLÍNICAS DA FACULDADE DE MEDICINA DA UNIVERSIDADE DE SÃO PAULO-HCFMUSP}

1 - Desenho do estudo e objetivo(s) "O objetivo geral deste estudo é analisar as palavras nos discursos orais de pessoas com mais de setenta anos, para comparar com as palavras dos discursos orais de pacientes com doença de Alzheimer".

Os objetivos específicos desta pesquisa são:

A- Identificar as palavras mais usadas e mais preservadas nos discursos orais de pessoas com mais de setenta anos.

B- Avaliar as palavras preservadas e mais usadas nos discursos de pessoas com mais de setenta anos para comparar com as palavras preservadas dos pacientes com doença de Alzheimer.

2 - Descrição dos procedimentos que serão realizados, com seus propósitos e identificação dos que forem experimentais e não rotineiros. Você fará testes de memória, atenção, raciocínio e de depressão antes de participar da entrevista.

3 - Relações dos procedimentos rotineiros e como são realizados - Você fará entrevista livre de 20 minutos com os temas: cidade, educação, família, saúde, alimentação e religião. A entrevista será transcrita e depois analisada por um programa de computação.

4 - Descrição dos desconfortos e riscos esperados nos procedimentos dos itens 2 e 3; Você poderá ficar incomodado com algumas perguntas, neste caso a entrevista será interrompida.

5 - Benefícios para o participante: Não há benefício direto para o participante. Trata-se de estudo experimental testando a hipótese de que os pacientes com doença de Alzheimer leve, seus parentes e seus cuidadores podem melhorar a comunicação verbal. Neste caso você fará parte do grupo controle.

6 - Relação de procedimentos alternativos que possam ser vantajosos, pelos quais o participante pode optar; Não existem outros procedimentos que possam ser vantajosos para os participantes. Caso você se recuse a participara desta pesquisa, isso não afetará em nada.

7 - Garantia de acesso: em qualquer etapa do estudo, você terá acesso aos profissionais responsáveis pela pesquisa para esclarecimento de eventuais dúvidas. O principal investigador é o Dr Cássio M. C. Bottino. que pode ser encontrado no endereço PROTER- - Instituto de Psiquiatria do HC/FMUSP. Rua Dr Ovídio Pires de Campos, 785. São Paulo/SP. CEP 05403-010 Telefone 30696973. Se você tiver alguma consideração ou dúvida sobre a ética da pesquisa, entre em contato com o Comitê de Ética em Pesquisa (CEP) - Rua Ovídio Pires de Campos, 225 - 5a andar tel: 3069-6442 ramais 16, 17, 18 ou 20, FAX: 3069-6442 ramal 26 - E-mail: cappesq@hcnet.usp.br

8 - É garantida a liberdade da retirada de consentimento a qualquer momento e deixar de participar do estudo.

09 - Direito de confidencialidade - As informações obtidas serão analisadas em conjunto com as de outros participantes, não sendo divulgada a identificação de nenhum participante;

10 - Direito de ser mantido atualizado sobre os resultados parciais das pesquisas, quando em estudos abertos, ou de resultados que sejam do conhecimento dos pesquisadores; 
11 - Despesas e compensações: não há despesas pessoais para o participante em qualquer fase do estudo. Também não há compensação financeira relacionada à sua participação.

12 - Compromisso do pesquisador de utilizar os dados e o material coletado somente para esta pesquisa.

Acredito ter sido suficientemente informado a respeito das informações que li, descrevendo o estudo "Análise dos aspectos lexicais do discurso oral dos pacientes com doença de Alzheimer" Eu discuti com o Dr. Cássio M.C. Bottino sobre a minha decisão em participar nesse estudo. Ficaram claros para mim quais são os propósitos do estudo, os procedimentos a serem realizados, seus desconfortos e riscos, as garantias de confidencialidade e de esclarecimentos permanentes. Ficou claro também que minha participação é isenta de despesas. Concordo voluntariamente em participar deste estudo e poderei retirar o meu consentimento a qualquer momento, antes ou durante o mesmo, sem penalidades ou prejuízo.

Assinatura do participante ou responsável legal

Data / /

(Somente para o responsável do projeto)

Declaro que obtive de forma apropriada e voluntária o Consentimento Livre e Esclarecido deste particpante neste estudo.

Assinatura do responsável pelo estudo Data / / 


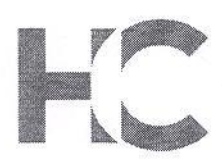

\section{APROVAÇÃO}

O Presidente da Comissão de Ética para Análise de Projetos de Pesquisa - CAPPesq da Diretoria Clínica do Hospital das Clínicas e da Faculdade de Medicina da Universidade de São Paulo, em 10.09.10, APROVOU ad-referendum o Protocolo de Pesquisa $n^{\circ}$ 0372/10, intitulado: "Análise dos aspectos lexicais do discurso oral dos pacientes com doença de Alzheimer", apresentado pelo Departamento de Psiquiatria, inclusive Termo de Consentimento Livre e Esclarecido.

Cabe ao pesquisador elaborar e apresentar a CAPPesq, os relatórios parciais e final sobre a pesquisa (Resolução do Conselho Nacional de Saúde n 196, de 10/10/1996, inciso IX.2, letra "c").

Pesquisador (a) Responsável: Dr. Cássio Machado de Campos Bottino

Pesquisador (a) Executante: Renné Panduro Alegria

CAPPesq, 10 de Setembro de 2010

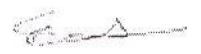

PROF. DR. EDUARDO MASSAD

Presidente

Comissão de Ética para Análise de Projetos de Pesquisa

\footnotetext{
Comissão de Ética para Análise de Projetos de Pesquisa do HCFMUSP da Diretoria Clínica do Hospital das Clínicas da Faculdade de Medicina da Universidade de São Paulo Rủa Ovídio Pires de Campos, 225, $5^{\circ}$ andar - CEP 05403010 - São Paulo - SP Fone: 01130696442 Fax: 01130696492 e-mail: cappesq@hcnet.usp.br / secretariacappesq2@hcnet.usp.br

Rita
} 


\section{Anexo B- Ficha de Consentimento do paciente na pesquisa \\ HOSPITAL DAS CLÍNICAS DA FACULDADE DE MEDICINA DA UNIVERSIDADE DE SÃO PAULO-HCFMUSP}

\section{TERMO DE CONSENTIMENTO LIVRE E ESCLARECIDO}

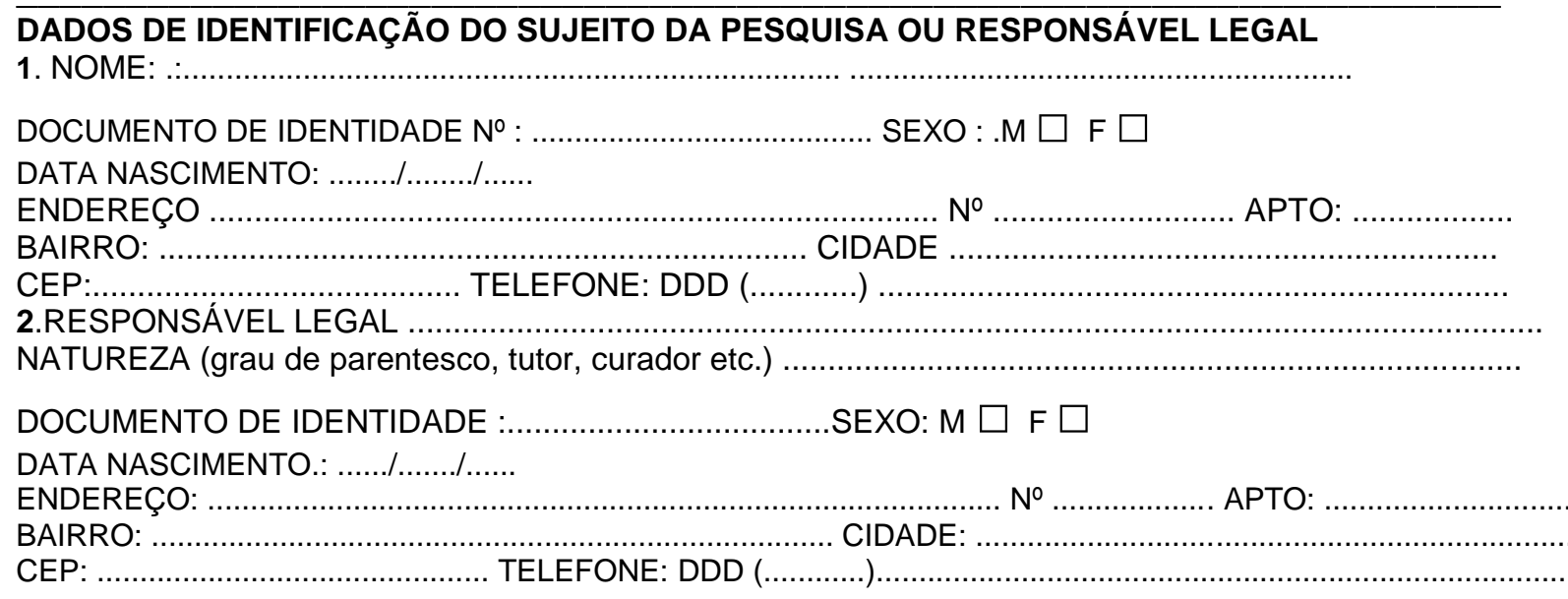

\section{DADOS SOBRE A PESQUISA}

1. TÍTULO DO PROTOCOLO DE PESQUISA.

Análise dos aspectos lexicais do discurso oral dos pacientes com doença de Alzheimer.

PESQUISADOR: Cássio Machado de Campos Bottino

CARGO/FUNÇÃO: médico assistente

INSCRIÇÃO CONSELHO REGIONAL № 61025

UNIDADE DO HCFMUSP: Instituto de Psiquiatria

3. AVALIAÇÃO DO RISCO DA PESQUISA:

$\begin{array}{llr}\text { RISCO MÍNIMO } & X & \text { RISCO MÉDIO } \square \\ \text { RISCO BAIXO } & \square & \text { RISCO MAIOR }\end{array}$

4.DURAÇÃO DA PESQUISA : 2 anos 


\section{HOSPITAL DAS CLÍNICAS DA FACULdADE DE MEDICINA DA UNIVERSIDADE DE SÃO PAULO-HCFMUSP}

1 - Desenho do estudo e objetivo(s) "O objetivo geral deste estudo é analisar as palavras nos discursos orais de pacientes com doença de Alzheimer, para elaborar estratégias de comunicação verbal entre cuidadores e pacientes.

Os objetivos específicos desta pesquisa são:

A- Identificar a presença de alterações das palavras nos discursos orais dos pacientes com doença de Alzheimer.

B- Avaliar as palavras preservadas nos discursos dos pacientes com doença de Alzheimer para melhorar a comunicação entre cuidadores e pacientes.

2 - Descrição dos procedimentos que serão realizados, com seus propósitos e identificação dos que forem experimentais e não rotineiros. Se você já está em acompanhamento nesse serviço, a informação sobre a doença que consta no seu prontuário médico será analisada. Você fará testes de memória, atenção e raciocínio antes de participar da entrevista.

3 - Relações dos procedimentos rotineiros e como são realizados - Você fará entrevista livre de 20 minutos com os temas: cidade, educação, família, saúde alimentação e religião.

4 - Descrição dos desconfortos e riscos esperados nos procedimentos dos itens 2 e 3; Você poderá ficar incomodado com algumas perguntas, neste caso a entrevista será interrompida.

5 - Benefícios para o participante: Não há benefício direto para o participante. Trata-se de um estudo experimental que testa a hipótese de que os pacientes com doença de Alzheimer leve, seus parentes e seus cuidadores podem melhorar a comunicação verbal.

6 - Relação de procedimentos alternativos que possam ser vantajosos, pelos quais o paciente pode optar; Não existem outros procedimentos que possam ser vantajosos para os pacientes. Caso você se recuse a participara desta pesquisa, isso não afetará em nada o seu atendimento neste hospital.

7 - Garantia de acesso: em qualquer etapa do estudo, você terá acesso aos profissionais responsáveis pela pesquisa para esclarecimento de eventuais dúvidas. O principal investigador é o Dr Cássio M. C. Bottino. que pode ser encontrado no endereço PROTER- - Instituto de Psiquiatria do HC/FMUSP. Rua Dr Ovídio Pires de Campos, 785. São Paulo/SP. CEP 05403-010 Telefone 30696973. Se você tiver alguma consideração ou dúvida sobre a ética da pesquisa, entre em contato com o Comitê de Ética em Pesquisa (CEP) - Rua Ovídio Pires de Campos, 225 - 5a andar tel: 3069-6442 ramais 16, 17, 18 ou 20, FAX: 3069-6442 ramal 26 - E-mail: cappesq@hcnet.usp.br

8 - É garantida a liberdade da retirada de consentimento a qualquer momento e deixar de participar do estudo, sem qualquer prejuízo à continuidade de seu tratamento na Instituição;

09 - Direito de confidencialidade - As informações obtidas serão analisadas em conjunto com as de outros pacientes, não sendo divulgada a identificação de nenhum paciente;

10 - Direito de ser mantido atualizado sobre os resultados parciais das pesquisas, quando em estudos abertos, ou de resultados que sejam do conhecimento dos pesquisadores;

11 - Despesas e compensações: não há despesas pessoais para o participante em qualquer fase do estudo. Também não há compensação financeira relacionada à sua participação. 
12 - Compromisso do pesquisador de utilizar os dados e o material coletado somente para esta pesquisa.

Acredito ter sido suficientemente informado a respeito das informações que li ou que foram lidas para mim, descrevendo o estudo "Análise dos aspectos lexicais do discurso oral dos pacientes com doença de Alzheimer"

Eu discuti com o Dr. Cássio M.C. Bottino sobre a minha decisão em participar nesse estudo.

Ficaram claros para mim quais são os propósitos do estudo, os procedimentos a serem realizados, seus desconfortos e riscos, as garantias de confidencialidade e de esclarecimentos permanentes. Ficou claro também que minha participação é isenta de despesas e que tenho garantia do acesso a tratamento hospitalar quando necessário. Concordo voluntariamente em participar deste estudo e poderei retirar o meu consentimento a qualquer momento, antes ou durante o mesmo, sem penalidades ou prejuízo ou perda de qualquer benefício que eu possa ter adquirido, ou no meu atendimento neste Serviço.

Assinatura do paciente/representante legal Data / /

(Somente para o responsável do projeto)

Declaro que obtive de forma apropriada e voluntária o Consentimento Livre e Esclarecido deste paciente ou representante legal para a participação neste estudo.

Assinatura do responsável pelo estudo Data / / 


\section{Anexo C}

Tabela da Lista das primeiras 150 palavras mais faladas pelos participantes do estudo

\begin{tabular}{|c|c|c|c|c|c|c|}
\hline ordem & controle & vezes & leve & vezes & moderado & vezes \\
\hline 01 & eu & 1932 & $\mathrm{eu}$ & 786 & não & 597 \\
\hline 02 & não & 1645 & não & 729 & eu & 568 \\
\hline 03 & que & 1459 & que & 537 & que & 398 \\
\hline 04 & $\mathrm{e}$ & 1412 & e & 397 & $\mathrm{e}$ & 278 \\
\hline 05 & de & 1219 & de & 378 & de & 229 \\
\hline 06 & $\mathrm{a}$ & 1123 & $\mathrm{a}$ & 368 & é & 220 \\
\hline 07 & o & 841 & é & 311 & $\mathrm{a}$ & 218 \\
\hline 08 & é & 776 & o & 238 & ele & 206 \\
\hline 09 & né & 731 & né & 236 & o & 198 \\
\hline 10 & ele & 692 & lá & 221 & eh & 183 \\
\hline 11 & eh & 608 & um & 216 & muito & 161 \\
\hline 12 & um & 594 & ele & 211 & era & 156 \\
\hline 13 & com & 544 & tem & 204 & né & 152 \\
\hline 14 & tem & 531 & em & 190 & em & 142 \\
\hline 15 & aí & 530 & com & 174 & tem & 139 \\
\hline 16 & uma & 513 & uma & 174 & mas & 136 \\
\hline 17 & na & 513 & ela & 173 & tenho & 131 \\
\hline 18 & lá & 492 & na & 173 & meu & 130 \\
\hline 19 & mas & 489 & mais & 163 & minha & 119 \\
\hline 20 & em & 461 & eh & 157 & porque & 113 \\
\hline 21 & era & 444 & tinha & 157 & mais & 112 \\
\hline 22 & pra & 444 & para & 149 & lá & 111 \\
\hline 23 & no & 436 & mas & 147 & para & 110 \\
\hline 24 & minha & 431 & minha & 143 & um & 106 \\
\hline 25 & tinha & 400 & no & 143 & com & 102 \\
\hline 26 & muito & 399 & muito & 140 & já & 97 \\
\hline 27 & anos & 385 & tenho & 140 & uma & 91 \\
\hline 28 & mais & 384 & era & 136 & também & 91 \\
\hline 29 & meu & 383 & meu & 130 & ela & 89 \\
\hline 30 & ela & 376 & agora & 129 & tudo & 88 \\
\hline 31 & então & 370 & já & 124 & como & 86 \\
\hline 32 & aqui & 352 & anos & 123 & tinha & 86 \\
\hline 33 & da & 343 & porque & 110 & na & 83 \\
\hline 34 & para & 340 & $\mathrm{da}$ & 106 & aqui & 81 \\
\hline 35 & porque & 325 & quando & 101 & agora & 74 \\
\hline 36 & foi & 297 & depois & 99 & da & 74 \\
\hline 37 & do & 294 & assim & 98 & faz & 73 \\
\hline 38 & assim & 278 & faz & 94 & só & 72 \\
\hline 39 & também & 276 & foi & 93 & ah & 72 \\
\hline 40 & tudo & 255 & aí & 92 & casa & 70 \\
\hline 41 & se & 252 & também & 91 & do & 68 \\
\hline
\end{tabular}




\begin{tabular}{|c|c|c|c|c|c|c|}
\hline 42 & me & 250 & aqui & 90 & mãe & 67 \\
\hline 43 & como & 240 & casa & 88 & são-paulo & 63 \\
\hline 44 & já & 231 & pra & 83 & então & 58 \\
\hline 45 & só & 229 & se & 83 & bem & 57 \\
\hline 46 & a-gente & 223 & do & 81 & eles & 56 \\
\hline 47 & gente & 223 & então & 80 & pra & 55 \\
\hline 48 & quando & 221 & tudo & 79 & filho & 54 \\
\hline 49 & agora & 219 & me & 78 & quando & 54 \\
\hline 50 & depois & 212 & vou & 75 & se & 54 \\
\hline 51 & tenho & 202 & por & 72 & assim & 53 \\
\hline 52 & por & 192 & só & 70 & sei & 53 \\
\hline 53 & sempre & 188 & coisa & 68 & isso & 52 \\
\hline 54 & casa & 184 & até & 66 & coisa & 51 \\
\hline 55 & pai & 173 & como & 66 & no & 51 \\
\hline 56 & ah & 173 & sei & 64 & aí & 50 \\
\hline 57 & você & 171 & acho & 63 & tempo & 50 \\
\hline 58 & são-paulo & 169 & sabe & 63 & pai & 47 \\
\hline 59 & bem & 164 & sempre & 61 & foi & 47 \\
\hline 60 & isso & 163 & bem & 60 & anos & 47 \\
\hline 61 & vai & 160 & fui & 59 & marido & 46 \\
\hline 62 & os & 156 & mãe & 59 & sempre & 45 \\
\hline 63 & fui & 153 & são-paulo & 59 & depois & 45 \\
\hline 64 & até & 152 & $\mathrm{ah}$ & 57 & gosto & 44 \\
\hline 65 & acho & 151 & filho & 57 & sabe & 44 \\
\hline 66 & coisa & 149 & a-gente & 56 & estou & 43 \\
\hline 67 & dois & 149 & tempo & 56 & a-gente & 42 \\
\hline 68 & mãe & 149 & dia & 52 & os & 42 \\
\hline 69 & nós & 144 & tá & 51 & me & 40 \\
\hline 70 & dia & 140 & três & 49 & dois & 38 \\
\hline 71 & vou & 140 & estou & 48 & vou & 37 \\
\hline 72 & tempo & 137 & fazer & 48 & até & 36 \\
\hline 73 & hoje & 136 & sou & 47 & meus & 36 \\
\hline 74 & fazer & 135 & filha & 46 & todos & 36 \\
\hline 75 & eles & 120 & pai & 46 & você & 35 \\
\hline 76 & sou & 118 & isso & 45 & igreja & 35 \\
\hline 77 & as & 116 & os & 45 & filhos & 35 \\
\hline 78 & fiz & 115 & você & 42 & as & 34 \\
\hline 89 & mesmo & 115 & fiz & 40 & filha & 34 \\
\hline 80 & sabe & 111 & vai & 40 & acho & 34 \\
\hline 81 & três & 111 & nós & 37 & são & 34 \\
\hline 82 & faz & 110 & esse & 36 & nada & 33 \\
\hline 83 & está & 110 & nunca & 36 & sou & 32 \\
\hline 84 & tá & 109 & trabalhei & 36 & deus & 31 \\
\hline 85 & ano & 108 & está & 34 & vai & 31 \\
\hline 86 & bom & 106 & bom & 33 & lembro & 31 \\
\hline 87 & nada & 103 & essa & 33 & por & 31 \\
\hline 88 & nunca & 103 & gosto & 33 & faço & 30 \\
\hline
\end{tabular}




\begin{tabular}{|c|c|c|c|c|c|c|}
\hline 89 & todo & 103 & nada & 33 & está & 29 \\
\hline 90 & $\operatorname{mim}$ & 101 & o-senhor & 33 & nem & 28 \\
\hline 91 & olha & 99 & ou & 33 & tá & 28 \\
\hline 92 & sei & 98 & filhos & 32 & mesmo & 27 \\
\hline 93 & escola & 96 & mesmo & 32 & falar & 26 \\
\hline 94 & gosto & 94 & trabalhava & 32 & nunca & 26 \\
\hline 95 & ia & 91 & vez & 32 & bom & 25 \\
\hline 96 & falou & 91 & vezes & 32 & ia & 24 \\
\hline 97 & essa & 90 & boa & 31 & quer & 24 \\
\hline 98 & pouco & 90 & cinco & 31 & fazer & 24 \\
\hline 99 & $\mathrm{ou}$ & 88 & estava & 31 & $\mathrm{ou}$ & 24 \\
\hline 100 & meus & 86 & ficou & 31 & fui & 23 \\
\hline 101 & vezes & 86 & tava & 31 & falei & 22 \\
\hline 102 & às-vezes & 86 & uns & 31 & boa & 22 \\
\hline 103 & deus & 85 & quatro & 30 & gostava & 22 \\
\hline 104 & filha & 84 & trabalhar & 30 & $\operatorname{sim}$ & 22 \\
\hline 105 & família & 81 & vida & 30 & uns & 22 \\
\hline 106 & nem & 81 & as & 29 & nasci & 21 \\
\hline 107 & outra & 79 & hoje & 29 & ainda & 21 \\
\hline 108 & cinco & 77 & casei & 28 & ter & 21 \\
\hline 109 & outro & 77 & dois & 28 & quatro & 21 \\
\hline 110 & estou & 76 & irmão & 28 & chama & 21 \\
\hline 111 & fiquei & 76 & nem & 28 & pouco & 20 \\
\hline 112 & estava & 75 & pouco & 28 & carne & 20 \\
\hline 113 & tive & 75 & todo & 28 & casei & 20 \\
\hline 114 & vim & 74 & deus & 27 & pais & 20 \\
\hline 115 & faço & 73 & ia & 27 & quê & 19 \\
\hline 116 & faleceu & 72 & negócio & 27 & coisas & 19 \\
\hline 117 & filhos & 72 & perto & 27 & netos & 19 \\
\hline 118 & marido & 71 & eles & 26 & crianças & 18 \\
\hline 119 & muita & 71 & tô & 26 & $\operatorname{mim}$ & 18 \\
\hline 120 & uns & 71 & ali & 25 & meio & 18 \\
\hline 121 & quatro & 71 & fiquei & 25 & muita & 18 \\
\hline 122 & ainda & 70 & outra & 25 & elas & 18 \\
\hline 123 & tava & 69 & ter & 25 & estudei & 18 \\
\hline 124 & vez & 69 & dele & 24 & morreu & 18 \\
\hline 125 & trabalhar & 69 & $\operatorname{mim}$ & 24 & viu & 18 \\
\hline 126 & $\operatorname{sim}$ & 68 & olha & 24 & católica & 18 \\
\hline 127 & teve & 68 & outro & 24 & nós & 18 \\
\hline 128 & daí & 68 & teve & 24 & estão & 18 \\
\hline 129 & esse & 66 & vim & 24 & menos & 18 \\
\hline 130 & irmão & 66 & carne & 23 & tão & 17 \\
\hline 131 & dez & 66 & coisas & 23 & hoje & 17 \\
\hline 132 & meio & 66 & igreja & 23 & dia & 17 \\
\hline 133 & quer & 65 & velho & 23 & três & 17 \\
\hline 134 & às & 64 & às & 22 & eram & 17 \\
\hline 135 & menos & 62 & dá & 22 & queria & 16 \\
\hline
\end{tabular}




$\begin{array}{lllllll}136 & \text { são } & 62 & \text { faleceu } & 22 & \text { olha } & 16 \\ 137 & \text { falei } & 61 & \text { morava } & 22 \text { ver } & 16 \\ 138 & \text { doutor } & 59 & \text { dela } & 21 \text { arroz } & 16 \\ 139 & \text { ser } & 58 & \text { onde } & 21 \text { família } & 16 \\ 140 & \text { filho } & 58 & \text { quer } & 21 \text { pode } & 15 \\ 141 & \text { vem } & 58 & \text { todos } & 21 \text { tava } & 15 \\ 142 & \text { ir } & 58 & \text { ainda } & 20 \text { falou } & 15 \\ 143 & \text { quê } & 57 & \text { faço } & 20 \text { ir } & 15 \\ 144 & \text { deu } & 57 & \text { graças-a-deus } & 20 \text { graças-a-deus } & 15 \\ 145 & \text { trabalhava } & 57 & \text { moro } & 20 \text { fiquei } & 15 \\ 146 & \text { duas } & 57 & \text { morreu } & 20 \text { quem } & 15 \\ 147 & \text { ficou } & 57 & \text { bastante } & 19 \text { fiz } & 15 \\ 148 & \text { época } & 56 & \text { cá } & 19 \text { café } & 15 \\ 149 & \text { veio } & 56 & \text { católica } & 19 \text { fica } & 14 \\ 150 & \text { cidade } & 55 & \text { faculdade } & 19 \text { outra } & 14\end{array}$


Tabela da lista dos primeiros 150 verbos e substantivos mais falados pelos participantes do estudo

\begin{tabular}{|c|c|c|c|c|c|c|}
\hline ordem & leve & vezes & moderado & vezes & controle & vezes \\
\hline 1 & é & 311 & é & 220 & é & 776 \\
\hline 2 & tem & 204 & era & 156 & tem & 531 \\
\hline 3 & tinha & 157 & tem & 139 & era & 444 \\
\hline 4 & tenho & 140 & tenho & 131 & tinha & 400 \\
\hline 5 & era & 136 & como & 86 & anos & 385 \\
\hline 6 & anos & 123 & tinha & 86 & foi & 297 \\
\hline 7 & faz & 94 & casa & 70 & como & 240 \\
\hline 8 & foi & 93 & mãe & 67 & gente & 223 \\
\hline 9 & casa & 88 & faz & 66 & tenho & 202 \\
\hline 10 & vou & 75 & são-paulo & 63 & casa & 184 \\
\hline 11 & coisa & 68 & filho & 54 & pai & 173 \\
\hline 12 & sei & 64 & sei & 53 & são-paulo & 169 \\
\hline 13 & acho & 63 & coisa & 51 & vai & 160 \\
\hline 14 & sabe & 60 & tempo & 50 & fui & 153 \\
\hline 15 & como & 60 & pai & 47 & acho & 151 \\
\hline 16 & fui & 59 & foi & 47 & coisa & 149 \\
\hline 17 & são-paulo & 59 & anos & 47 & mãe & 149 \\
\hline 18 & mãe & 59 & marido & 46 & dia & 140 \\
\hline 19 & filho & 57 & gosto & 44 & vou & 140 \\
\hline 20 & tempo & 56 & sabe & 43 & tempo & 137 \\
\hline 21 & dia & 52 & estou & 43 & fazer & 135 \\
\hline 22 & tá & 51 & vou & 37 & sou & 118 \\
\hline 23 & fazer & 48 & igreja & 35 & fiz & 115 \\
\hline 24 & estou & 48 & filos & 35 & sabe & 111 \\
\hline 25 & sou & 47 & filha & 34 & faz & 110 \\
\hline 26 & filha & 46 & acho & 34 & está & 110 \\
\hline 27 & pai & 46 & são & 34 & tá & 109 \\
\hline 28 & vai & 40 & sou & 32 & ano & 108 \\
\hline 29 & fiz & 40 & deus & 31 & olha & 99 \\
\hline 30 & trabalhei & 36 & vai & 31 & sei & 98 \\
\hline 31 & está & 34 & lembro & 31 & escola & 96 \\
\hline 32 & gosto & 33 & faço & 30 & gosto & 94 \\
\hline 33 & trabalhava & 32 & está & 29 & ia & 91 \\
\hline 34 & vez & 32 & falar & 26 & falou & 91 \\
\hline 35 & filhos & 32 & ia & 24 & vezes & 86 \\
\hline 36 & ficou & 31 & quer & 24 & deus & 85 \\
\hline 37 & estava & 31 & fazer & 24 & filha & 84 \\
\hline 38 & tava & 31 & fui & 23 & família & 81 \\
\hline 39 & vezes & 31 & tá & 23 & estou & 76 \\
\hline 40 & trabalhar & 30 & falei & 22 & fiquei & 76 \\
\hline 41 & vida & 30 & gostava & 22 & estava & 75 \\
\hline 42 & casei & 28 & nasci & 21 & tive & 75 \\
\hline 43 & irmão & 28 & ter & 21 & vim & 74 \\
\hline 44 & ia & 27 & chama & 21 & faço & 73 \\
\hline
\end{tabular}




\begin{tabular}{|c|c|c|c|c|c|}
\hline 45 & deus & 27 & carne & 20 & faleceu \\
\hline 46 & negócio & 27 & casei & 20 & filhos \\
\hline 47 & tô & 26 & país & 20 & marido \\
\hline 48 & ter & 25 & coisas & 19 & tava \\
\hline 49 & fiquei & 25 & netos & 19 & vez \\
\hline 50 & olha & 24 & crianças & 18 & trabalhar \\
\hline 51 & vim & 24 & estudei & 18 & teve \\
\hline 52 & teve & 24 & morreu & 18 & irmão \\
\hline 53 & igreja & 23 & dia & 17 & quer \\
\hline 54 & coisas & 23 & eran & 17 & são \\
\hline 55 & carne & 23 & quería & 16 & falei \\
\hline 56 & dá & 22 & ver & 16 & doutor \\
\hline 57 & faleceu & 22 & arroz & 16 & ser \\
\hline 58 & morava & 22 & familia & 16 & filho \\
\hline 59 & quer & 21 & pode & 15 & vem \\
\hline 60 & morreu & 20 & tava & 15 & ir \\
\hline 61 & faço & 20 & falou & 15 & deu \\
\hline 62 & sai & 19 & ir & 15 & trabalhava \\
\hline 63 & ver & 19 & viu & 15 & ficou \\
\hline 64 & faculdade & 19 & fiquei & 15 & época \\
\hline 65 & irmã & 18 & fiz & 15 & veio \\
\hline 66 & comecei & 18 & café & 15 & cidade \\
\hline 67 & ir & 18 & olha & 14 & morreu \\
\hline 68 & rua & 18 & fica & 14 & horas \\
\hline 69 & fazia & 18 & saúde & 14 & coisas \\
\hline 70 & casou & 18 & fala & 14 & fez \\
\hline 71 & vem & 18 & manhã & 14 & dá \\
\hline 72 & peixe & 18 & escola & 14 & morar \\
\hline 73 & cheguei & 17 & religião & 14 & comer \\
\hline 74 & hospital & 17 & trabalhei & 14 & fica \\
\hline 75 & mulher & 17 & negócio & 14 & morava \\
\hline 76 & quero & 17 & estão & 14 & lugar \\
\hline 77 & moro & 17 & falo & 14 & arroz \\
\hline 78 & quería & 17 & nome & 14 & comecei \\
\hline 79 & tive & 17 & feijão & 13 & trabalhei \\
\hline 80 & eram & 17 & tive & 13 & tomo \\
\hline 81 & trabalha & 17 & dava & 13 & estudar \\
\hline 82 & fez & 17 & comida & 13 & irmã \\
\hline 83 & días & 17 & vezes & 13 & feijão \\
\hline 84 & viu & 17 & verduras & 12 & mulher \\
\hline 85 & vinha & 16 & irmãos & 12 & começou \\
\hline 86 & falei & 16 & peixe & 12 & ficar \\
\hline 87 & cidade & 16 & filhas & 12 & médico \\
\hline 88 & chama & 16 & trabalha & 12 & fazia \\
\hline 89 & lugar & 16 & moro & 12 & interior \\
\hline 90 & dar & 16 & vieram & 12 & carne \\
\hline 91 & arroz & 16 & militar & 11 & noite \\
\hline
\end{tabular}




\begin{tabular}{|c|c|c|c|c|c|}
\hline 92 & posso & 16 & quero & 11 & semana \\
\hline 93 & aula & 16 & homem & 11 & morei \\
\hline 94 & veio & 15 & vem & 11 & vida \\
\hline 95 & marido & 15 & idade & 11 & comida \\
\hline 96 & deu & 15 & vim & 11 & irmãos \\
\hline 97 & aposentei & 15 & verdade & 11 & estudei \\
\hline 98 & feijão & 15 & falando & 11 & nasci \\
\hline 99 & cabeça & 14 & origen & 11 & mora \\
\hline 100 & família & 14 & pessoas & 10 & queria \\
\hline 101 & mora & 14 & dá & 10 & tô \\
\hline 102 & ser & 14 & ficar & 10 & falar \\
\hline 103 & estudei & 14 & posso & 10 & ter \\
\hline 104 & há & 14 & pera & 10 & sai \\
\hline 105 & comer & 14 & mndo & 10 & aula \\
\hline 106 & dizer & 14 & dinheiro & 10 & problema \\
\hline 107 & casar & 14 & dizer & 10 & medo \\
\hline 108 & horas & 14 & irmão & 10 & negócio \\
\hline 109 & escritório & 14 & vez & 10 & hora \\
\hline 110 & café & 14 & morei & 10 & pais \\
\hline 111 & vi & 13 & ginásio & 10 & casei \\
\hline 112 & lembro & 13 & criança & 9 & igreja \\
\hline 113 & falar & 13 & sair & 9 & pode \\
\hline 114 & fico & 13 & estado & 9 & dava \\
\hline 115 & fazendo & 12 & comer & 9 & fala \\
\hline 116 & chegou & 12 & pão & 9 & ficava \\
\hline 117 & parei & 12 & quis & 9 & trabalho \\
\hline 118 & inerior & 12 & veio & 9 & eram \\
\hline 119 & fala & 12 & vida & 9 & meses \\
\hline 120 & conta & 12 & ficou & 9 & dias \\
\hline 121 & campinas & 12 & cozinha & 9 & dizer \\
\hline 122 & come & 12 & tarde & 9 & água \\
\hline 123 & comia & 12 & fé & 8 & fazenda \\
\hline 124 & tomo & 12 & ficava & 8 & remédio \\
\hline 125 & conheci & 12 & salada & 8 & senhor \\
\hline 126 & criança & 11 & conta & 8 & fazendo \\
\hline 127 & minas & 11 & tomo & 8 & domingo \\
\hline 128 & ficava & 11 & mulher & 8 & há \\
\hline 129 & comprei & 11 & almoço & 8 & dinheiro \\
\hline 130 & voltava & 11 & causa & 8 & tomar \\
\hline 131 & falou & 11 & parece & 8 & pessoa \\
\hline 132 & nasci & 11 & fez & 8 & trabalha \\
\hline 133 & gosta & 11 & estaba & 8 & dor \\
\hline 134 & noite & 11 & casamento & 8 & mundo \\
\hline 135 & são & 11 & mamãe & 8 & falava \\
\hline 136 & escola & 11 & professora & 8 & idade \\
\hline 137 & dormir & 11 & faleceu & 8 & religião \\
\hline 138 & problema & 11 & aula & 8 & saúde \\
\hline
\end{tabular}




$\begin{array}{lllllll}139 & \text { pressão } & 11 & \text { faculdade } & 8 & \text { bairro } & 30 \\ 140 & \text { parece } & 11 & \text { entendeu } & 7 & \text { rua } & 30 \\ 141 & \text { menina } & 10 & \text { morar } & 7 & \text { almoço } & 29 \\ 142 & \text { hora } & 10 & \text { acredito } & 7 & \text { posso } & 29 \\ 143 & \text { ficar } & 10 & \text { amor } & 7 & \text { viu } & 29 \\ 144 & \text { país } & 10 & \text { tempinho } & 7 & \text { carro } & 29 \\ 145 & \text { firma } & 10 & \text { deixa } & 7 & \text { entendeu } & 29 \\ 146 & \text { parte } & 10 & \text { debe } & 7 & \text { conheci } & 28 \\ 147 & \text { bairro } & 10 & \text { rezo } & 7 & \text { salada } & 28 \\ 148 & \text { idade } & 10 & \text { comia } & 7 & \text { serviço } & 28 \\ 149 & \text { comida } & 10 & \text { fico } & 7 & \text { café } & 28 \\ 150 & \text { doutor } & 10 & \text { escritorio } & 7 & \text { manhã } & 28\end{array}$

